\title{
Le collectif Front paysan : films de luttes et travail syndical dans les années 1970
}

The Front Paysan Collective: Films of Struggle and Trade Union Work in the 1970 s

Édouard Lynch

\section{OpenEdition}

Journals

Édition électronique

URL : https://journals.openedition.org/itti/2203

DOI : $10.4000 /$ itti.2203

Éditeur

Université de Poitiers

Référence électronique

Édouard Lynch, «Le collectif Front paysan : films de luttes et travail syndical dans les années 1970 », Images du travail, travail des images [En ligne], 12 | 2022, mis en ligne le 22 février 2022, consulté le 02 avril 2022. URL : http://journals.openedition.org/itti/2203 ; DOI : https://doi.org/10.4000/itti.2203

Ce document a été généré automatiquement le 2 avril 2022.

Images du travail, travail des images 


\section{Le collectif Front paysan : films de luttes et travail syndical dans les années 1970}

The Front Paysan Collective: Films of Struggle and Trade Union Work in the $1970 s$

Édouard Lynch

Dans l'histoire du monde du travail et des luttes syndicales au $x^{e}$ siècle en France, les mondes agricoles ont été longtemps délaissés, conséquence de leurs orientations politiques conservatrices réelles ou supposées (maintien de la tutelle de notables anciens et modernes) et d'une structure économique et sociale marquée par la résistance de l'exploitation familiale et paysanne (réelle ou supposée). On peut y voir tout à la fois les conséquences de l'histoire même du mouvement ouvrier français et de la structuration des forces politiques, mais aussi le reflet d'une historiographie longtemps sensible à un "ouvriérisme » plus ou moins inconscient, pour qui travail rime avec usine.

2 De fait, l'historiographie des luttes paysannes $d u x^{e}$ siècle s'est longtemps trouvée tiraillée entre cette approche "ouvrière", incarnée par les travaux pionniers de Philippe Graton (1971) au début des années 1970, et la difficulté d'approcher la diversité des campagnes françaises, notamment de la place maintenue des exploitants, voire même leur renforcement à la faveur du processus de modernisation et leur implication croissante dans le champ syndical. À l'exception sans doute des travailleurs viticoles, souvent abordés à travers le prisme de 1907 et de la révolte du Midi (Sagnes, 1980; Frader 1991) ou des « ouvriers paysans » des forêts du Cher, magistralement étudiés par Michel Pigenet, les luttes paysannes peinent à trouver leur place, ou sont renvoyées, notamment pour les années trente, à une approche plus politique, autour du fascisme vert (Paxton, 1997) et des nouvelles formes d'engagement militant (Belloin, 1993). Les évolutions de l'après-guerre et l'effacement - tout au moins la faible visibilité - du salariat agricole recentre la question paysanne sur la mobilisation des exploitants. 
3 En dépit de l'unité syndicale qui s'impose après la Libération avec la création de la Fédération nationale des syndicats d'exploitants agricoles, le monde des producteurs agricoles demeure particulièrement hétérogène et, en dépit des promesses de la révolution productiviste, les tensions restent vives avec l'émergence de contestation externe (le Mouvement de défense des exploitants familiaux) et interne (le comité de Guéret [Conord, 2008]). À la faveur des années 1960 et du révélateur que constitue mai 1968, de nouveaux clivages apparaissent et donnent naissance au mouvement dit des paysans travailleurs, nébuleuse complexe, mais particulièrement active.

4 Si les grandes lignes de son histoire sont relativement bien connues, notamment dans le sillage des travaux sur les origines de la Confédération paysanne, ou des liens avec mai 1968 (Martin, 2005), la diversité des formes de mobilisation et d'action syndicale n'a pas nécessairement été explorée. Tel est le cas en particulier des actions de mobilisation par l'image, menées dans cet âge d'or du cinéma militant que constituent les années 1970, un cinéma militant appréhendé une nouvelle fois principalement dans sa dimension politique, ouvrière et révolutionnaire, laissant un peu à la marge les expérimentations paysannes, même si celles-ci sont en fin de compte présentes (quelques pages par exemple dans la synthèse de Grant [2016]), dans un moment rare de convergence des luttes entre les gauches paysannes et les gauches ouvrières, en pleine recomposition.

5 Le point central de cette étude portera sur les films du Front paysan, petit groupe de militants cinéastes qui se construit dans l'effervescence de l'immédiat post-1968 au sein du département cinéma de l'université de Vincennes. Cette petite équipe réalise entre 1972 et $1975^{1}$ quatre films qui constituent un corpus documentaire sans équivalent sur les luttes collectives de la paysannerie, à la fois par l'homogénéité de leur processus de création et de diffusion, mais aussi par leur capacité à traduire, en quatre opus, les nouveaux visages de la question agraire des années 1970: La Guerre du lait (52 mn), relate le conflit de mai 1972 qui oppose en Bretagne coopératives et producteurs laitiers ; Des dettes pour salaire ( $26 \mathrm{mn}$ ), tourné en 1973 dénonce les méfaits des élevages intégrés ; La Reprise abusive (46 mn), 1974, met en scène la revendication en faveur d'un accès plus équitable à la terre ; et enfin N'y a pro, $(68 \mathrm{mn})$ est une plongée dans la crise du Midi viticole en 1975-1976. Articulés autour de luttes exemplaires, ils constituent une mise en images particulièrement percutante des «insurrections paysannes » conduites par un syndicalisme agricole en pleine structuration.

6 La présente étude s'appuiera principalement sur ces quatre films, accessibles au chercheur grâce au site animé par leur principal artisan, Guy Chapouillié2, cheville ouvrière du groupe Front paysan (faute d'étude précise, on renverra à l'un des manifestes du groupe, publié dans le numéro spécial dirigé par Hennebelle, 1976), et qui n'a jamais cessé de filmer le monde rural, mais aussi de réfléchir aux usages politiques et cinématographiques de la caméra (Chapouillié, 2017). Pour approfondir le processus de fabrication de ces films, on dispose de plusieurs témoignages ou entretiens déjà réalisés sur cette expérience (G. Chapouillié revient dans un long entretien à la fois sur ses origines, son engagement militant et les conditions de production des différents films, dans Stellati et Piot [2016]), comme ceux de Bernard Peré (2016) ou de Claude Bailblé, un des principaux animateurs de la section cinéma de Vincennes ${ }^{3}$ et qui a co-signé deux des films. En ce qui concerne Guy Chapouillié, nous avons réalisé deux questionnaires précisant notamment les conditions d'élaboration des films. Si les sources filmiques sont au cœur de l'analyse, elles sont travaillées ici par 
un historien spécialiste du monde rural, utilisateur assidu des sources audiovisuelles, mais pas un spécialiste du cinéma. Aussi cet article mobilisera-t-il des recherches récentes menées sur l'histoire des manifestations paysannes au Xx ${ }^{e}$ siècle (Lynch, 2020), qui brasse, notamment pour les années 1970, de nombreuses sources judiciaires et politiques qui, sans être directement mentionnées, constituent un socle de connaissances indispensables à l'analyse de la matière cinématographique.

7 Parmi les nombreuses entrées possibles dans l'analyse de ce corpus, l'attention s'est portée sur l'étude des formes du travail militant, en questionnant notamment l'éventuelle originalité de sa mise en image. En quoi celle-ci renouvelle-t-elle ou transforme-t-elle l'action militante, à la fois dans et hors le monde paysan? L'une de nos hypothèses est qu'il est nécessaire d'inscrire ces films dans le prolongement de la fabrication et la diffusion d'un "récit militant » tel qu'il est construit depuis le début $\mathrm{du} \mathrm{xx}^{\mathrm{e}}$ siècle dans la presse professionnelle ouvrière et paysanne. Au-delà du récit factuel et des analyses, il convient de faire de ces récits un support de lutte largement imaginaire ou tout au moins reconstruite au service de l'éducation et de la propagande. Cette approche est néanmoins rendue plus complexe par le positionnement des différents acteurs : le petit groupe du Front paysan n'est pas une émanation directe des Paysans travailleurs dont il serait le simple porte-voix, et ces derniers sont eux-mêmes une structure hétérogène, parcourue de nombreuses tensions, tandis que sur le terrain, les stratégies des minoritaires au sein des fédérations départementales de la FNSEA sont le produit de rapports de forces locaux aussi divers que mouvants (Bruneau, 2006). Si l'historiographie a mis à juste titre en avant le rôle des Paysans travailleurs (Lagrave, 1990), ceux-ci constituent une nébuleuse mouvante et fragile dont "l'institutionnalisation » est largement inaboutie, et dont les films du Front paysan reflètent la complexité et les tensions.

Un premier moment sera consacré à remettre les films du Front paysan dans le contexte plus large des luttes collectives de la fin des années 1960, et du rôle nouveau du cinéma dans le travail politique et syndical. C'est dans ce climat d'intense circulation des pratiques militantes que nait le Front paysan. Dans un second temps, nous exposerons comment ses quatre films constituent des lieux d'observation privilégiés des luttes paysannes des années 1970, des objectifs, des acteurs et des modes d'action. Enfin, un dernier temps s'attachera à mettre en évidence les principaux invariants de ce récit militant en image.

\section{Les films du Front paysan, nouveaux outils, nouveaux combats}

\subsection{Le mai 1968 des paysans}

Avant d'entrer dans le détail de l'analyse des quatre films, il est indispensable de préciser les conditions particulières de leur émergence. Depuis le milieu des années 1950, le monde agricole est soumis à une transformation rapide et profonde que l'historiographie a longtemps qualifiée de "révolution silencieuse", reprenant la formule de l'un de ses emblématiques protagonistes, Michel Debatisse (1962), alors à la tête du Centre national des jeunes agriculteurs qu'il mène dans l'aventure d'une modernisation à marche forcée, gravissant les échelons professionnels (secrétaire général puis président de la FNSEA) puis politiques. Cette révolution silencieuse a été 
pourtant fort bruyante, puisqu'avant même la mise en place de la $V^{e}$ République et pour des raisons complexes, mais convergentes, elle s'est accompagnée de mobilisations collectives sans précédent, marquées par des actions de plus en plus violentes, et ce jusqu'à leur reflux à partir du milieu des années 1970 (Duclos, 1995).

Des mobilisations qui témoignent des effets particulièrement dévastateurs d'un processus de modernisation, qui loin des objectifs initiaux de parité et d'émancipation fait disparaître en quelques années des centaines de milliers d'exploitations et de paysans et engage ceux qui restent dans une révolution technique et entrepreneuriale à l'issue incertaine. C'est dans ce contexte de fortes tensions que l'organisation syndicale dominante, la FNSEA, mobilise ses adhérents pour obtenir, par la pression de la rue, de meilleures conditions de revenus, notamment par le biais des prix garantis et encadrés par l'État et la politique agricole commune, délaissant les réformes de "structures ", initialement brandies par les jeunes réformateurs des années 1960. Ces questions de structures (remembrement, production collective, rémunération du travail) qui touchent plus directement l'enjeu brulant de la propriété du sol et les mécanismes d'intégration au système agro-industriel sont laissées aux mains de la frange la plus contestataire du syndicalisme, principalement concentrée dans les sections du CNJA, renouvelées en profondeur dans les années 1960. De telles revendications facilitent les relations avec le mouvement ouvrier, notamment dans la région du grand Ouest où, depuis le milieu des années 1960, des contacts se nouent à l'occasion des conflits sociaux qui s'intensifient, notamment pour les paysans, en 1967 (Porhel, 2008), où l'Ouest comme le Midi viticole connaissent une vague de mobilisation ample et radicale, qui inquiète jusqu'aux autorités policières, notamment à Redon et à Quimper, par les risques de contagion avec le mouvement ouvrier.

11 En comparaison, l'année 1968 est plutôt calme, même si localement, les paysans participent aux manifestations du printemps 1968 (Lynch, 2011), tandis que la direction nationale de la FNSEA freine des quatre fers pour ne pas mettre en difficulté le pouvoir gaulliste. Mais le feu couve sous la braise, et les mots d'ordre et les modes d'action circulent de manière intense, sans qu'il soit nécessaire de recourir au «retour à la terre " des étudiants plus parisiens que maoïstes. Le déclic s'opère donc majoritairement après mai 1968 qui concrétise l'affirmation, au sein du syndicalisme paysan, d'un courant à la fois légitime, ample et dynamique autour duquel vont se cristalliser un certain nombre de luttes emblématiques des années 1970. Légitime, car, en rupture avec la tradition syndicale française, ce courant aux positions idéologiques très marquées à l'extrême gauche s'est épanoui au sein du syndicat majoritaire et non comme l'émanation de formation plus marquée politiquement comme le Modef, qui, dans le sillage du PCF mène, depuis la fin des années 1950, des mobilisations selon un répertoire d'action assez proche de celui de la FNSEA. Ces contestations, au sein même de la «forteresse agricole» (Luneau, 2004) disposent de nouveaux relais locaux sur le terrain, notamment à travers les animateurs, mis en place par les CDJA les plus actifs et dont le rôle s'amplifie après mai 1968, accélérant le basculement d'un certain nombre de fédérations. Le journal Vent d'Ouest, créé à l'origine pour la Bretagne, en devient le trait d'union. Ample, car la contestation menée par le CNJA rencontre un large écho au niveau national, au-delà des bastions que constituent l'Ouest ou le Sud-Est, et que la vague semble même capable de faire basculer la majorité syndicale de la branche jeune lors du congrès de Blois en 1970. Dynamique enfin, car ce mouvement est porté par les jeunes générations d'agriculteurs, dont l'engagement politique est emblématique du 
climat politique du tournant des années 1960, marqué par de nouvelles relations avec le monde du travail et de la classe ouvrière. Une efficacité d'autant plus grande qu'elle découle d'un long processus de construction politique, menée notamment à travers le PSU et la figure de Bernard Lambert, député MRP puis PSU qui s'engage résolument sur le terrain des luttes agraires, tout en théorisant un socle idéologique commun (Martin, 2014) et que l'on retrouvera dans un des films du Front paysan. Le cas de la Bretagne, densément peuplée et très agricole, est en première ligne dans le processus de transformation économique accélérée frappant l'agriculture et dans la convergence des luttes entre ouvriers et paysans. Ce n'est pas un hasard si c'est là que commence l'aventure du Front paysan.

\subsection{Les nouveaux usages du film militant}

12 Parmi les transformations des pratiques militantes des années 1960, le recours à la caméra fait l'objet d'une histoire de mieux en mieux documentée pour un médium, le cinéma, qui a réussi à concilier succès populaire et aura avant-gardiste. La révolution des formes est notamment permise par les évolutions techniques et la libération des codes de l'expression cinématographique hérités des années d'avant-guerre. C'est dans ce registre ancien que l'on peut classer les premiers films «paysans » du PCF, comme l'emblématique La Vie est à nous de Jean Renoir de 1936 et sa séquence de ventes saisies, ou les initiatives similaires de l'après-guerre comme La Révolte des gueux, reconstitution du soulèvement de $1907^{4}$. Le PCF partage ce privilège avec les milieux d'actions catholiques, et notamment la Jeunesse agricole catholique qui utilise ce vecteur pour animer les mobilisations de ses nombreux adhérents, mais dans une veine plus «classique» de vitrine des pratiques et des messages de l'organisation catholique ${ }^{5}$. Enfin, et même si les paysans n'en sont pas les producteurs, bien au contraire, l'essor des actualités cinématographiques et surtout de la télévision font un large écho des manifestations paysannes et en multiplient les images, encourageant les militants et les responsables à penser de manière nouvelle la médiatisation de leurs actions. La prise de la sous-préfecture de Morlaix en 1962, ou l'assaut donné à la propriété de Jean Gabin quelques mois plus tard, en plein débat sur la loi d'orientation agricole, en constituent des exemples emblématiques.

Dans le champ de la nouvelle production militante, les thèmes privilégiés de ce cinéma sont les luttes révolutionnaires et ouvrières, portées par les avant-gardes urbaines, au sein desquelles le monde paysan n'a pas vraiment sa place, même si, à partir des années 1960 et la généralisation des luttes tiers-mondiste, la dimension révolutionnaire des luttes agraires retrouve une réelle actualité. Une autre difficulté réside dans le fait que comme objet d'étude et comme destination, les films militants ont d'abord vocation à circuler dans les centres urbains et ouvriers, espaces idéologiques dominants. La question de la diffusion et plus encore de la discussion que doit engendrer ce type de support est essentielle, et le monde rural, dépourvu d'espaces dédiés, n'est pas le mieux armé en ce domaine. Des réflexions et des initiatives émergent d'ailleurs durant ces années, à l'image du lancement dans l'Ouest de l'association Télé promotion rurale, autour de Louis Malassis, qui utilise les nouveaux supports de la télévision régionale et collective pour renouveler les modalités de la formation professionnelle des agriculteurs, et qui abordent progressivement, sous l'influence des responsables syndicaux, des sujets plus en phase avec l'actualité sociale. Et le passage de la petite lucarne aux arrière-salles militantes s'observe aussi dans la trajectoire de Roger Louis, 
qui fonde Scopcolor après son éviction de l'ORTF et met sa caméra au service des luttes, notamment paysannes ${ }^{6}$.

La dimension ouvriériste et révolutionnaire du cinéma militant (Perron, 2000) connaît son âge d'or avec mai 1968 qui constitue un laboratoire des idées et des pratiques nouvelles, comme celles des groupes Medvedkine (Layerle, 2008; Vigna, 2007). La question paysanne reste ainsi relativement discrète durant la première phase du cinéma militant, c'est-à-dire la phase pré-1968, avant de monter en puissance au début des années 1970, comme en témoigne la revue Écran qui recense entre 1974 et $198128 \%$ de films consacrés aux luttes paysannes, rurales et maritimes (Gauthier et al., 2004). Pour la période antérieure, faute d'un bilan plus précis le thème de la paysannerie reste donc marginal, à l'exception de quelques films comme celui de Jean Lefaux, Écoute Joseph, on est tous solidaires qui synthétise la convergence des ouvriers et des paysans autour de mai 1968, ou celui de Jacques Loiseleux, La Passerelle (1970), qui porte déjà sur les luttes foncières. De manière significative, la présence des paysans dans ces films est souvent là pour mettre en évidence la convergence entre ouvriers et paysans, qui constitue l'alpha et l'oméga des slogans de la gauche révolutionnaire depuis le $\mathrm{XIX}^{\mathrm{e}}$ siècle, tout en s'inscrivant pleinement dans la nouvelle grammaire du cinéma militant (Lecler, 2013).

\subsection{De Vincennes à Guiscriff}

C'est dans ce contexte qu'il faut comprendre les rapprochements qui s'opèrent, d'abord en Bretagne, en 1967-1968, puis à Paris en 1969-1970, entre les militants venus du PSU et des groupes de la gauche révolutionnaire et maoïstes et les responsables syndicalistes locaux, soucieux de mieux faire connaitre leurs luttes (Martin et Drouet, 2010). En effet, à la différence de la FNSEA majoritaire, qui dispose d'un répertoire d'action efficace, mais bien cadré, une fraction des CDJA font le choix de mener des opérations plus médiatiques et plus politiques, à l'image de la séquestration temporaire du ministre Olivier Guichard en novembre 1969, qui enclenche une vague de répression/mobilisation permettant aux futurs paysans travailleurs d'émerger sur la scène nationale. L'échec du congrès de Blois en 1970 ouvre paradoxalement la voie à une nouvelle dynamique protestataire, en rupture de plus en plus marquée avec la ligne majoritaire de la FNSEA. Guy Chapouillié, monté à la capitale pour des raisons tant politiques que professionnelles, s'en fait l'écho:

Certes, le CDJA du Finistère était en pointe, mais il s'agissait d'une des équipes de la forte minorité du Congrès de Blois (juillet 1970, un mouvement vraiment postsoixante-huit), largement engagée dans la sécession. Ils avaient une forte envie de faire entendre leurs voix [...]. Pour La Guerre du lait tout a vraiment commencé grâce aux contacts que j'avais avec la tendance gauche révolutionnaire, les maoïstes $d u$ PSU de Rennes. Ils nous ont présenté Édouard et Marthe Morvan qui seront les activateurs de notre intégration sur le terrain de la lutte ${ }^{7}$.

Cela se cristallise dans le cadre du département cinéma de l'université de Vincennes, véritable « laboratoire » qui associe étudiants, chercheurs, cinéastes et militants autour des usages politiques du cinéma et notamment du cinéma d'action. Là encore, si l'on dispose de plusieurs témoignages et de recherches sur ce lieu emblématique des luttes politiques et esthétiques autour du cinéma, la dimension rurale est sans doute moins bien connue, même si de fait, elle n'était pas si incongrue, comme le rapporte à nouveau Guy Chapouillié : 
À peine né, le département cinéma de Vincennes affichait, chose curieuse, rassurante aussi, une unité de valeur intitulée Front paysan. Mais en raison de l'absence chronique de celui qui en avait la charge et en raison de mon premier film La Guerre du lait, une AG m'a coopté pour en prendre l'animation. Je n'ai donc pas créé l'UV Front paysan, mais j'en ai hérité, avant de fonder le groupe de réalisation Front Paysan avec Claude Bailblé, lui-même chargé de cours ${ }^{8}$.

Un témoignage qui rappelle aussi les conditions périlleuses de production et notamment l'enjeu essentiel de la pellicule, bien rare et précieux que l'on se partageait en assemblée générale ou que l'on récupérait "sur le tas » au gré d'engagements professionnels parallèles, auprès de l'ORTF ou du CNRS :

En tout cas, chaque présentation devant le collectif des projets du Front paysan reçut un soutien unanime avec, à la clé, une dotation de quelques bobines de $16 \mathrm{~mm}$ inversible. Pourquoi l'inversible? Tout simplement parce que nous profitions d'un réseau issu de l'ORTF qui offrait du film à un prix défiant toute concurrence, le développement également. L'inversible n'avait pas la qualité du négatif, mais nous pouvions monter nos films, comme les actualités des JT de l'époque, sans passer par un tirage. Bref, à moindre prix, un processus réduit, nous pouvions envisager un cinéma de résistance à notre portée?.

De fait, le Front paysan parvient à maintenir sa production pendant plusieurs années, organisant également, toujours à Vincennes, un colloque «Paysannerie et Cinéma ", en 1977, occasion de ramener les luttes paysannes, leurs images et leurs acteurs au cœur de l'université.

Figure 1 : Colloque « Paysannerie et Cinéma », Université de Vincennes, 1977

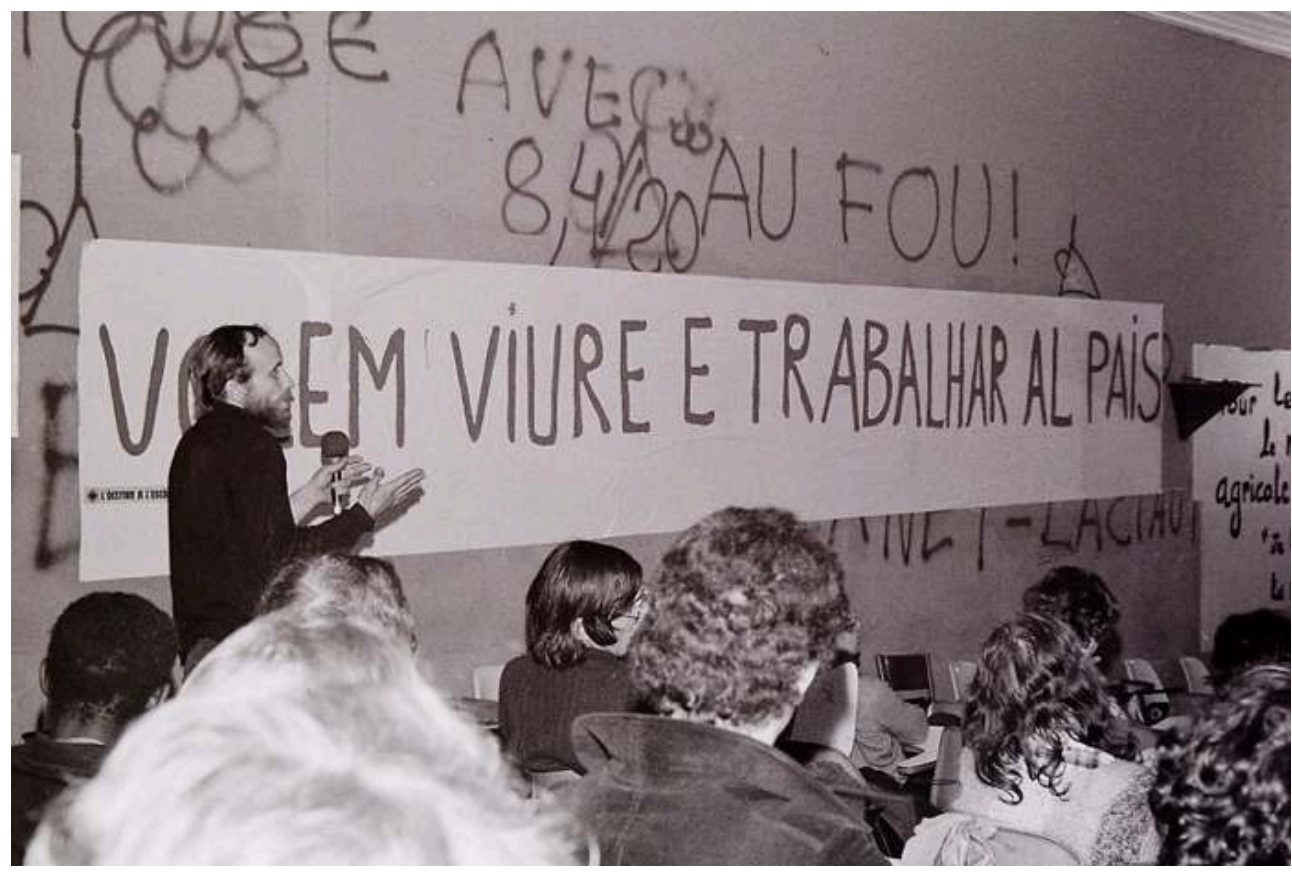

Photographies confiées par G. Chapouillié. 
Figure 2 : Colloque "Paysannerie et Cinéma », Université de Vincennes, 1977

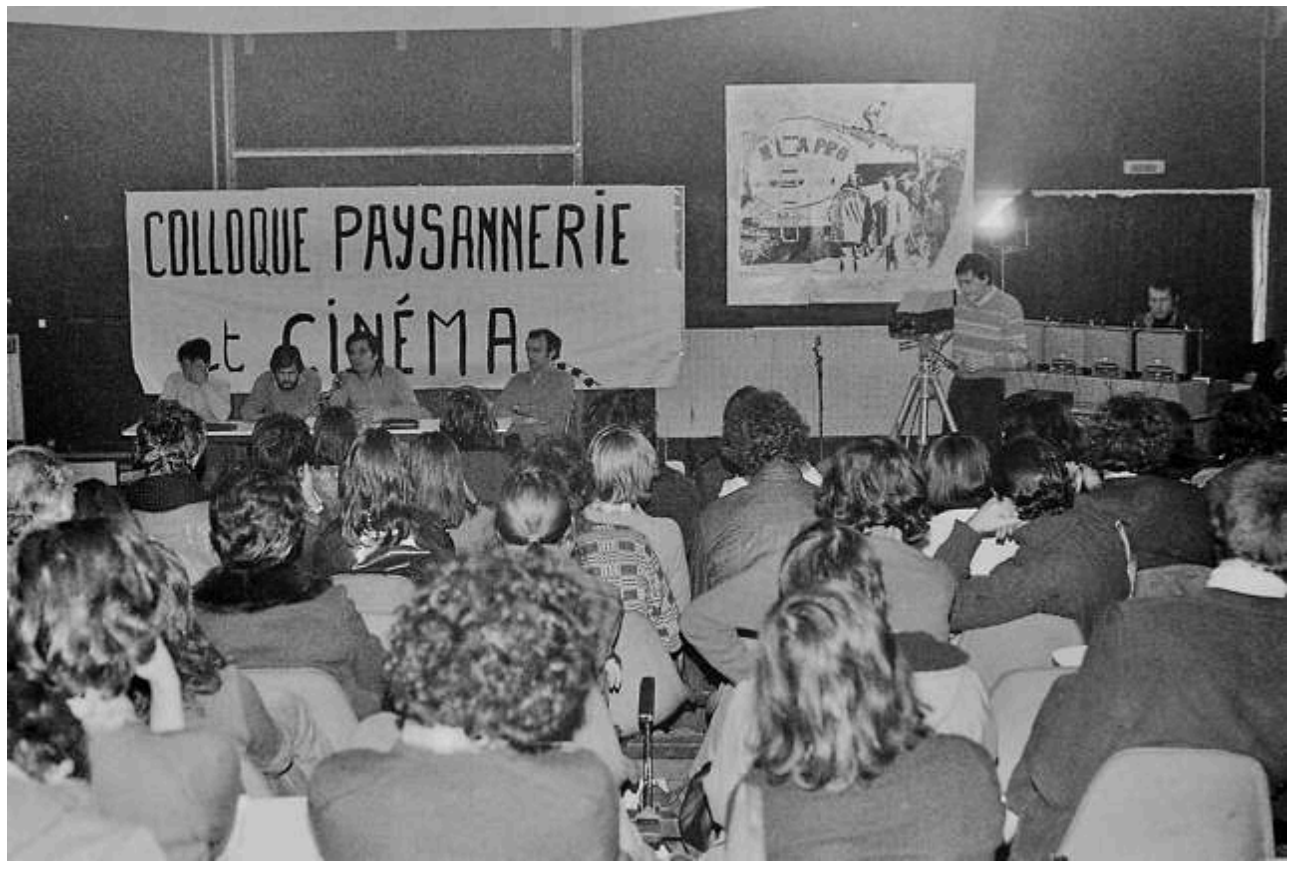

Photographies confiées par G. Chapouillié.

\section{Mettre en scène la mobilisation syndicale}

\subsection{Des combats exemplaires}

Tournés entre 1972 et 1976, ces quatre films ciblent les revendications principales de la gauche paysanne, s'efforçant tout à la fois de faire connaître les motifs « réels » de la lutte, son insertion dans une dynamique politique et économique plus large, et en mettant au premier plan la force de l'organisation collective que ces films entendent à la fois montrer, mais aussi relayer et amplifier.

Inaugurer la série par La Guerre du lait n'est pas anodin, car il s'agit d'un conflit à la fois emblématique des luttes paysannes, mais aussi relativement original ${ }^{10}$, à la différence des luttes foncières ou de la dénonciation des pratiques léonines des entreprises agroalimentaires. Original, car, de manière pionnière, les protestations ne visent pas l'État ni l'Europe à travers le contrôle des marchés et la fixation des prix, mais bien les coopératives laitières elles-mêmes, théoriquement au service des producteurs, et qui de fait poursuivent leur propre intérêt, en ne répercutant pas la hausse des prix garantis vers les producteurs. Il s'agit bien d'une lutte des classes, interne à la paysannerie, relayant sur le terrain, le manifeste de Bernard Lambert (2005), d'où l'importance du sous-titre du film, «La Paie du lait», qui renvoie les producteurs du côté du monde ouvrier et du salariat. C'est aussi un conflit qui met clairement en évidence les lignes de fracture au sein du syndicalisme opposant les «dirigeants" parvenus à la tête des organisations à la masse des petits producteurs restés dans l'ombre (Sainclivier, 2011). D'ailleurs, de par son originalité et le contexte idéologique de son émergence, ce conflit a été immédiatement un objet de fascination et d'étude pour les intellectuels engagés, comme en témoigne l'enquête de terrain menée par de jeunes chercheurs de l'INRA (Barres, Coulomb, Nallet, 1973). Mais c'est aussi un conflit qui permet l'émergence de 
nouveaux sujets, et notamment celui de la place des agricultrices, totalement invisibilisées dans les luttes syndicales «traditionnelles ", et dont le rôle, à la fois dans la production laitière, mais aussi dans l'élaboration d'un répertoire de protestation spécifique, apparaît clairement dans ce conflit et plus encore dans le film, qui sert de révélateur à une question encore relativement souterraine, même si le cœur du sujet n'est pas là.

21 Pour les deux films suivants, sur les méfaits de l'élevage intégré et la question foncière, la situation est différente. Identifier l'adversaire dans le cadre du deuxième film est plus aisé : Des dettes pour salaire, tourné en 1973 dans le Lot-et-Garonne dénonce une entreprise privée, symbole de l'essor d'un agrocapitalisme mettant les petits producteurs sous tutelle et sans défense. Ce type de lutte est plus "novateur », dans le sens où il est le produit de la mutation en cours des pratiques de l'élevage, de plus en plus visible à partir des années 1970, qui lient par contrat les agriculteurs à des firmes qui leur fournissent à la fois la nourriture, les animaux, et tout un ensemble de "services » qui accompagnent la phase d'engraissement jusqu'à l'abattage. Face à un système qui divise et qui isole, la lutte passe par le regroupement des producteurs et la prise de conscience de leur force collective, réflexion initiée au plan national par les paysans travailleurs de l'Ouest, avec la création du Comité de lutte des éleveurs intégrés (Breton, 2013). L'affrontement est donc moins frontal et passe d'abord par la médiatisation de la lutte, à laquelle le film lui-même contribue largement. La dimension syndicale y est sans doute la moins présente, même si l'activisme des militants locaux et notamment des jeunes est indispensable au succès de l'opération.

La Reprise abusive cible un type de revendication mieux identifié, depuis le début des années 1960, avec les premières luttes contre les cumuls des terres agricoles par des propriétaires non exploitants ou déjà bien pourvus, lors du vote de la loi complémentaire d'août 1962 et la création des Sociétés agricoles foncières et d'établissement rural censées les prévenir. Elle s'inscrit même dans une tradition plus ancienne, celle des combats pour obtenir un statut du fermage et du métayage, à partir des années 1930, avec, en arrière-plan, la protection des exploitants non propriétaires. Les affaires de cumul resurgissent ainsi ponctuellement dans les luttes locales, mais elles connaissent un nouvel usage syndical dès lors que la FNSEA s'en désintéresse, laissant le champ libre aux contestataires. Pour ces derniers, leur médiatisation permet de remettre au premier plan la question du foncier et de faire vivre le slogan « La terre, propriété de celui qui la travaille». Mais elles témoignent aussi de l'affrontement avec la ligne majoritaire dont les représentants participent désormais aux décisions combattues - des SAFER. Quelques-unes de ces affaires, qui s'étalent sur plusieurs années, sont au cœur de la structuration du mouvement des paysans travailleurs. Mais l'État est aussi sur la sellette, lorsqu'il refuse de faire appliquer la loi sur les cumuls, ou tout au moins l'interprète en défaveur des paysans.

Pour N'y a pro, tourné en 1975 sur les routes de l'Aude et de l'Hérault enfin, la situation est différente, à l'image d'un secteur viticole qui possède ses propres revendications, son propre calendrier protestataire et son propre répertoire d'action. L'épuisement du modèle coopératif qui avait permis le renouveau du vignoble méridional après le phylloxera, le changement des modes de consommation, la concurrence croissante des vins algériens puis italiens ont placé les producteurs dans une situation explosive, portée par un mouvement protestataire qui s'est précocement radicalisé, avec un usage croissant de l'action directe et de la violence, notamment les destructions matérielles, 
ancré de surcroit dans une longue tradition historique, depuis 1907, et réactivé par la renaissance occitane. Outre l'État, la lutte se cristallise contre les négociants, accusés, par des importations aussi illégales que massives, de peser sur les prix. En 1975, la situation est à son point de rupture lorsque débarquent les caméras du Front paysan, entre attaques de convois, expéditions punitives qui conduisent au drame de Montredon. Donner du sens à la lutte, trouver des issues à une situation qui leur échappe de plus en plus, en se réappropriant les formes de l'organisation collective, à l'image des premiers plans du film qui ouvrent sur la réunion syndicale et le verbe haut en couleur de Jean Huillet. On notera pour conclure qu'un dernier film avait été mis sur l'établi Le Bon Sens près de chez vous, portant sur le Crédit agricole, autre acteur incarnant la "face noire» de la modernisation. Faute de moyens et suite à des dissensions fatales au groupe Front paysan, semblables à celles qui fracturent les Paysans travailleurs celui-ci n'a pu aboutir ${ }^{11}$. Preuve s'il est en de l'étroite communion entre le groupe et le mouvement syndical dont il se fait le porte-voix.

\subsection{Incarner les paysans travailleurs}

Au-delà de ces différences qui colorent la structure et la construction des films, la dimension syndicale et militante occupe une place centrale, qui sert de révélateur, de détonateur et parfois de solutions aux difficultés rencontrées par les paysans en lutte. Que ce soit sur le terrain, au premier plan au côté des acteurs, où en tant que "figure ressource", exposant les motifs de la lutte, les responsables syndicaux occupent une place centrale. Ainsi, dans la grève du lait, après avoir rapidement présenté les modes et les motifs de la lutte, c'est une des figures du mouvement, Jean Cadiou, l'un des responsables du mouvement en Loire-Atlantique qui synthétise les mots d'ordre, avant d'entendre la parole des "salariée's du lait », un dispositif que l'on retrouve aussi dans Des dettes pour salaire.

Figure 3 : Jean Cadiou, La Guerre du lait

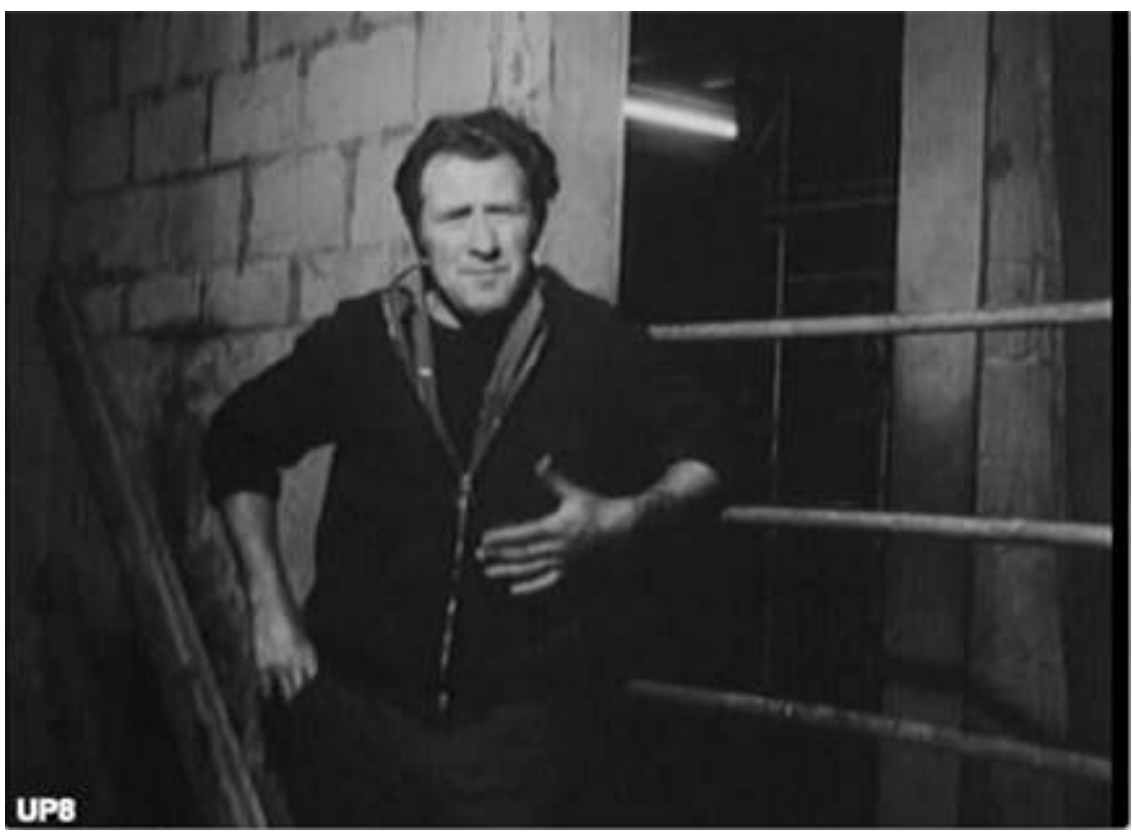

https://les-films-du-beret.jimdofree.com 
Hasard, fascination, ou nécessité de l'incarnation par le verbe et par l'image, deux autres figures des luttes paysannes des années 1970 sont au centre de deux des autres films, La Reprise abusive et N'y a pro. Dans le premier, c'est Bernard Lambert qui domine, apparaissant dès la première scène du film, après le long générique rythmé par une chanson militante (2'20). Nous ne reviendrons pas sur la très riche biographie du leader breton (Guiheneuf, 2019), incarnation du militantisme paysan et personnage central du film de Christian Rouaud, ${ }^{12}$ mais nous noterons simplement sa place structurante tout au long du film, matérialisant les différentes phases de la lutte : les réunions de soutien aux paysans, où il faut à la fois rassembler et convaincre, mais aussi sur le terrain face au sous-préfet. Une fascination qu'assume G. Chapouillié, bien des années plus tard :

J'ai toujours le souci de représenter des figures complexes et non réifiées, à contrecourant des images de défaite, d'abandon, de fin des paysans; il y a tant à faire avec leur connaissance de la terre, leur héritage, leur intelligence du métier, leur envie de vie. Bernard Lambert a changé mon regard, il était malicieux et a souvent pris la parole pour montrer que les idées mobilisatrices et les gestes de leur mise en pratique venaient de la base ${ }^{13}$.

Figure 4 : Chapeau et $B$. Lambert lors d'une réunion de soutien

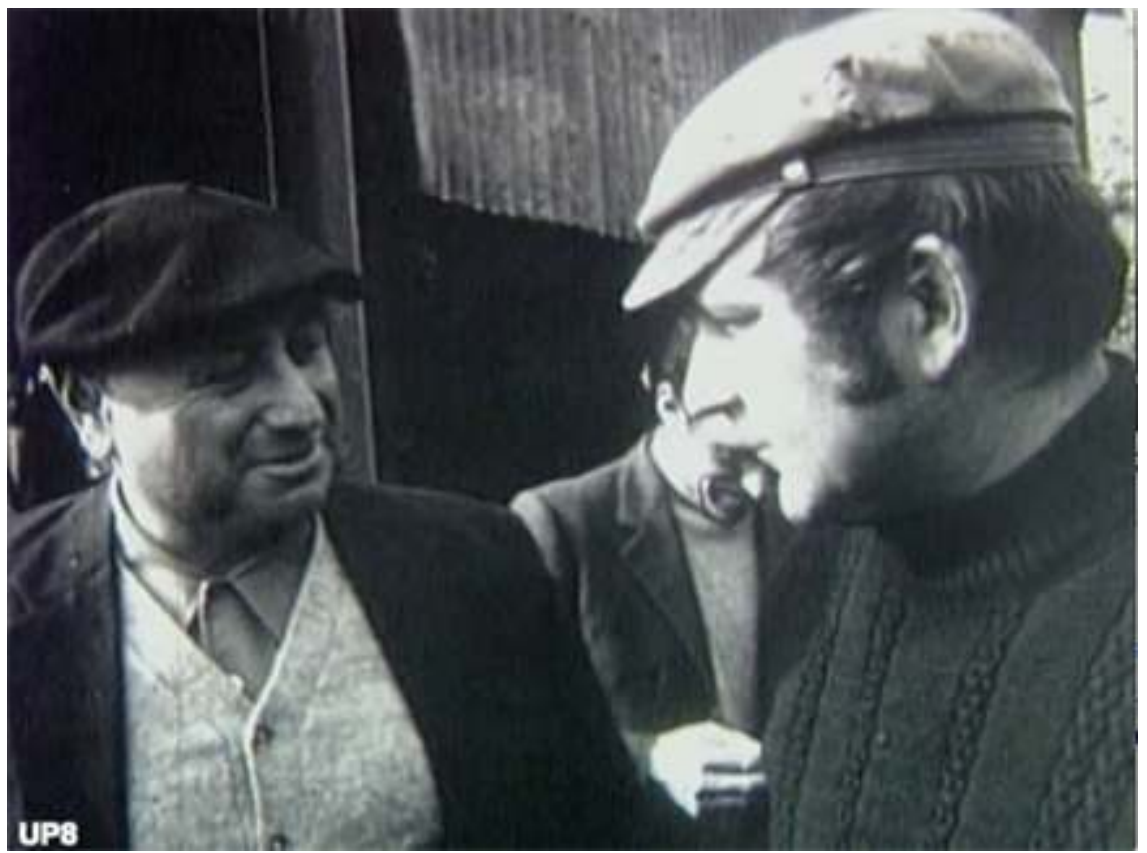

https://les-films-du-beret.jimdofree.com

L'ancien député est également présent dans une autre scène, emblématique des pratiques militantes des paysans travailleurs, celle des pique-niques ou barbecues festifs, témoignant de l'interpénétration des répertoires urbains et ouvriers. En effet, le pique-nique militant et collectif n'appartient pas à la culture contestataire paysanne, et il est clairement introduit dans le répertoire des Paysans travailleurs dans le cadre des luttes organisées conjointement avec les étudiants et les ouvriers. Si la dimension festive et récréative domine, la politique n'est évidemment pas absente. 
Figure 5 : Un barbecue militant (La Reprise abusive)

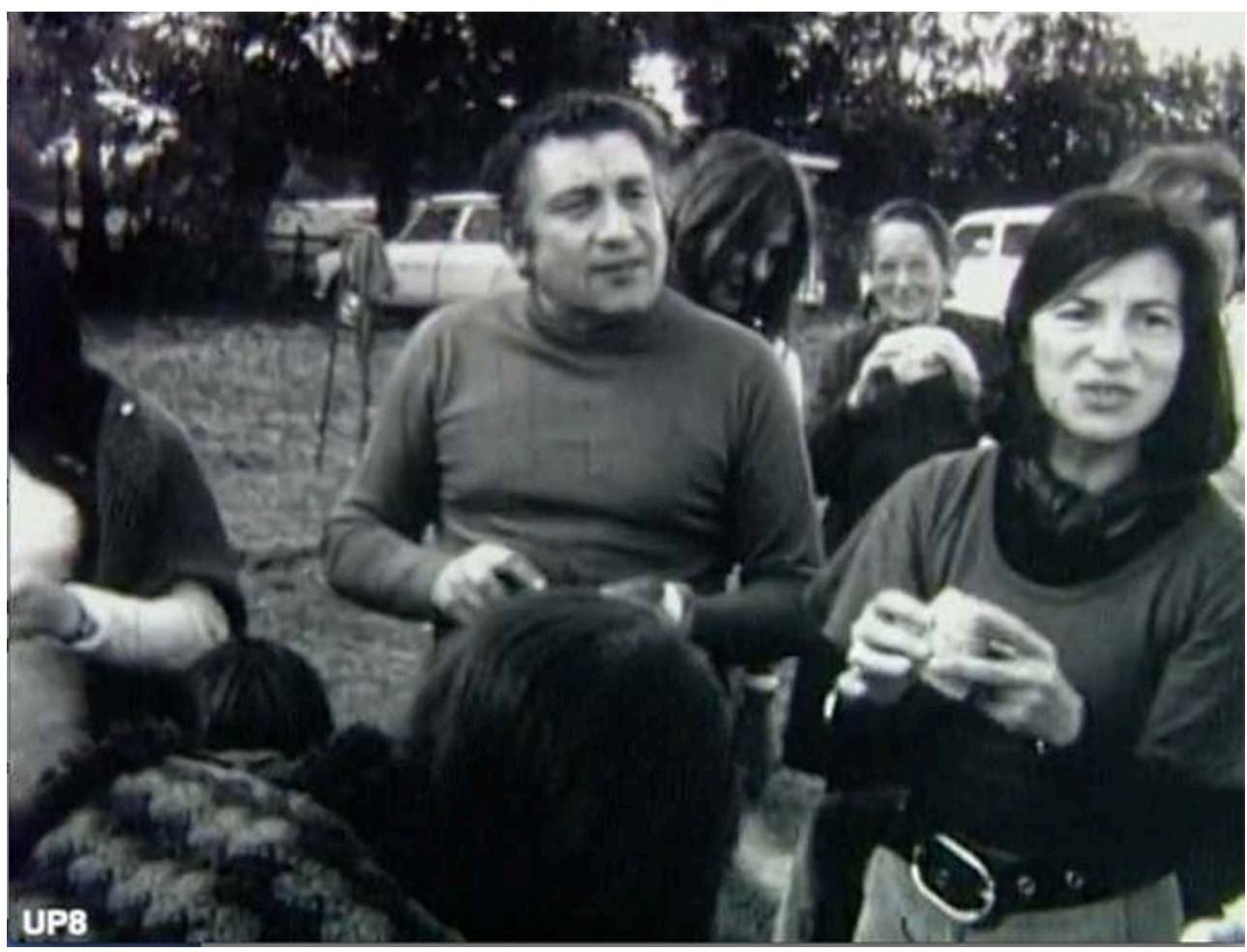

https://les-films-du-beret.jimdofree.com

27 Mener la lutte enfin, dans les échanges parfois tendus lors des choix stratégiques entre responsables syndicaux où Bernard Lambert est encore présent, mais aussi sur le terrain, dans la scène de la "visite » au sous-préfet, où ,filmé de dos et au milieu des militants, sa truculence et son verbe font mouche. 
Figure 6 : B. Lambert devant la sous-préfecture (La Reprise abusive)

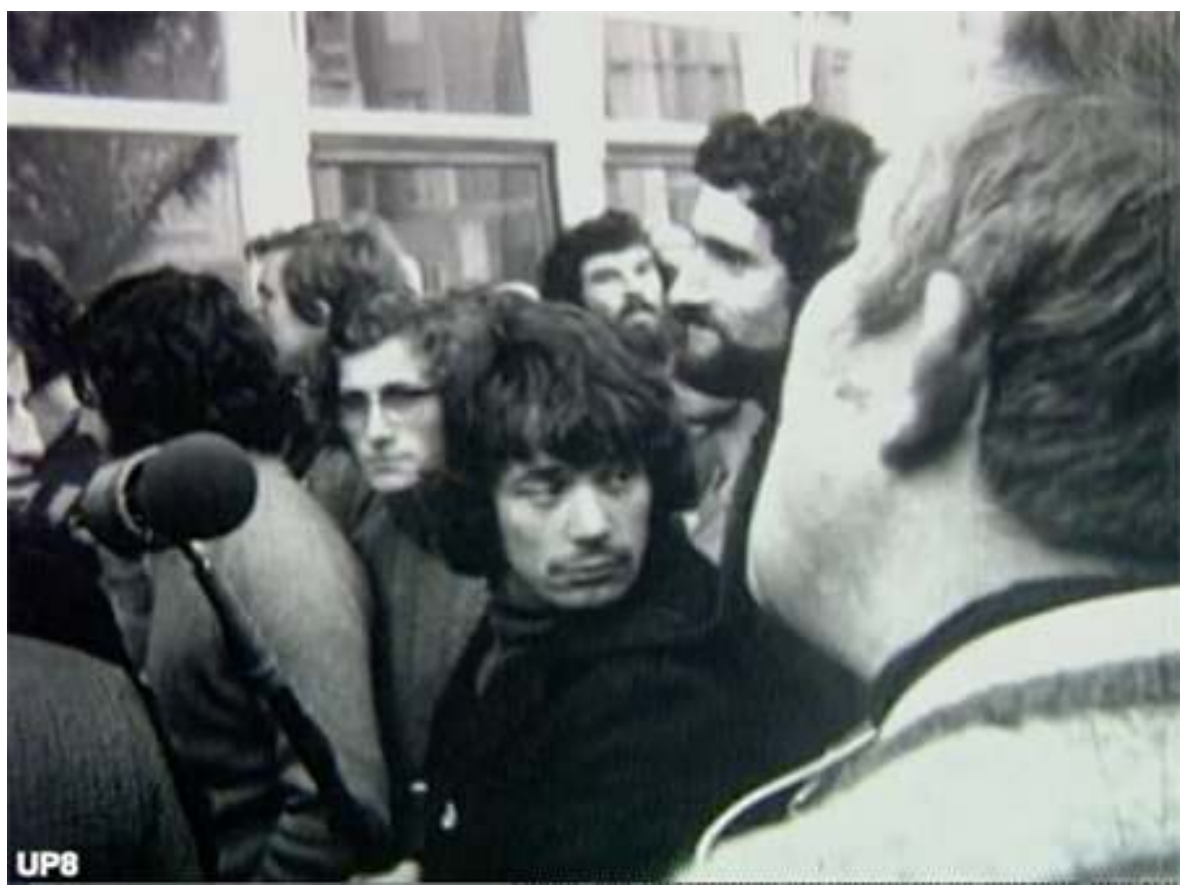

https://les-films-du-beret.jimdofree.com

La figure du leader est également centrale dans le dernier opus du Front paysan, autour de Jean Huillet, lui aussi passé par le CDJA de l'Hérault, avant de fonder en 1975, au moment même du tournage du film, le Mivoc (Mouvement d'intervention des viticulteurs occitans) (Martin, 2008). De manière explicite, le film débute sur une longue prise de parole de J. Huillet dans une réunion publique qui projette le spectateur au cœur des enjeux du conflit viticole, avant le lancement du générique. 
Figure 7 : Jean Huillet en réunion

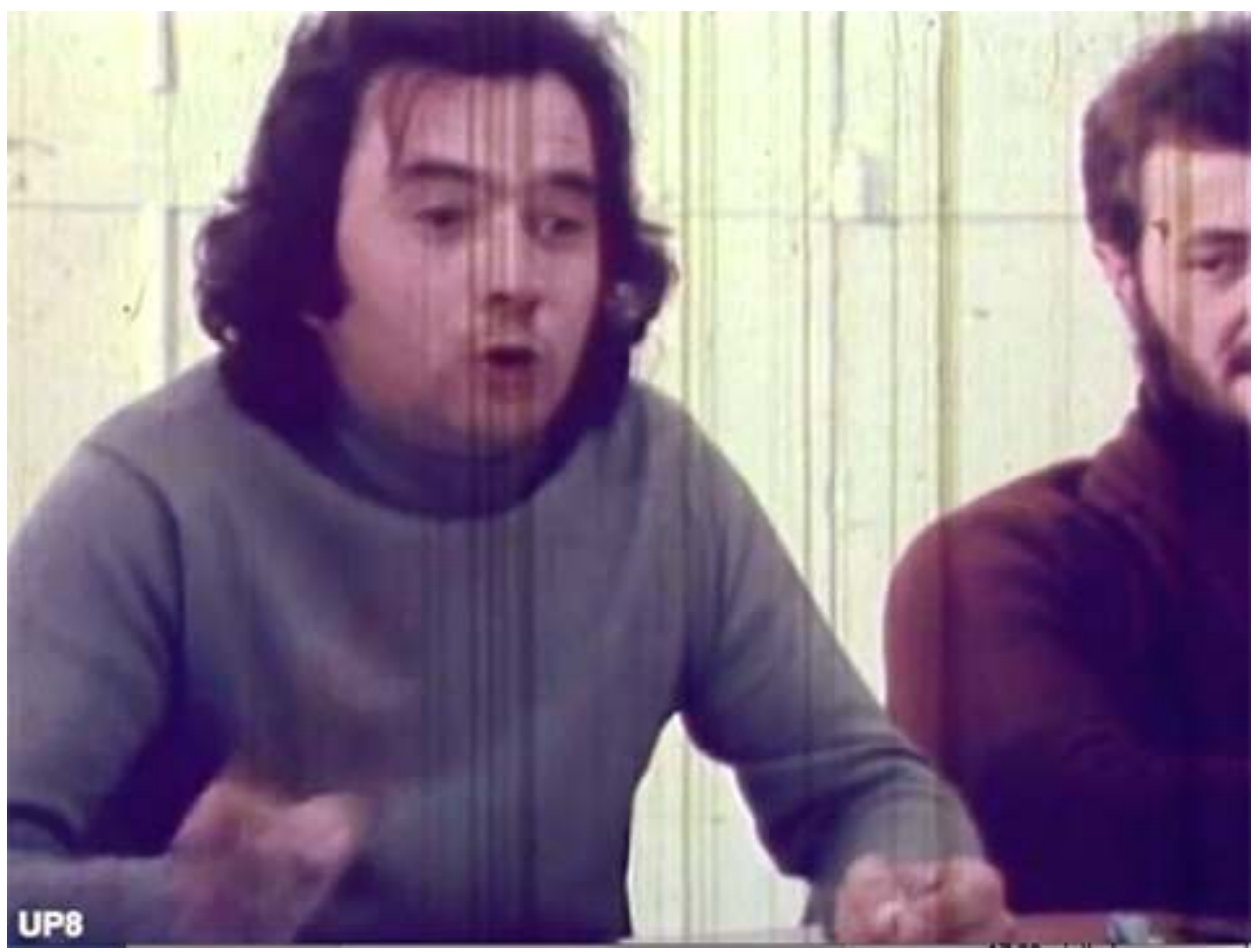

https://les-films-du-beret.jimdofree.com

Figure 8 : Jean Huillet sur les barrages

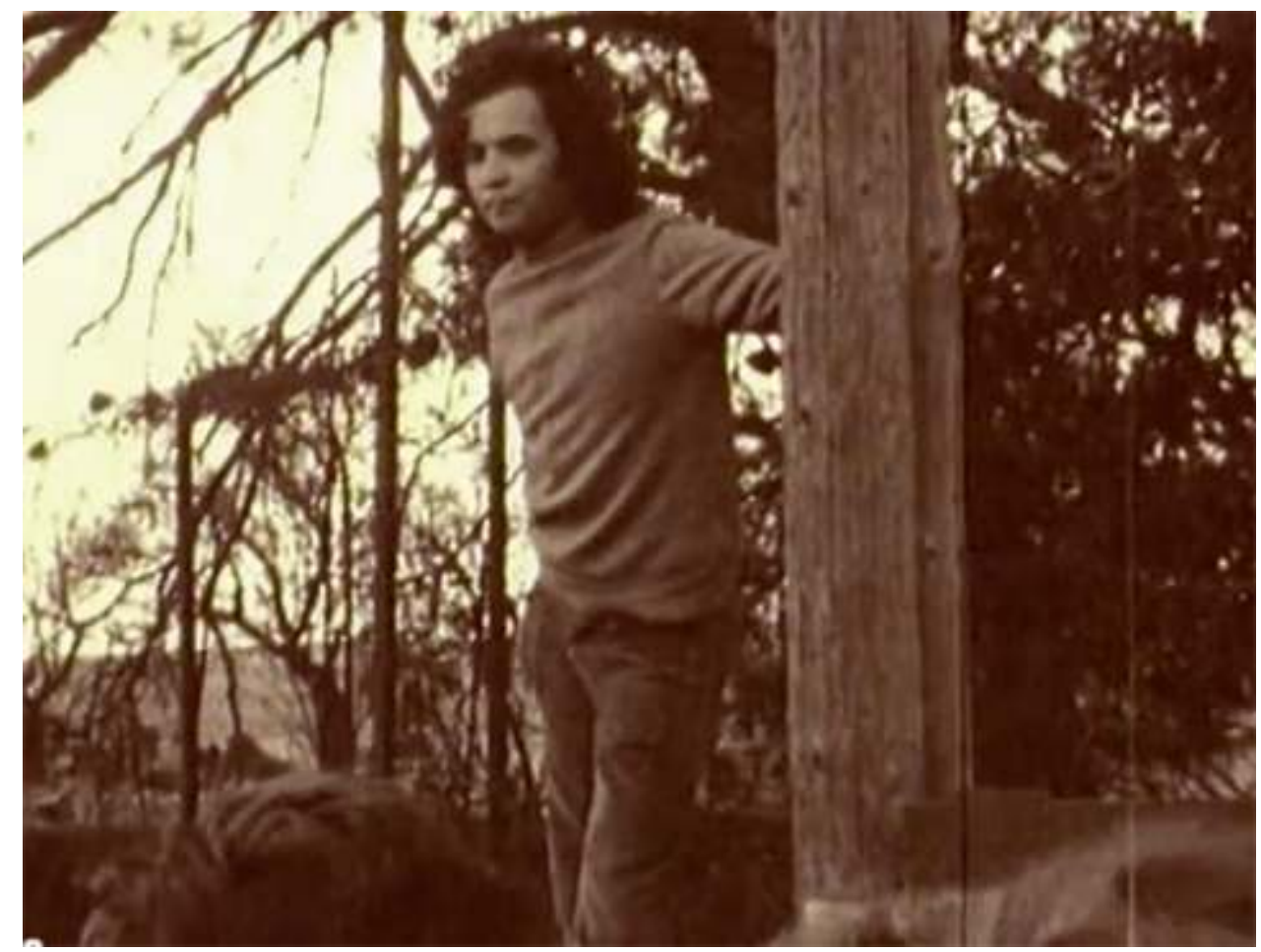

https://les-films-du-beret.jimdofree.com 
On trouve ensuite la figure du chef de guerre haranguant ses troupes dans une des multiples opérations d'un Midi viticole où la tension avec les forces de l'ordre est à son comble, quelques mois seulement avant la fusillade de Montredon.

Enfin, autre spécificité, la filiation avec la grande histoire du Midi viticole et la révolte de 1907 que le film met en scène confrontant le récit du grand-père, victime de la répression, mettant en garde son digne héritier.

Figure 9 : Jean Huillier et son grand-père évoquent les luttes du passé ( $N$ 'y a pro)

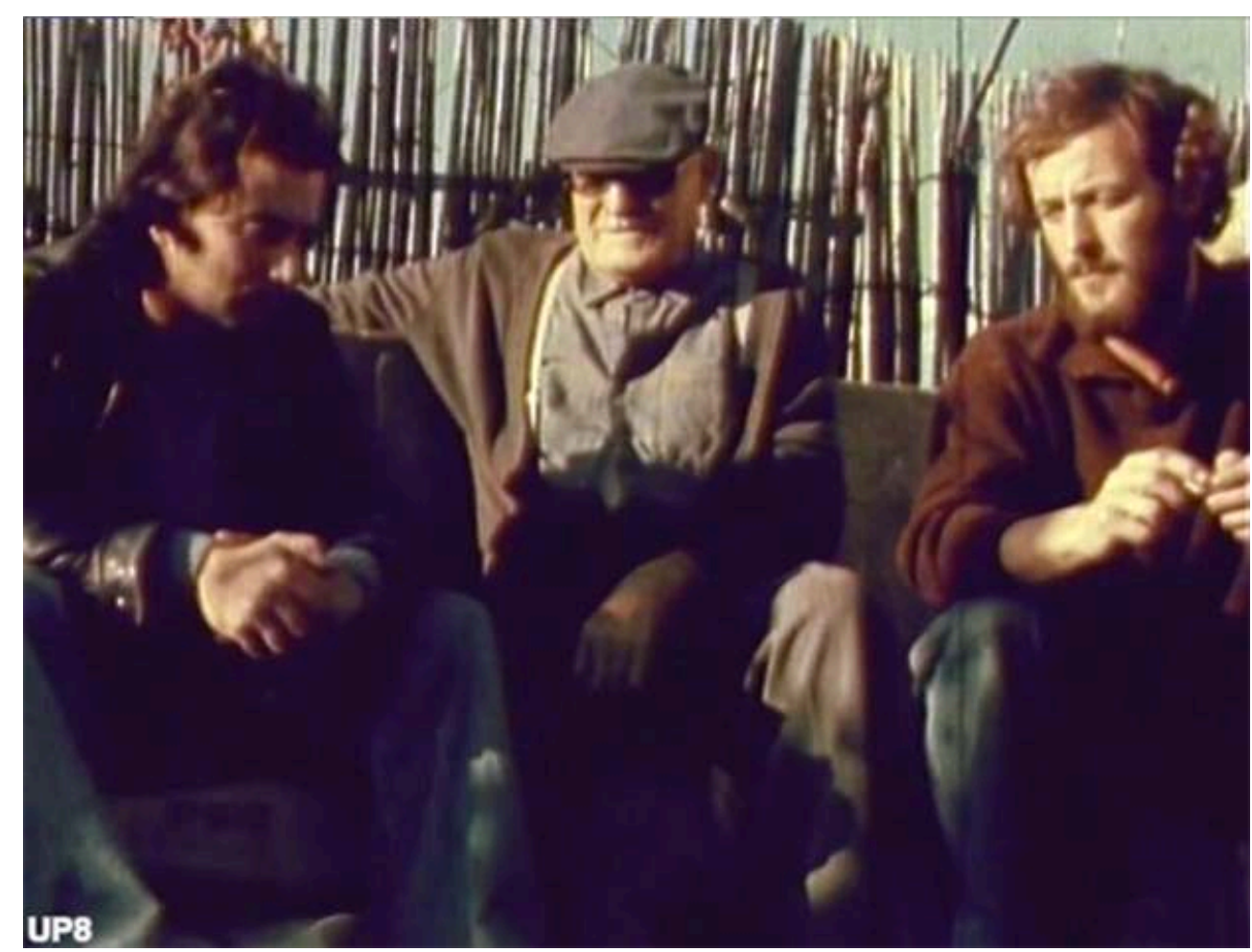

https://les-films-du-beret.jimdofree.com

Si Bernard Lambert et Jean Huillet crèvent l'écran, la mise en avant de la force du groupe et l'affirmation des pratiques transversales constituent aussi un point central pour un collectif militant, le Front paysan et une organisation, les Paysans travailleurs qui revendiquent la primauté de la base et du collectif, contre les logiques d'appareils et les hiérarchies figées. Dans tous les films, de nombreuses séquences rendent compte de ces débats et de ces échanges. Ainsi dans La Reprise abusive, la figure dominante de Bernard Lambert est contrebalancée par plusieurs scènes de réunion filmées à «hauteur de militants", au milieu des participants, tandis que résonne l'appel à la solidarité. 
Figure 10 : Au milieu des militants (La Reprise abusive)

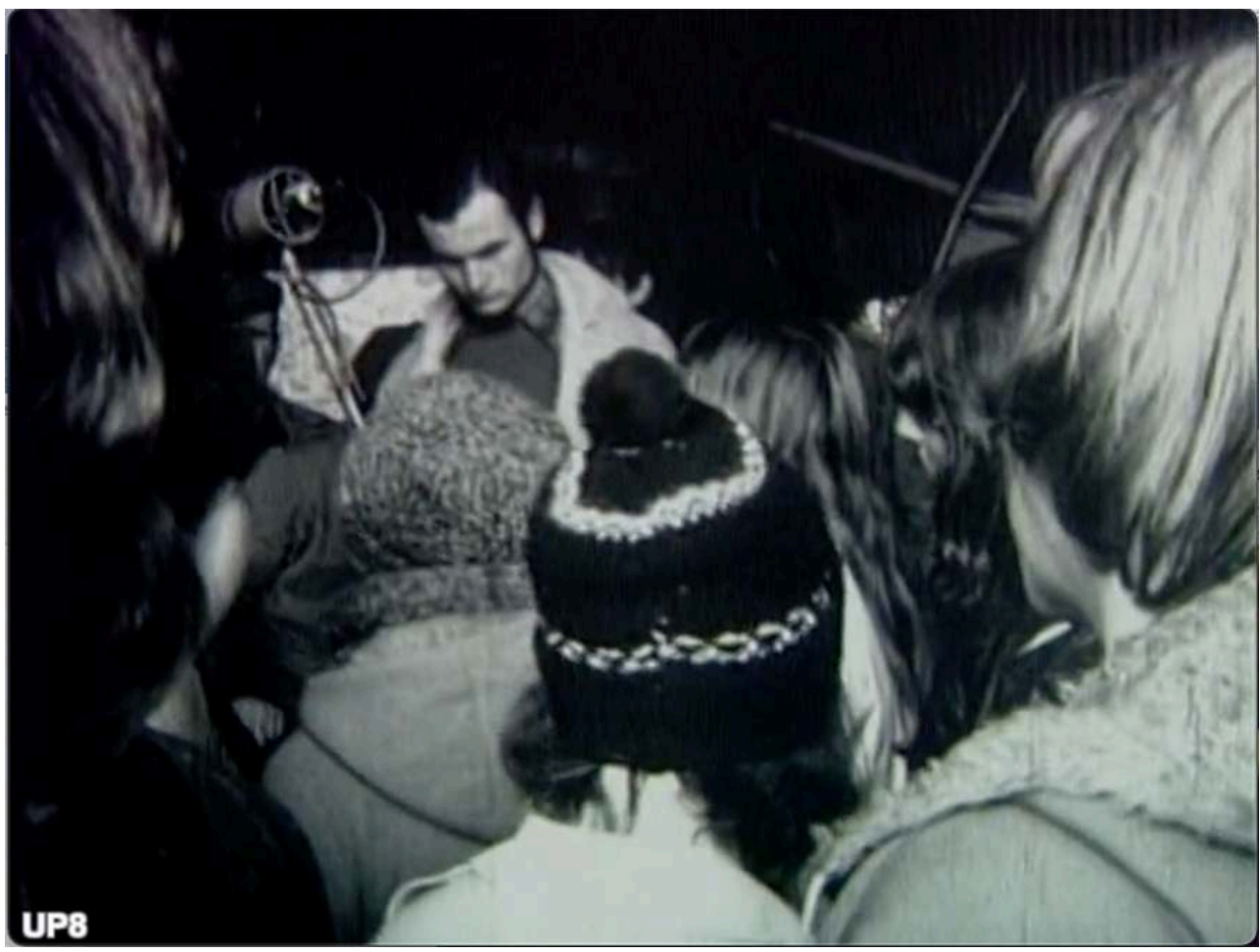

https://les-films-du-beret.jimdofree.com

Des dettes pour salaire constitue un contre-exemple encore plus convaincant, où il n'apparaitt pas de leaders clairement identifiés, mais bien davantage une convergence des actions et des luttes, la mise en commun des savoir-militer et des expériences. Un mot d'ordre que relaie le dispositif filmique choisi. 
Figure 11 : Militer sur un pied d'égalité (Des dettes pour salaire)

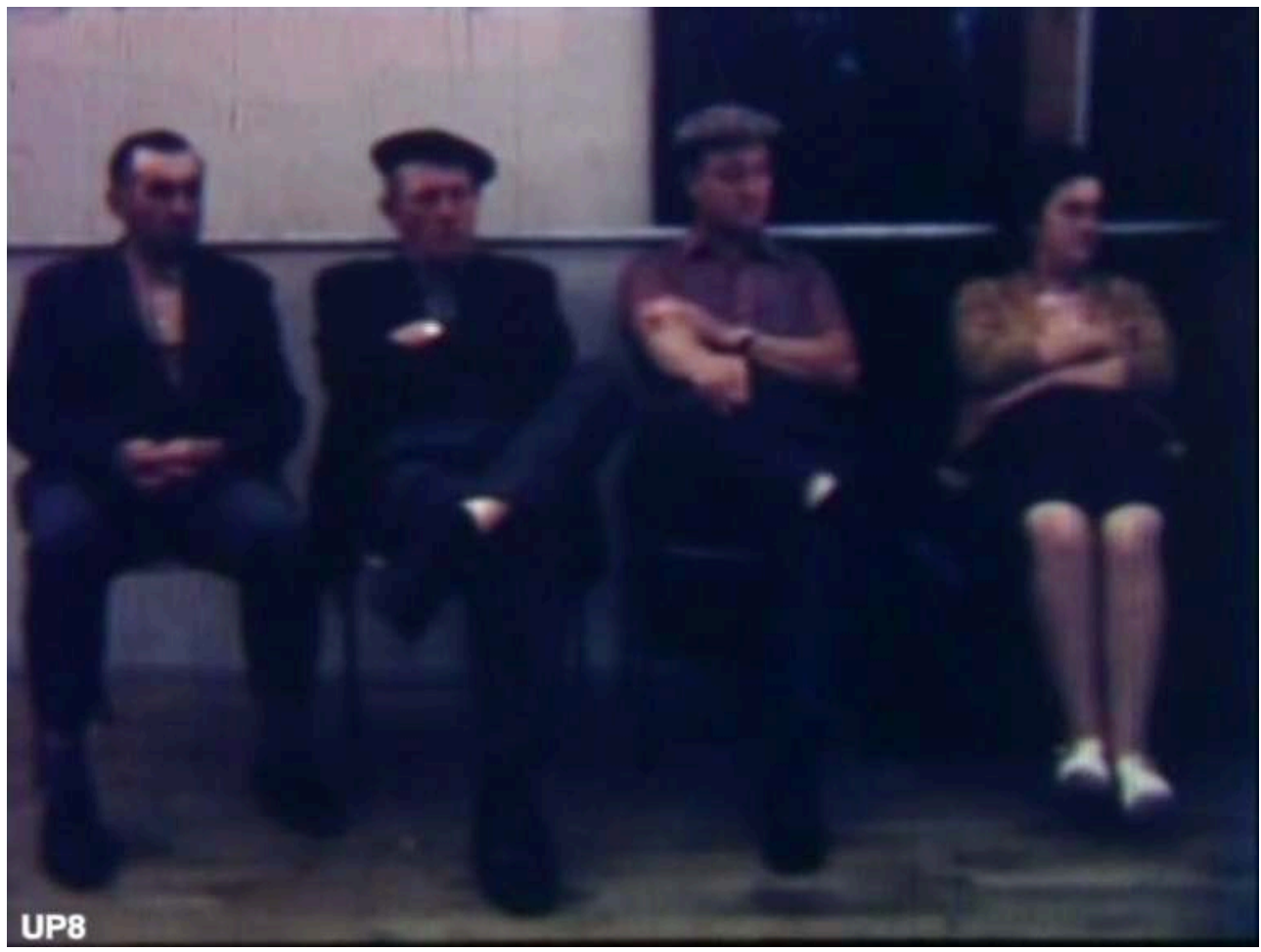

https://les-films-du-beret.jimdofree.com

33 À l'occasion d'une longue séquence relatant le processus d'organisation du collectif, la voix off accompagne un long travelling sur les participants à la réunion, qui renforce cette volonté d'égaliser les conditions: " pour atteindre cet objectif, les éleveurs avec les paysans travailleurs constituent l'association de défense des éleveurs-agriculteurs avec à sa tête un collectif et non pas un président responsable ${ }^{14} »$.

\subsection{Les espaces de la lutte: de la ferme à la rue}

34 Au-delà des acteurs, les films explorent aussi les espaces de la lutte collective, et notamment les fermes, lieu de travail et d'organisation de la résistance. Cela pourrait sembler du domaine de l'évidence, surtout dans l'imaginaire des luttes sociales ouvrières, où l'usine est le cœur vivant de la contestation, même si elle n'est pas toujours directement accessible aux grévistes et aux militants. Dans le cas des paysans, la situation est relativement différente, car depuis les années 1960, la structuration d'un répertoire protestataire très largement tourné contre l'État a fait de l'espace public, des routes et des rues, ainsi que des espaces urbains les hauts lieux de l'expression collective, avec le recours systématique à de vastes "manifestations pétitions ", voire à des « manifestations destructions ${ }^{15}$ ".

Or, les films du Front paysan révèlent une certaine inflexion de ce répertoire, pour des raisons diverses. D'un point de vue «théorique » tout d'abord, les militants entendent se distinguer de ces grandes manifestations de rue, orchestrées à l'échelle nationale par la FNSEA et dont l'efficacité est jugée de plus en plus faible et surtout qui brouille la diversité voire l'antagonisme des revendications. Plus concrètement, même dans les départements où ils sont bien implantés, ils restent minoritaires et ne peuvent pas 
nécessairement mobiliser aussi massivement. Mais la vraie raison est sans doute ailleurs, dans l'évolution des objectifs de la lutte, qui vise moins l'État que d'autres acteurs de la filière, accusés d'être les principaux responsables des difficultés d'une majorité des agriculteurs. Dans ces conditions, même si l'État, notamment dans son usage dévoyé de la force publique et dans son soutien sans faille aux « puissants », peut être pris pour cible, ce n'est pas la principale, et l'action peut se concentrer sur d'autres espaces, au cœur même de l'exploitation paysanne.

Cette inflexion de la géographie contestataire remet pour partie la ferme au cœur de la contestation, à la fois comme espace de travail, comme espace de sociabilité politique et comme espace de lutte. Espace de travail permettant de rendre compte des conditions concrètes de l'existence paysanne, tant dans les prises de vue, servant parfois à introduire le film comme dans les premiers plans de La Reprise abusive, où se succèdent de manière "classique " le travail féminin et le travail masculin, basse-cour/tracteur (fig. 12 et 13).

Figure 12 : La famille Chapeau au travail (La Reprise abusive)

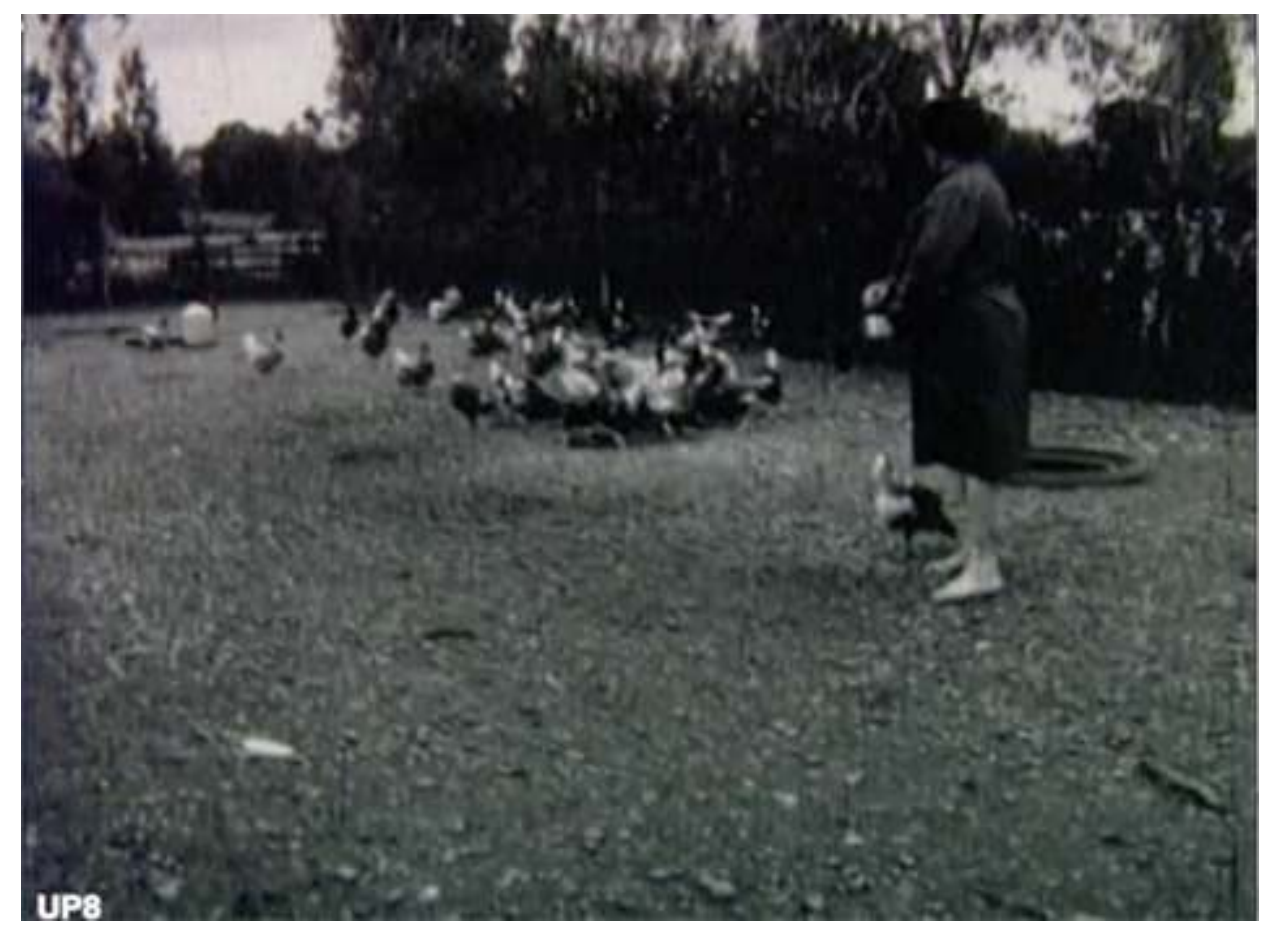

https://les-films-du-beret.jimdofree.com 
Figure 13 : La famille Chapeau au travail (La Reprise abusive)

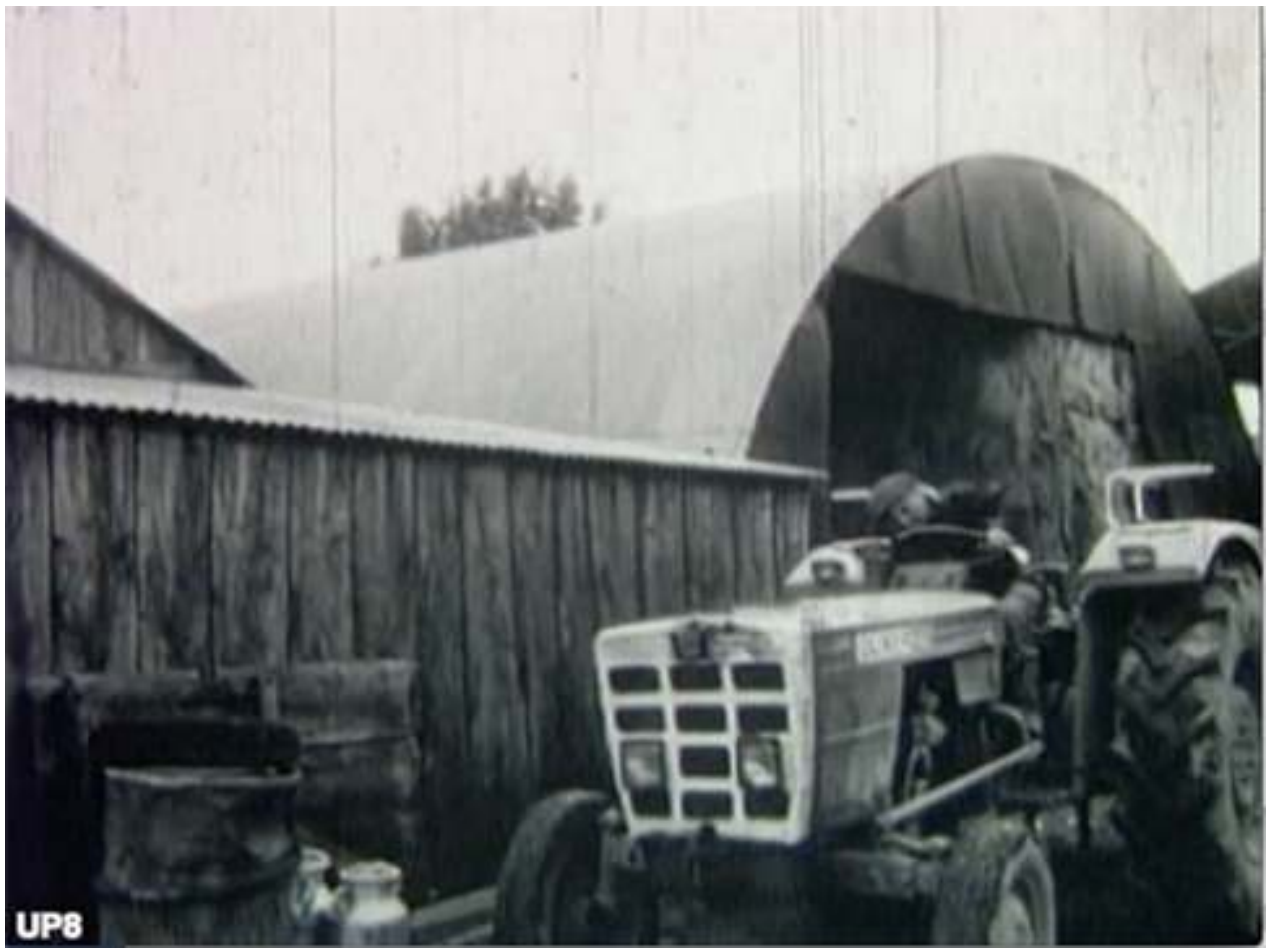

https://les-films-du-beret.jimdofree.com paysan, notamment pour dénoncer la pénibilité des conditions de travail des producteurs. L'étable sert également de décor dans lequel s'exprime un certain nombre de protagonistes. Derrière la mise en image d'un travail paysan souvent méconnu ou idéalisé figure également la volonté de souligner sa pénibilité, comme dans la séquence où les cultivatrices détaillent avec minutie leur journée de travail, dont la longueur contraste avec la faiblesse des revenus tirés de la " paie du lait ». On retrouve dans Des dettes pour salaire, dans une moindre mesure mais dès le générique, les tâches quotidiennes des éleveurs-engraisseurs, notamment l'alimentation à base d'aliments fournis par la firme Sander, qui sont présents à de très nombreuses reprises à l'arrièreplan.

38 La ferme est encore plus centrale dans La Reprise abusive, puisqu'elle est l'objet même de la lutte entre le fermier et son propriétaire. La présentation des bâtiments et des terres, plan à l'appui, en est une parfaite illustration, tout comme les réunions qui y sont organisées, soit pour informer ou mobiliser les militants, soit pour la protéger contre une éventuelle action des forces de l'ordre ${ }^{16}$. Ici, le parallèle est particulièrement fort avec l'usine en lutte, notamment dans les propos tenus par les acteurs, surtout lors de la mise en défense de la ferme Pellerin: "Voilà le dispositif, et dès le lundi, on a renforcé les piquets de grève, les gars sont venus de tous les cantons, il y avait des jours où il y avait 12, 15, 20 gars. » (46' 25) 
Figure 14 : La ferme Pellerin, «protégée » par la solidarité paysanne

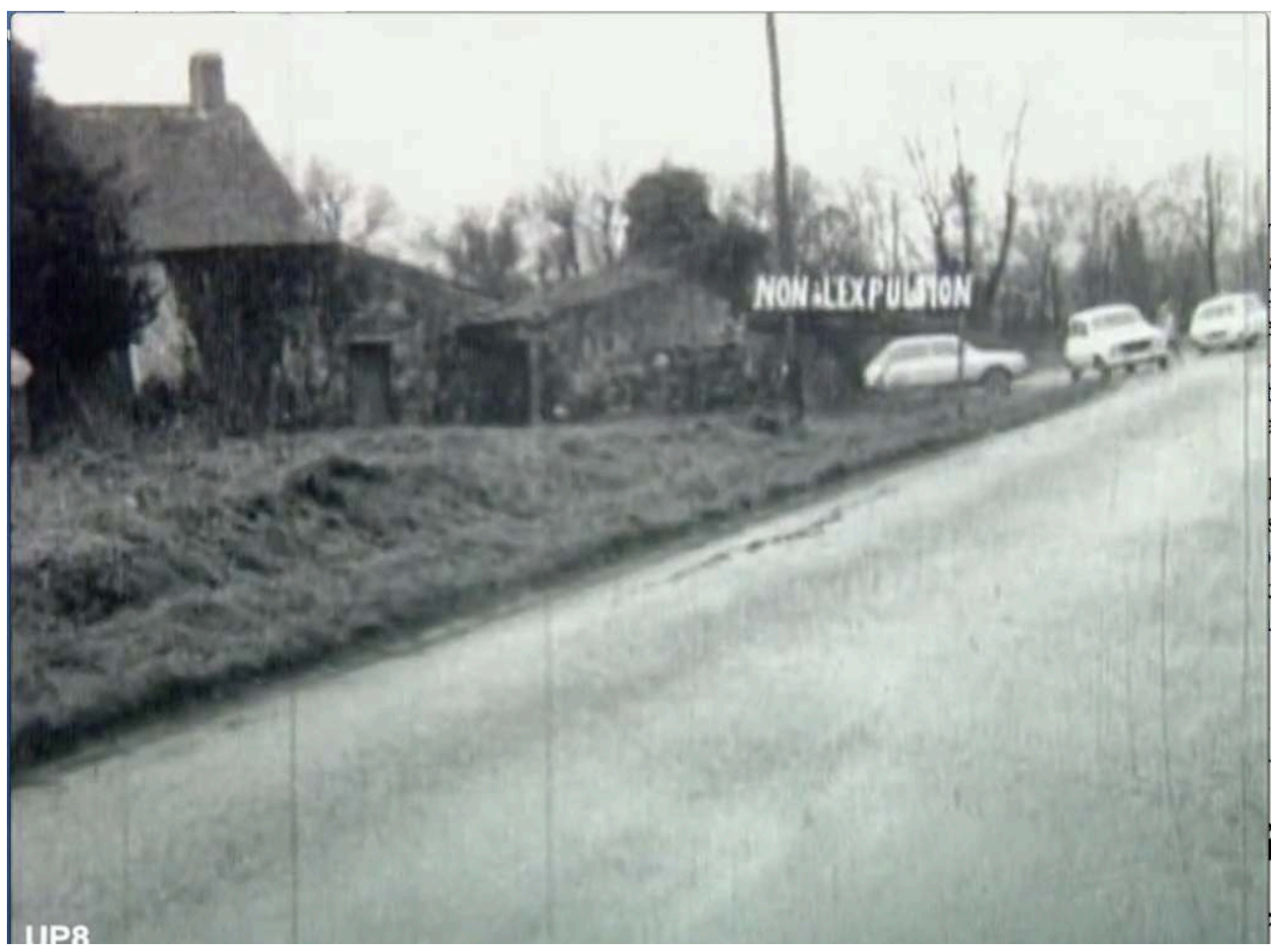

https://les-films-du-beret.jimdofree.com

Enfin, la ferme est le lieu privilégié de la sociabilité militante, des échanges et des discussions qui sont très présentes dans les trois premiers films. Au collectif qui s'exprime dans la cour ou les hangars se juxtapose l'individuel, à l'intérieur de la ferme : tel est le cas des très nombreuses scènes tournées dans les cuisines, autour d'un café ou d'un verre, où les protagonistes exposent leurs difficultés. Dans le long conflit de la grève du lait, la salle commune prend des airs de salle de commandement, le téléphone relayant les mots d'ordre des militants engagés sur les lieux de mobilisation. 
Figure15 : Une étable salle de réunion (La Reprise abusive)

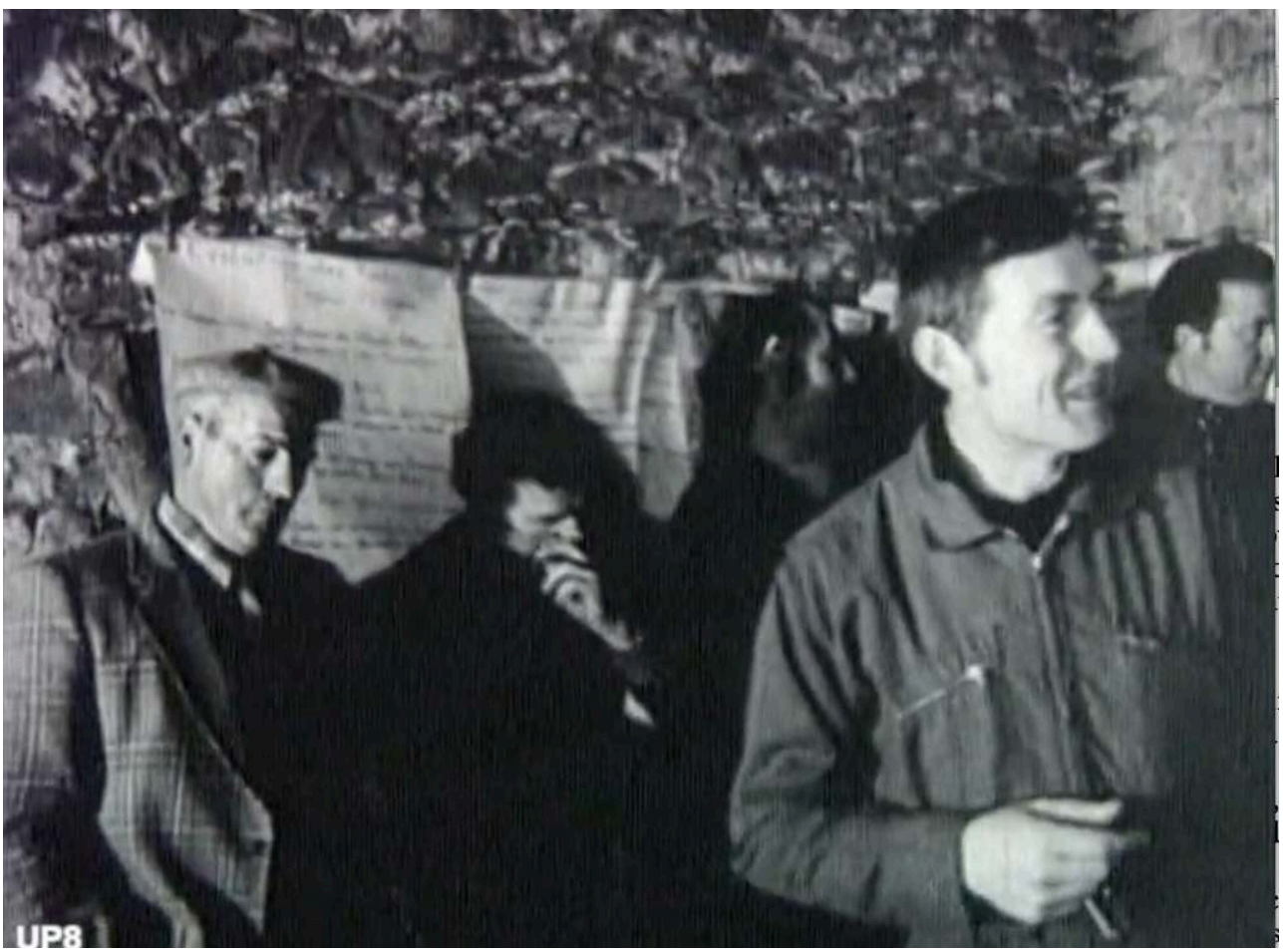

Figure 16 : La cuisine, QG des luttes (La Guerre du lait)

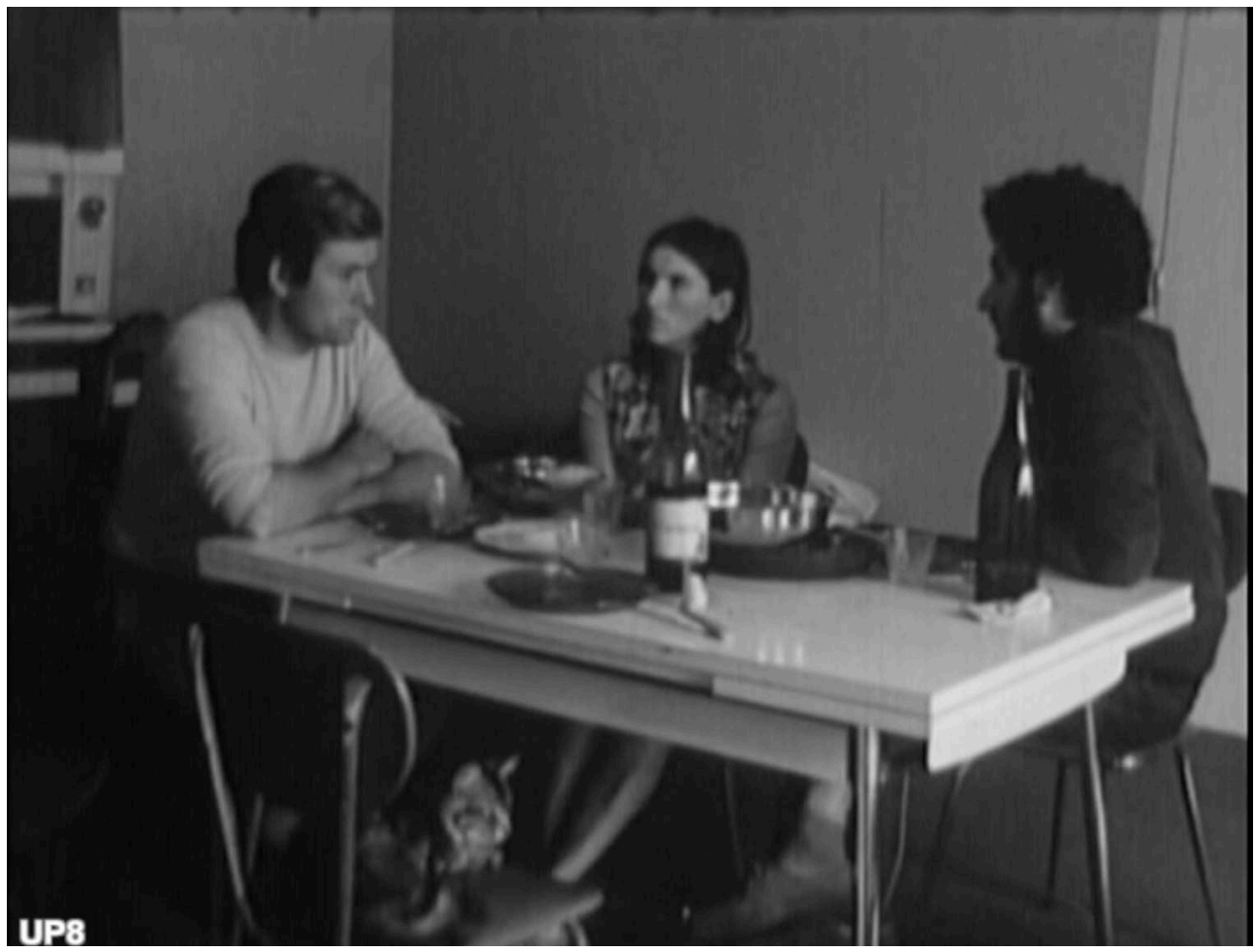

https://les-films-du-beret.jimdofree.com

Pour autant, l'espace public n'est pas négligé, et la manifestation reste un élément essentiel de l'action collective, surtout dans le cadre de deux des conflits, La Guerre du lait et N'y a pro. En effet, qu'il s'agisse dans le premier de bloquer les camions de lait et 
de faire pression sur les coopératives, ou dans le Midi, en interceptant les camions de vins italiens, la lutte exige de contrôler les routes et les accès des zones de stockage ou de production. C'est un mode d'action que maitrisent bien les militants : il constitue, depuis «l'invention » des barrages en 1953 dans le Midi viticole puis dans le Sud-Ouest quelques mois plus tard, un moyen efficace de pression, à la fois sur les pouvoirs publics, sur l'opinion et sur les protagonistes de la lutte. Toutefois, une fois encore, les Paysans travailleurs se le réapproprient. À l'origine, en 1953, puis dans les années 1960, lorsqu'ils sont adoptés et diffusés par la FNSEA, ces barrages visent d'abord à perturber la circulation et donc à faire pression sur les pouvoirs publics et l'opinion. Ce qui n'est pas tout à fait le cas pour la grève du lait, où il s'agit de bloquer les approvisionnements de laiteries, comme dans les premières images de La Guerre du lait, où les camions sont parqués en désordre sur la place de l'église de Guiscriff (Morbihan). De même, dans $N$ y'a pro, la séquence centrale de "vidange » des camions par les commandos viticoles, avec en fond sonore la chanson de Marti, est particulièrement emblématique du répertoire d'actions des viticulteurs.

41 La rue est enfin le théâtre de manifestations plus classiques, comme la manifestationpétition des femmes pendant la grève du lait, ainsi que les distributions gratuites permettant de populariser la lutte. La pression exercée par les manifestants sur les lieux de pouvoir, comme le siège des coopératives ou la tentative d'occupation de la sous-préfecture d'Ancenis donnent lieu à plusieurs séquences filmées ou de récits. Des manifestations qui mettent aussi en jeu les forces de l'ordre, lorsque celles-ci interviennent, renvoyant à des issues plus classiques des mobilisations paysannes, même si dans le Midi viticole, depuis le début des années 1970, la dimension violente et radicale s'est intensifiée, avec de très nombreuses destructions, notamment sur les infrastructures de transport. Même si les moyens de lutte diffèrent, les films et leur diffusion contribuent à la construction d'une identité militante commune.

\section{Des films militants pour les militants ? Une grammaire de la contestation}

\subsection{Raconter des luttes exemplaires}

Au-delà des spécificités propres à chaque épisode, de l'histoire qu'ils racontent, des choix de mises en scène et de construction, il est stimulant de considérer ces films pour ce qu'ils sont, c'est-à-dire des outils de diffusion et de débat au service des militants. Par leur narration d'ensemble, ils constituent une sorte de modèle, d'étendard d'une lutte réussie, assez similaire au compte rendu des manifestations et des réunions que l'on trouve de manière récurrente dans la presse syndicale et partisane tout au long $\mathrm{du}$ $\mathrm{xx}^{\mathrm{e}}$ siècle, et dont le but est tout à la fois d'informer, mais aussi de donner les cadres et les structures d'une action exemplaire.

On trouve tout d'abord les "victimes ", ici de petits agriculteurs, à la situation précaire, placés en situation de misère extrême par la pression du système capitaliste : prix du lait tiré à la baisse, expulsion de fermiers de leur exploitation, éleveurs endettés « de force " par les firmes d'élevage intégré, viticulteurs ne pouvant vendre leur récolte à des prix rémunérateurs. Les protagonistes peuvent être très nombreux, comme dans $L a$ Guerre du lait ou N'y a pro, ou davantage individualisés, comme dans Des dettes pour salaire, où plusieurs éleveurs se succèdent devant la caméra, filmés au plus près de leur 
exploitation et de leur condition d'existence. Leur situation est explicitée par des informations techniques (graphiques, paroles d'expert ou recours à des titres de presse.) Dans La Guerre du lait, en raison sans doute de sa dimension pionnière, plusieurs séquences du film traitent des autres aspects de la pression capitaliste sur l'exploitation paysanne.

Puis vient le temps de l'espoir, apporté par des militants, qui sont à la fois proches et efficaces, mettant des mots et des explications sur les situations les plus confuses, et surtout nouant une chaine de solidarité en mobilisant les soutiens locaux et nationaux. Les meetings, les manifestations, les actions collectives sont autant de moyens de créer une dynamique positive et de rassembler les énergies dispersées, de faire renaitre l'espoir. C'est là que les dispositifs filmiques évoqués précédemment, le cadre familier et familial de la cuisine ou de la cour de ferme jouent à plein pour renforcer la dimension solidaire et les processus d'identification.

Le temps de la lutte constitue nécessairement un moment essentiel de ces quatre films, matérialisant la capacité des acteurs de faire évoluer le rapport de force initial. Selon les situations, le recours à l'action se positionne de manière plus ou moins précoce dans le récit: pour La Guerre du lait, elle est présente dès le générique, avec les camions rassemblés sur la place, au son d'une cloche - qui évoque une sorte de glas - mais elle se concentre dans le premier tiers du film, entre la douzième et la vingtième minute, avec plusieurs scènes de manifestation. Dans La Reprise abusive, les scènes de lutte apparaissent après un long processus " préparatoire ", pour culminer entre la 29' et la 38', avec d'abord la visite au sous-préfet et surtout la mise en défense de la ferme des Pellerin, qui matérialise la solidarité paysanne et la convergence des luttes. C'est dans Des dettes pour salaire, que la mobilisation est la moins présente, les manifestations de soutien étant rapidement évoquées par la voix off, avec quelques photographies et titres de presse, sans doute faute d'images disponibles. 


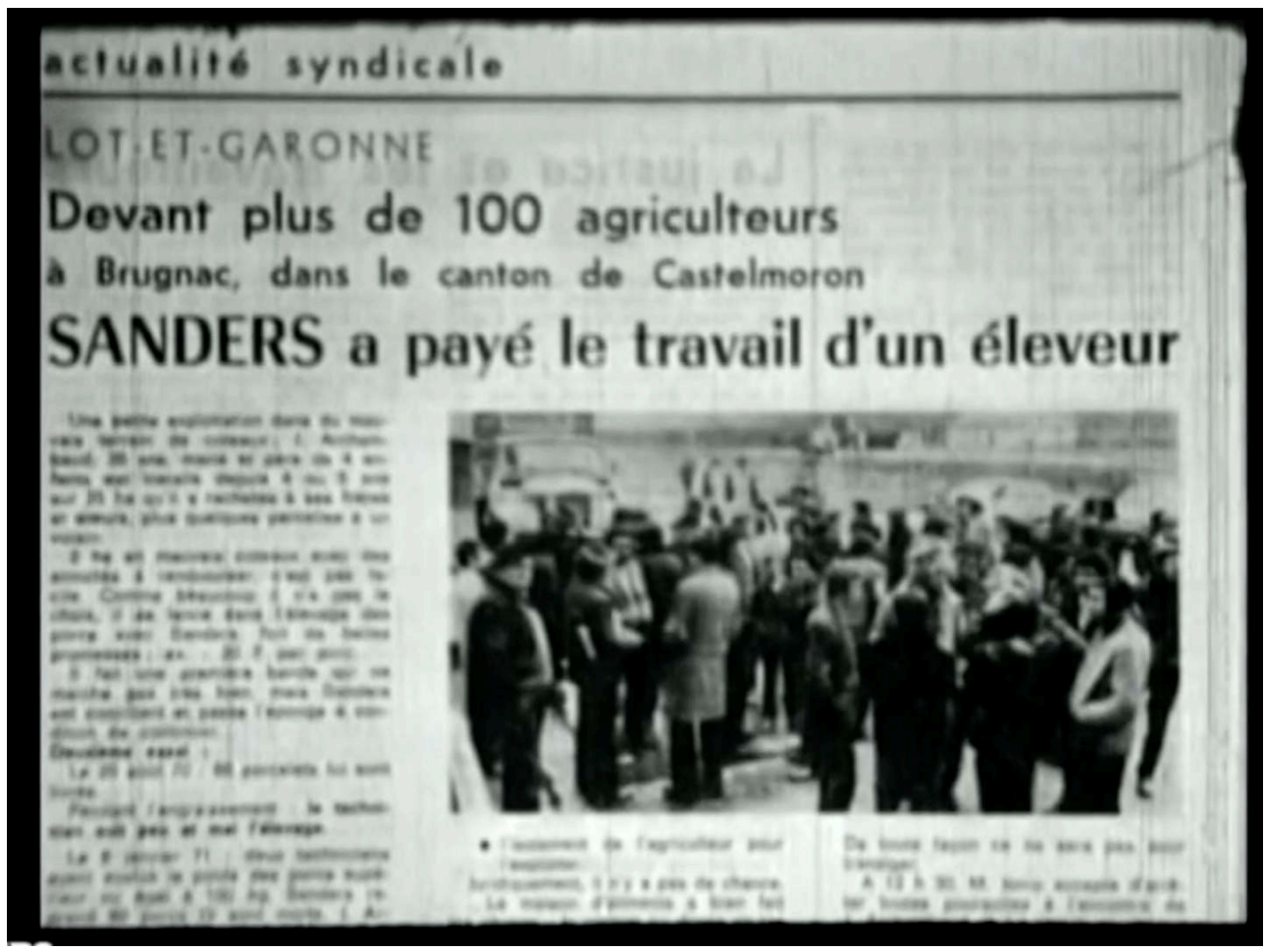

https://les-films-du-beret.jimdofree.com structure la construction du film, sous la forme de trois séquences assez brèves l'épisode des barrages et de cache-cache avec les forces de l'ordre (3'-8'); une seconde séquence, avec la vidange des camions comme réponse aux manœuvres de négociants $\left(20^{\prime}-22^{\prime}\right)$; et enfin l'opération contre l'entreprise Ramel et l'embrasement de Montredon (58'-100').

Enfin, comme dans tout bon récit militant, il faut finir sur une note positive et mobiliser les spectateurs autour d'un projet commun. Dans la plupart des films, cela se traduit par la mise en avant de l'union entre ouvriers et paysans, l'établissement d'un parallèle entre les luttes ouvrières et sociales des années 1970. C'est le cas de la séquence conclusive assez brève de La Guerre du lait, avec des images de différentes luttes du Midi et du Larzac sur fond de chanson militante «Paysans en lutte debout ». Dans Des dettes pour salaire, après une profession de foi d'un paysan en faveur des paysans travailleurs, se succèdent des images de mobilisations : grève du lait, Larzac... avec voix off, puis une chanson de Claude Marti. Le schéma est encore plus appuyé dans $N^{\prime} y$ a pro, où les dernières séquences du film insistent de manière plus précise, argumentée et filmée sur la solidarité avec les luttes ouvrières locales des mineurs de la Grande Combe, des grévistes de Pezenas et de l'usine Griffet, illustrées par des images de manifestations communes. Le dispositif sonore enchaine deux voix off, celle de Guy Chapouillié puis celle d'un participant à une manifestation commune de 1976, la parole d'un viticulteur racontant son expérience avec les ouvriers de Griffet, le tout conclu par une chanson de Claude Marti exaltant les luttes communes. N'y a pro pousse sans doute le plus loin l'insertion dans des luttes plus larges, à travers la voix off qui met des mots sur les maux des viticulteurs : "la crise du Midi viticole ne tombe pas du ciel, elle s'insère dans la crise d'ensemble du monde capitaliste. Les luttes du peuple du tiers

Images du travail, travail des images, 12 | 2022 
monde s'opposent de plus en plus au pillage que leur font subir les pays impérialistes, comme les États-Unis, la Russie ${ }^{17}$ ». Cet élargissement au contexte international se matérialise à l'écran par deux séquences très brèves (fig. 18). Si ces images peuvent paraitre un peu plaquées aux spectateurs d'aujourd'hui, leur présence témoigne aussi de la très forte porosité des luttes et des engagements, et pas seulement d'une phraséologie révolutionnaire, lorsque l'on sait que G. Chapouillié avait été engagé, avec le collectif Vincennes, sur le tournage de deux films relayant la lutte du peuple palestinien ${ }^{18}$.

Figure 18 : Luttes agraires et anticapitalistes (N'y a pro)

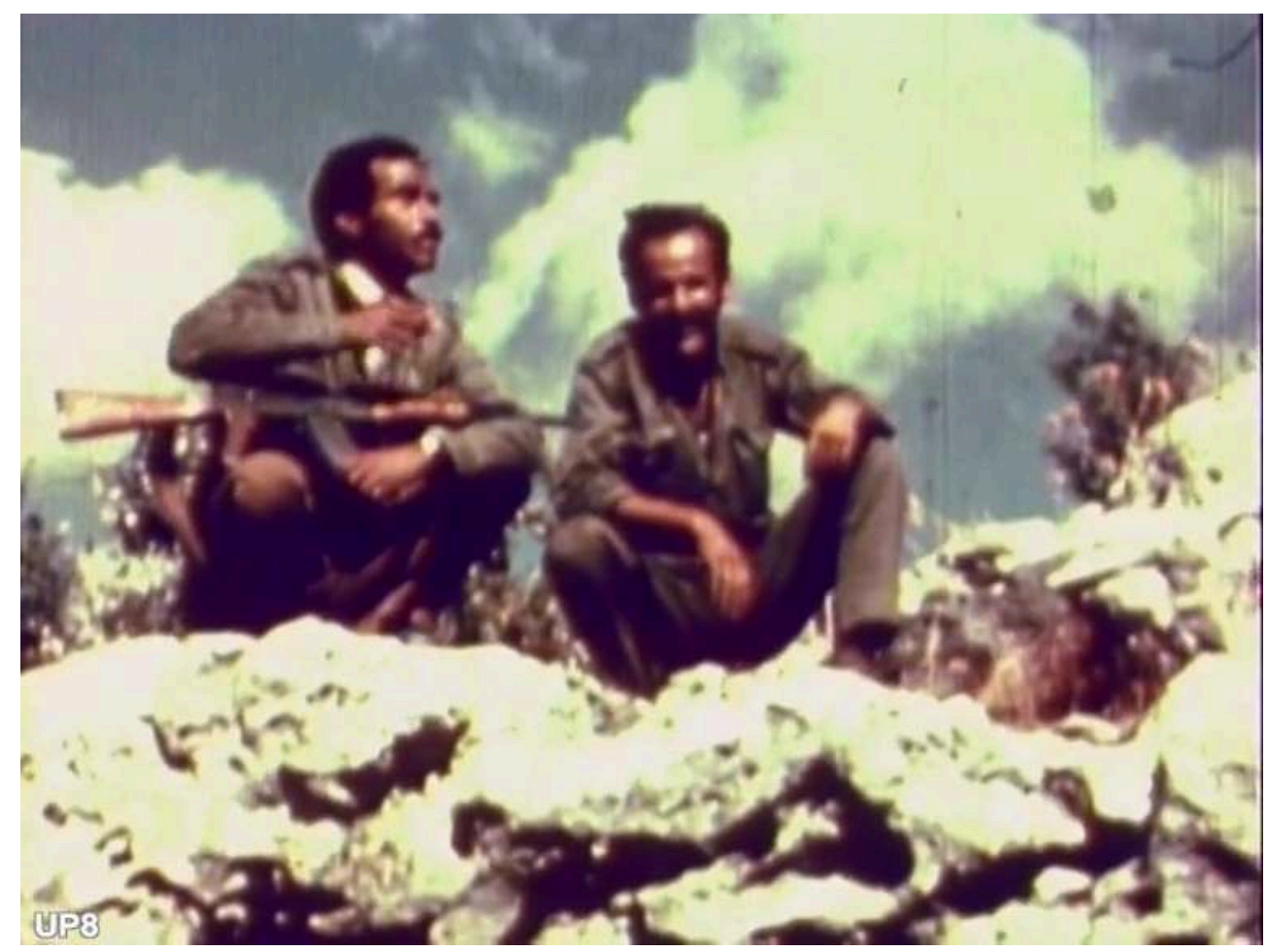

https://les-films-du-beret.jimdofree.com 
Figure 19 : Luttes agraires et anticapitalistes ( $N^{\prime} y$ a pro)

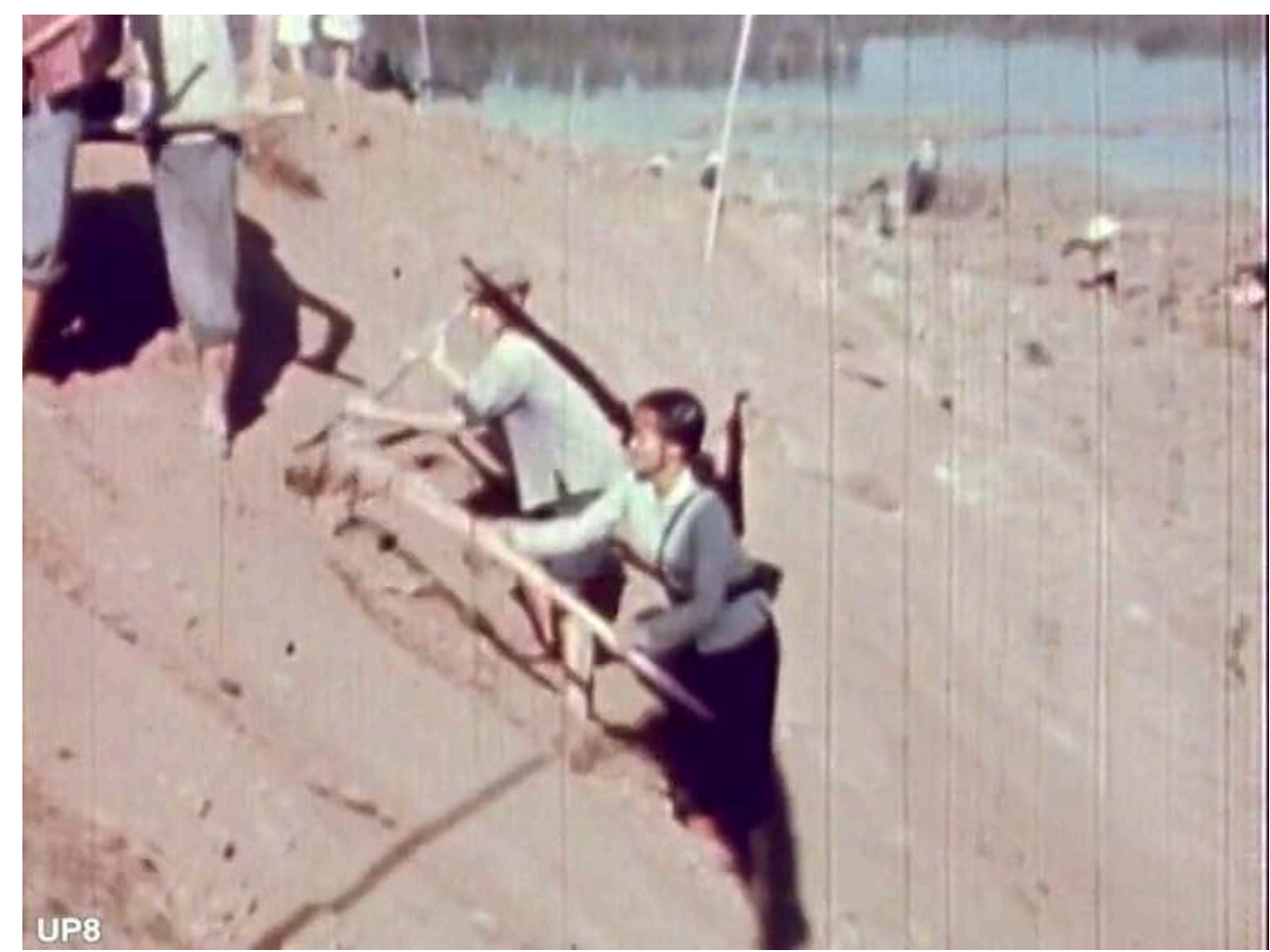

https://les-films-du-beret.jimdofree.com

Dans ce schéma classique d'espoir dans des lendemains qui chantent, seule La Reprise abusive fait exception : elle n'ouvre pas vers des luttes communes, même si la solidarité entre ouvriers et paysans est bien présente, à travers quelques images de la manifestation du 20 novembre de Nantes, où l'orateur annonce en direct à la foule l'intervention des CRS, finalement déjouée par la solidarité paysanne. À la fin du film, c'est malgré tout un message d'espoir qui est envoyé, celui d'une histoire qui, on l'espère, finira bien, autour d'un verre pris en commun dans la cuisine de chapeau où les participants trinquent « À la victoire, y’a pas de raison », avant le générique chanté. 
Figure 20 : Des lendemains qui chantent pour la famille Chapeau, (La Reprise abusive)

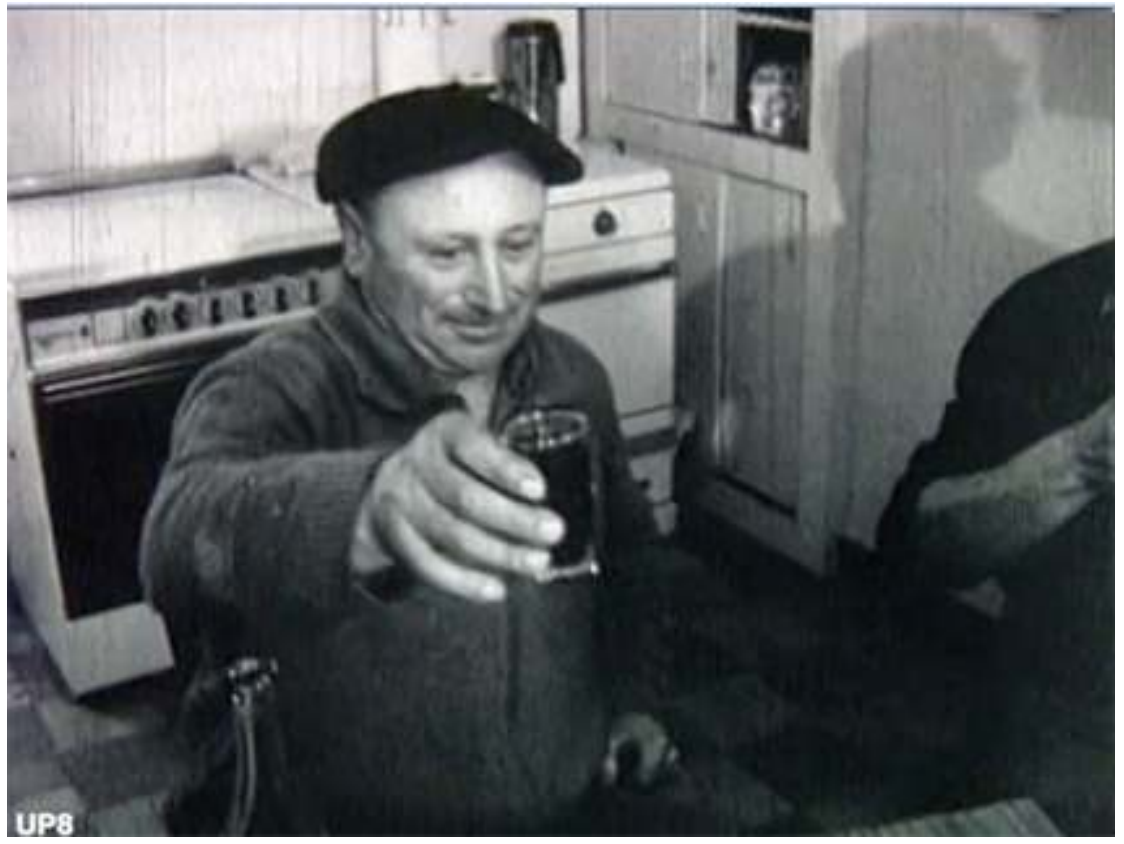

https://les-films-du-beret.jimdofree.com

Figure 21 : Des lendemains qui chantent pour la famille Chapeau, (La Reprise abusive)

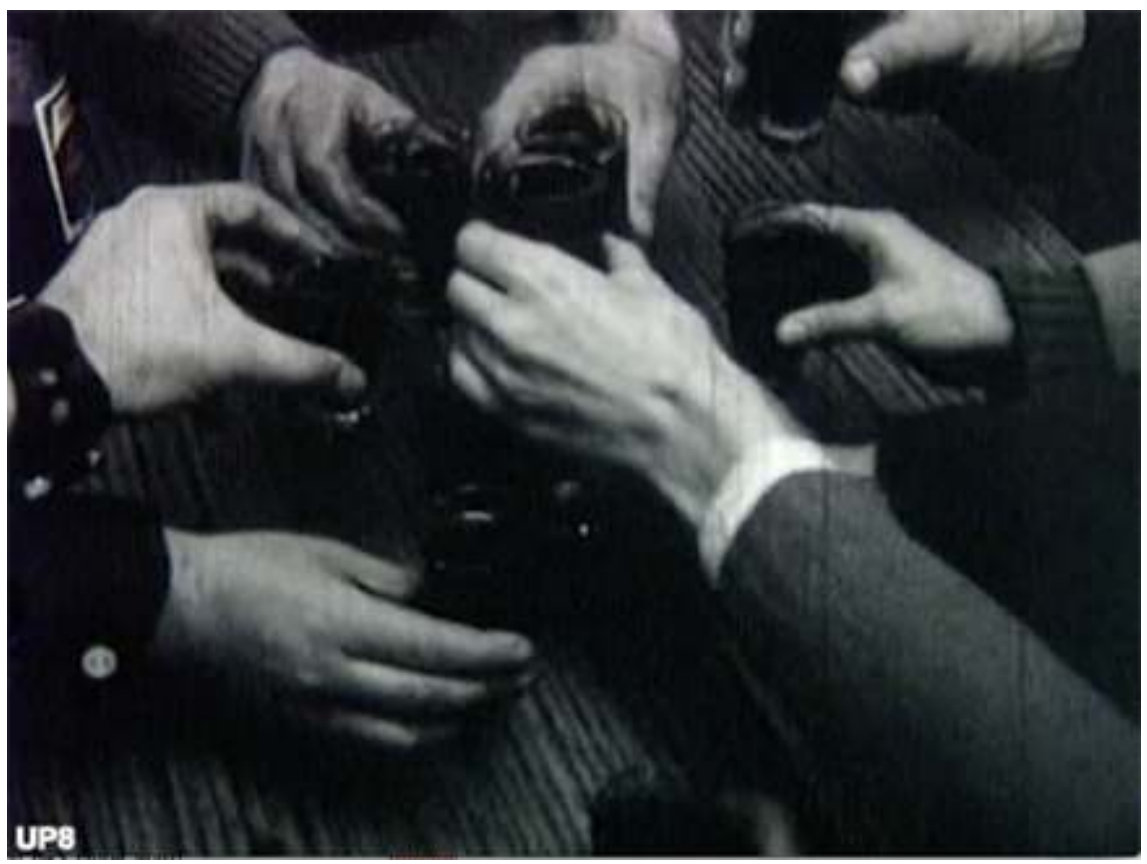

https://les-films-du-beret.jimdofree.com

\subsection{Ridiculiser l'adversaire}

Dans cette mise en image d'une lutte idéale, il est aussi indispensable d'identifier et de fustiger les responsables de la misère paysanne. Derrière les chiffres et les faits se dissimulent aussi des groupes et des idéologies qu'il faut combattre. Au-delà de la 
typologie sans surprise de ces adversaires, avec de fortes similarités avec le monde ouvrier (le patronat, le capitalisme, l'État), la méthode de l'usage disqualifiant de la dérision et du ridicule est privilégiée. Là encore le parallèle avec la presse militante est stimulant, car on y retrouve les mêmes processus visant à caricaturer et à décrédibiliser l'adversaire tant au niveau moral que physique, l'image et l'écriture filmique permettant toutefois de nombreuses innovations. Les quatre films couvrent tout à la fois la diversité des adversaires, mais explorent aussi des formes variées de stigmatisation. Des adversaires puisqu'on y trouve, comme évoqués précédemment, à la fois les protagonistes des luttes intersociales (sur cette classification, voir Braud, 1993) : propriétaires accapareurs ou capitalistes, firmes agro-industrielles, responsables de coopératives, dirigeants syndicaux, État et groupes politiques, force de répression et oligarchie capitaliste financière internationale. Certaines de ces figures sont spécifiques aux luttes paysannes, d'autres s'inscrivent plus classiquement dans la dénonciation du capitalisme.

D'un point de vue filmique, trois procédés majeurs sont utilisés, pour des raisons à la fois pratiques et théoriques, car il n'est pas évidemment facile de disposer de la parole ou de l'image de ses opposants. Le plus «simple » est l'utilisation de la voix off et de documents créés pour l'occasion, comme les caricatures produites par la presse militante et qui sont reprises dans les films.

Figure 22 : Dessins de presse (La Guerre du lait)

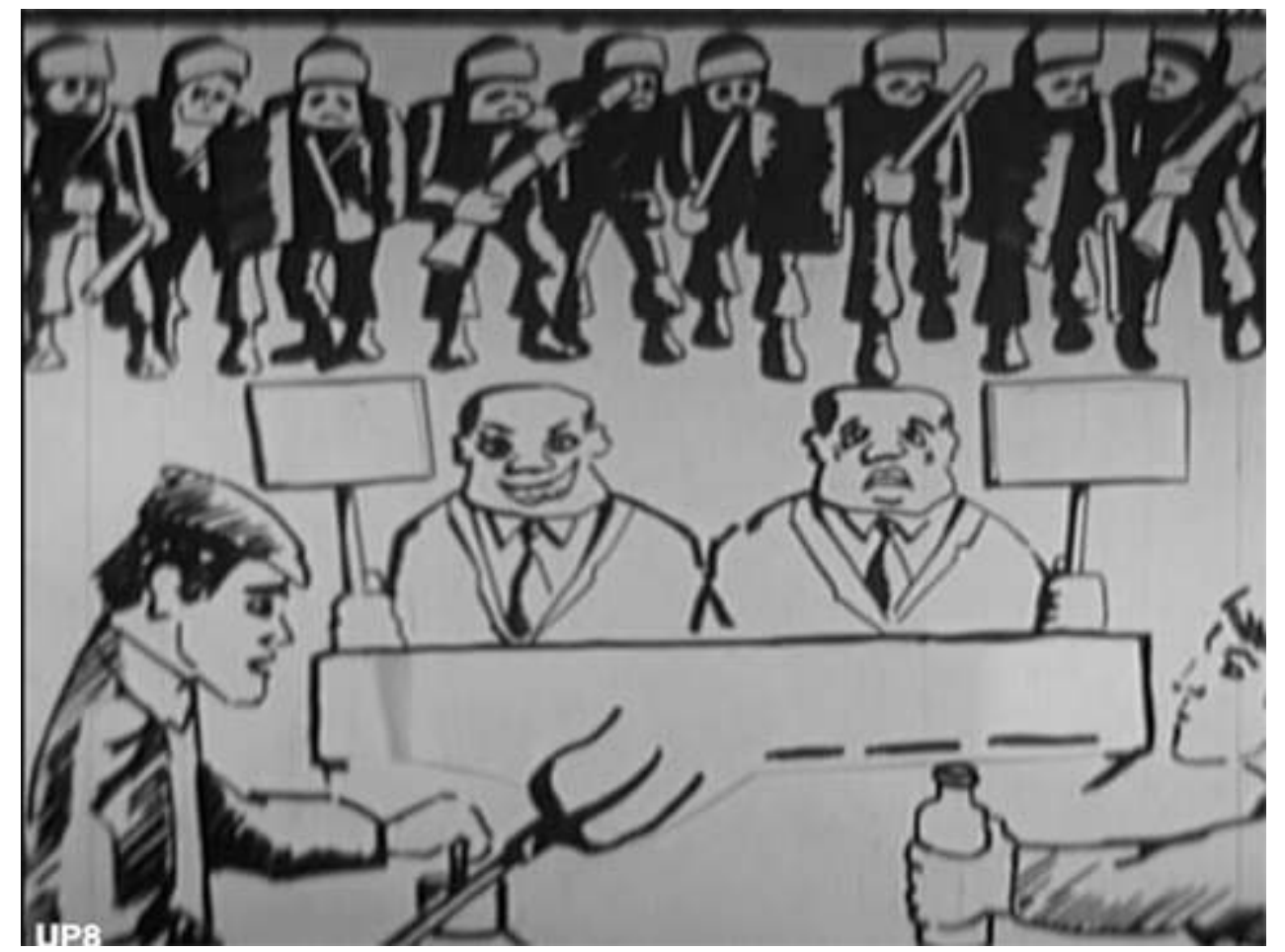

https://les-films-du-beret.jimdofree.com 
Figure 23 : La pieuvre Sanders (Des dettes pour salaire)

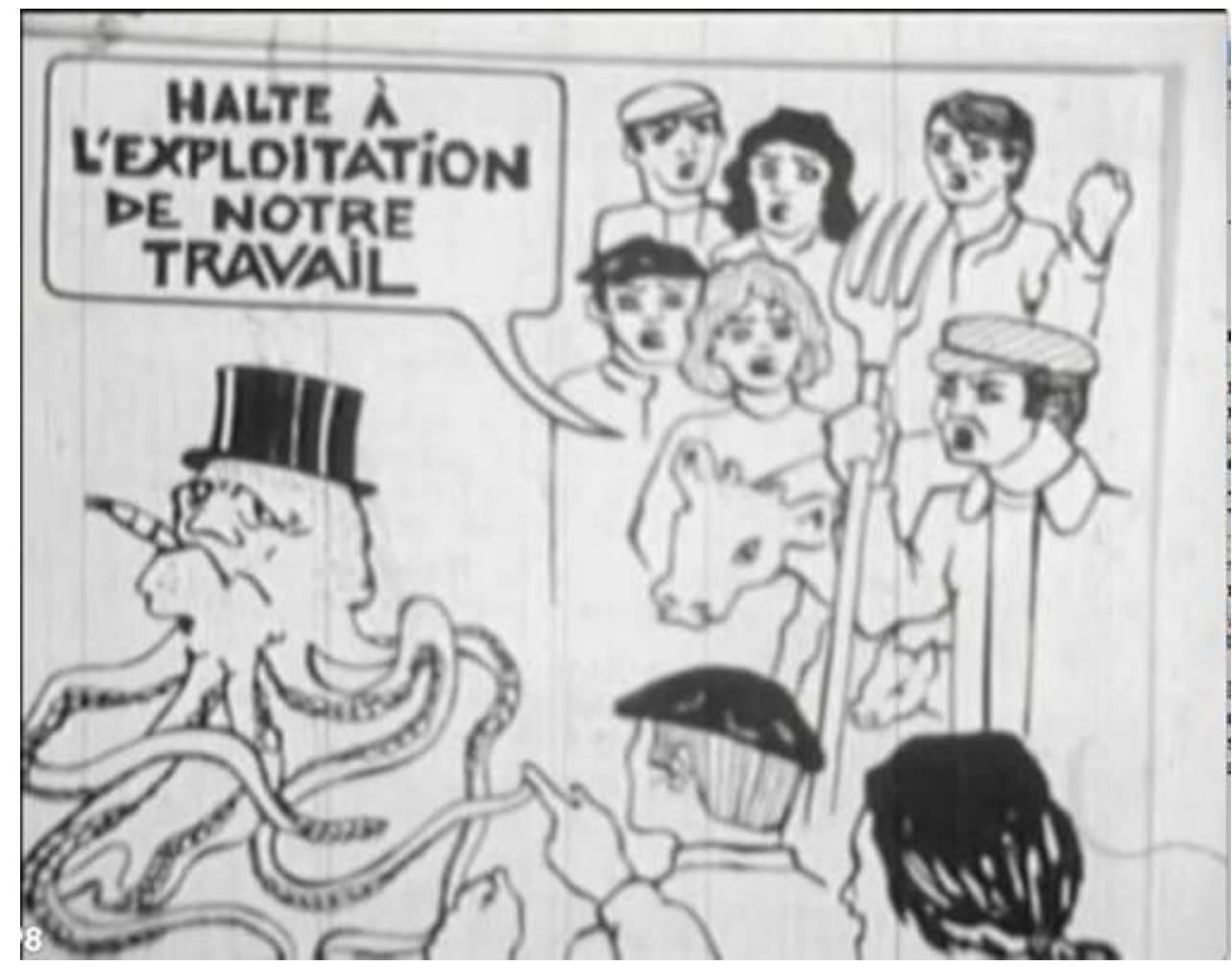

https://les-films-du-beret.jimdofree.com

51 De même, pour dénoncer l'attitude des pouvoirs publics une séquence de N'y a pro détourne des images de la télévision, dont la voix off reconstruit largement le sens, les images n'ayant que peu à voir avec le message qui les accompagne (fig. 24). 
Figure 24 : Détourner les images officielles

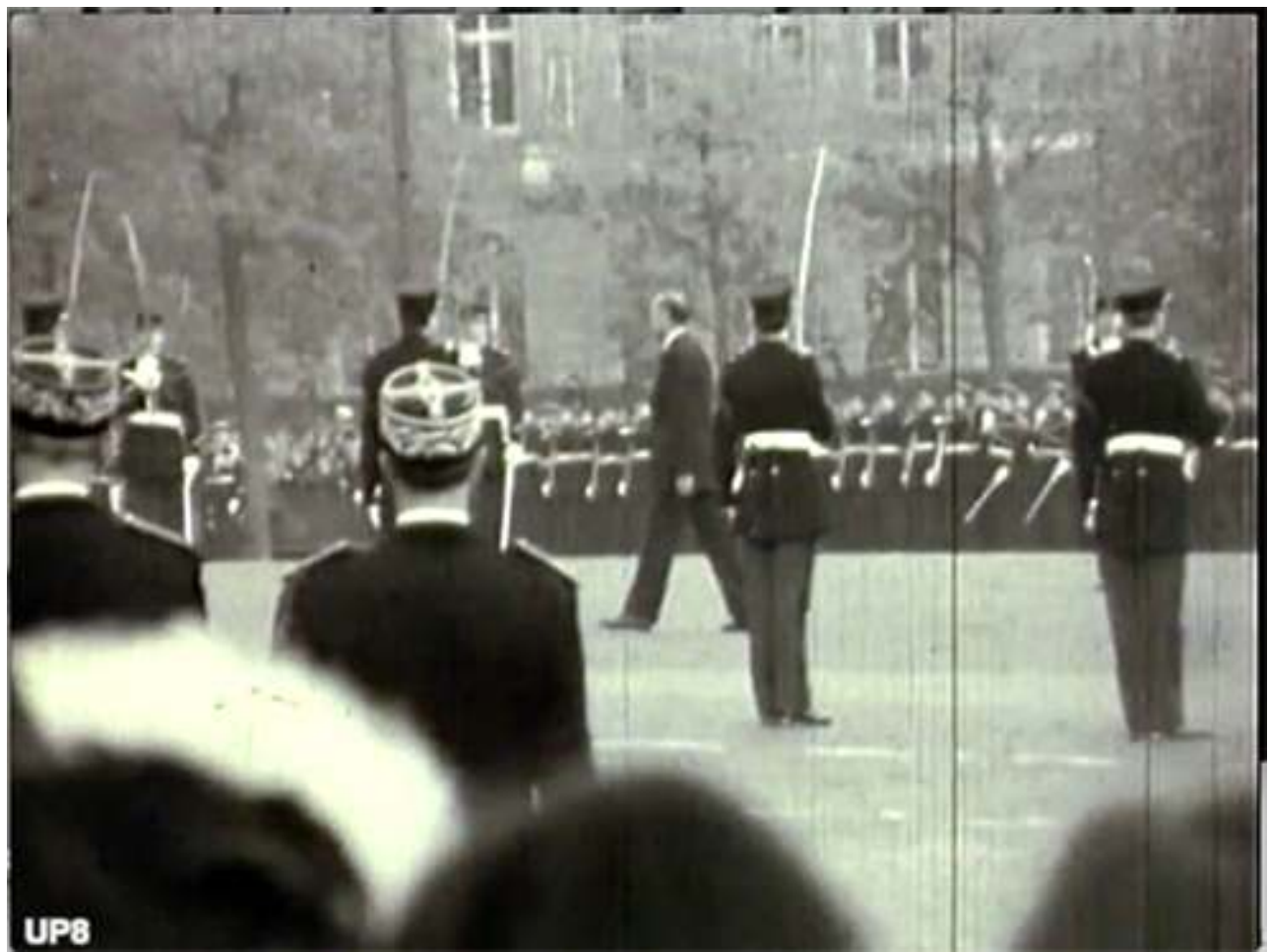

https://les-films-du-beret.jimdofree.com

Figure 25 : Ou les déconstruire : « la bourgeoisie à sa propre vérité » (N'y a pro)

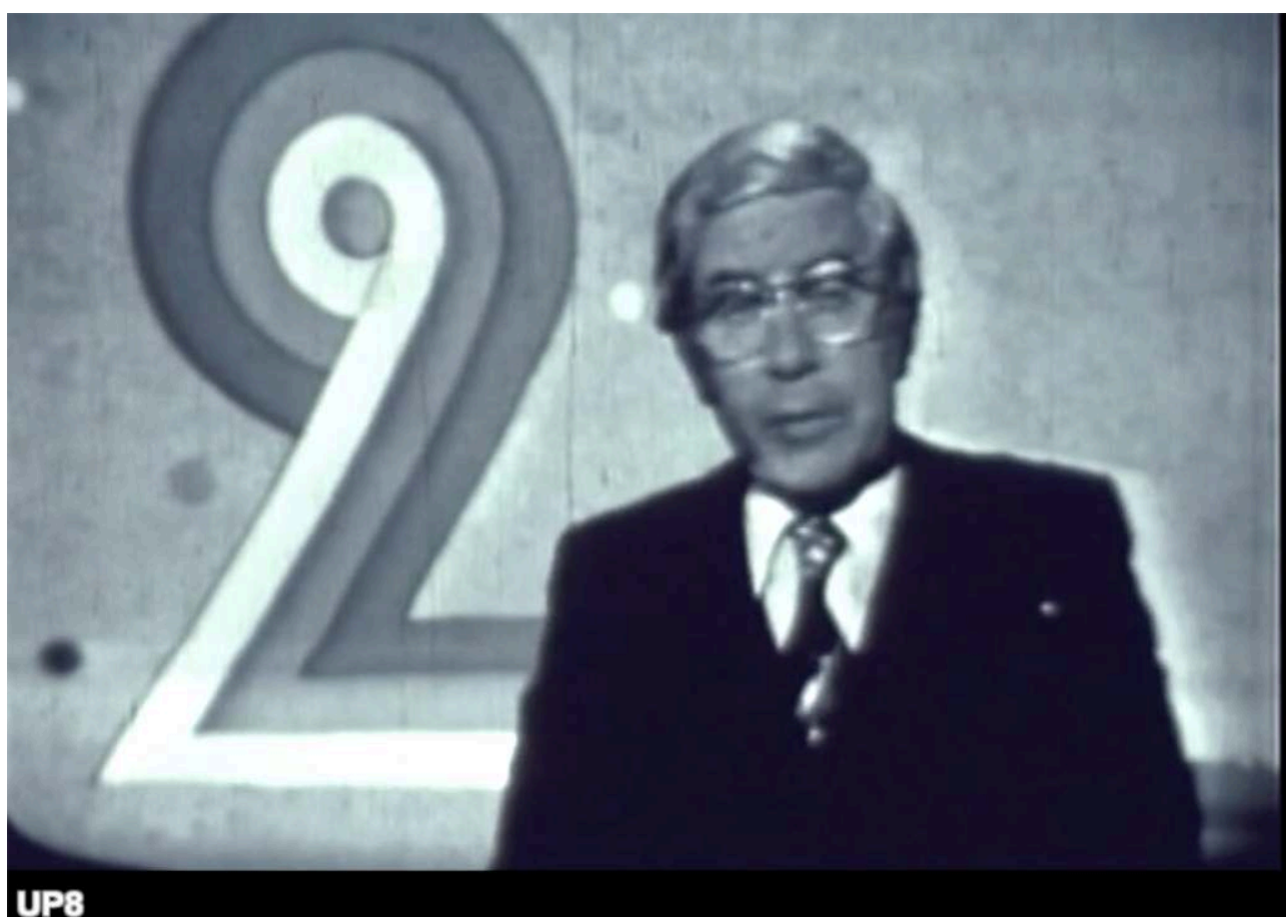

https://les-films-du-beret.jimdofree.com

Bien que le gouvernement français soit un agent du capitalisme qui organise le marché commun, il fait semblant de reculer. D'une main, il tend une carotte en proposant des mesures immédiates comme la taxation des vins importés, et plus 
lointaines, comme la création de l'office du vin. De l'autre, il agite le bâton et individualise la répression ${ }^{19}$. $1968^{20}$, les films du Front paysan sont aussi pensés comme des outils de lutte et de contre-propagande, contre la télévision et la radio qui trompent l'opinion, et contre lesquelles se dressent les militants, comme en témoignent plusieurs séquences dans $N^{\prime} y$ a pro (fig. 25).

Le deuxième procédé est l'utilisation d'acteurs qui campent, de manière souvent caricaturale, les "méchants » : c'est le cas du patron de coopérative dans La Guerre du lait qui, intervenant à trois reprises, incarne la trahison de ces organismes contre l'intérêt des paysans. Le portrait reste toutefois « modéré » dans la charge, à l'image de la séquence où, désemparé, il appelle à la "concertation » (fig. 26). Le même procédé est à l'œuvre dans la mise en cause des forces de l'ordre, en l'occurrence d'un CRS, filmé dans son appartement après une dure journée à réprimer l'agitation paysanne et à qui sa femme demande d'aller chercher du lait «à la ferme, c'est beaucoup moins cher ${ }^{21}$ ».

Figure 26 : Les coopératives dévoyées

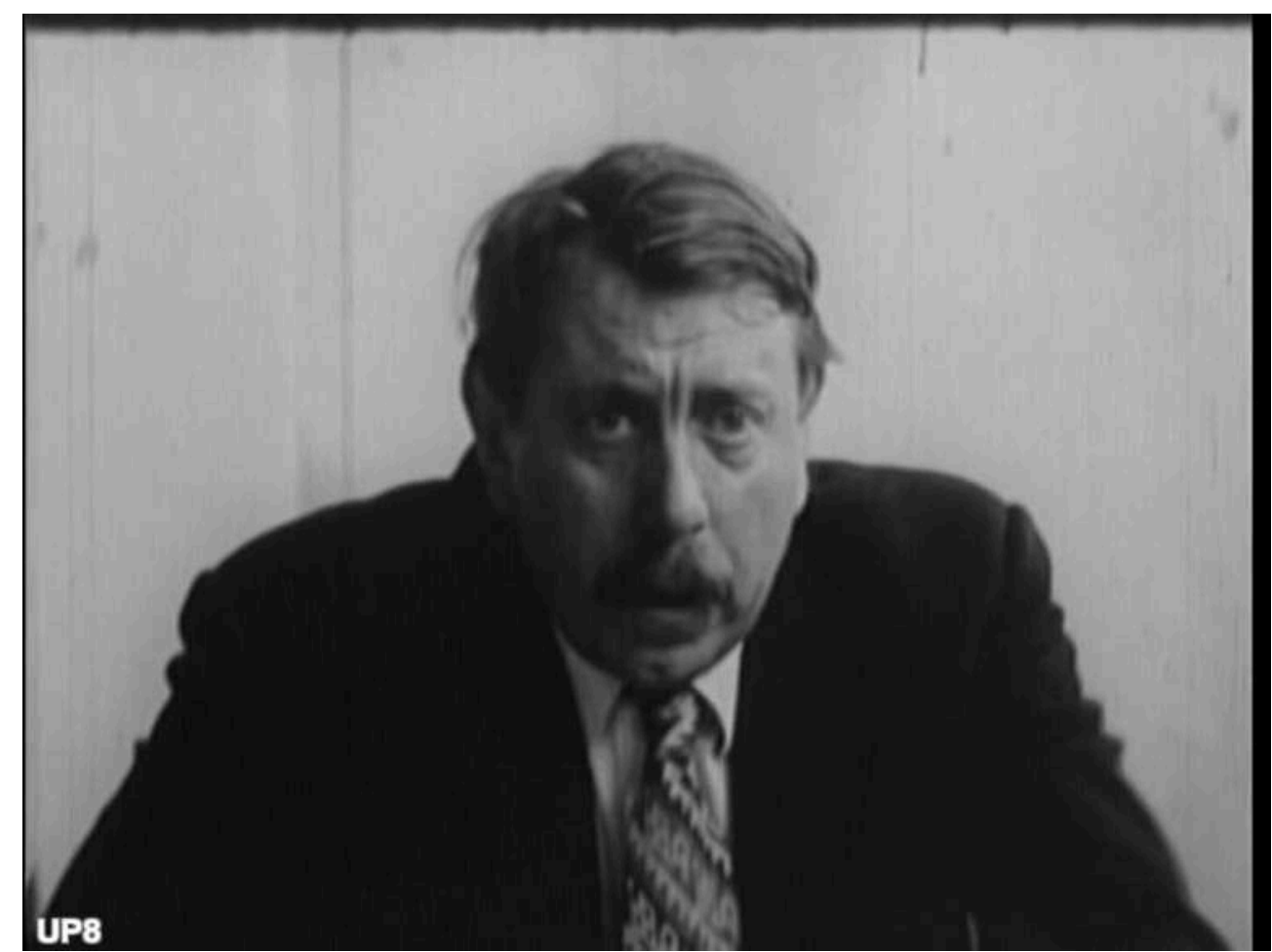

https://les-films-du-beret.jimdofree.com 


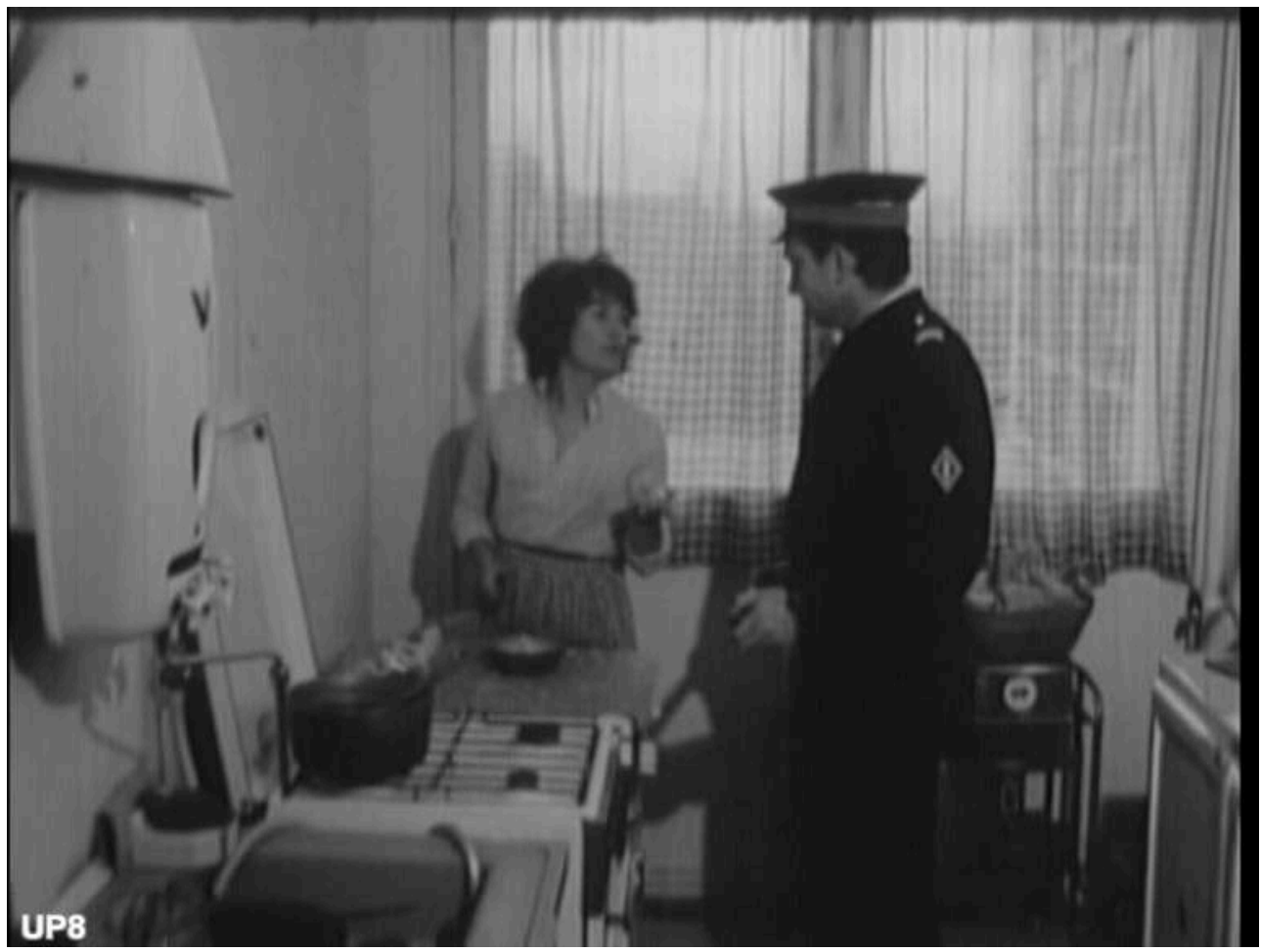

https://les-films-du-beret.jimdofree.com

Beaucoup plus caricaturale est la mise en scène du «dirigeant » de la firme Sanders dans Des dettes pour salaire, adepte de tous les coups tordus, qui se présente comme un "ancien militaire» chargé de "nettoyer» et d'"assainir» les finances d'une multinationale sans foi ni loi, dominée par les « Rothschild» et les «Goldsmith ». Dans ses apparitions successives, $\mathrm{M}$. Joignot, acteur professionnel venu mettre ses talents au service $\mathrm{du}$ film ${ }^{22}$ est de tous les mauvais coups : truquant les abattoirs, tentant de soudoyer ses interlocuteurs, sollicitant l'appui du préfet et enfin, faisant condamner les éleveurs, avec une séquence particulièrement saisissante, où tandis que d'une voix mielleuse il invite les éleveurs à venir discuter avec lui, la prise de vue se resserre progressivement sur sa cravate en cuir. (fig. 28). 
Figure 28 : « Joignot », l'homme de Sanders
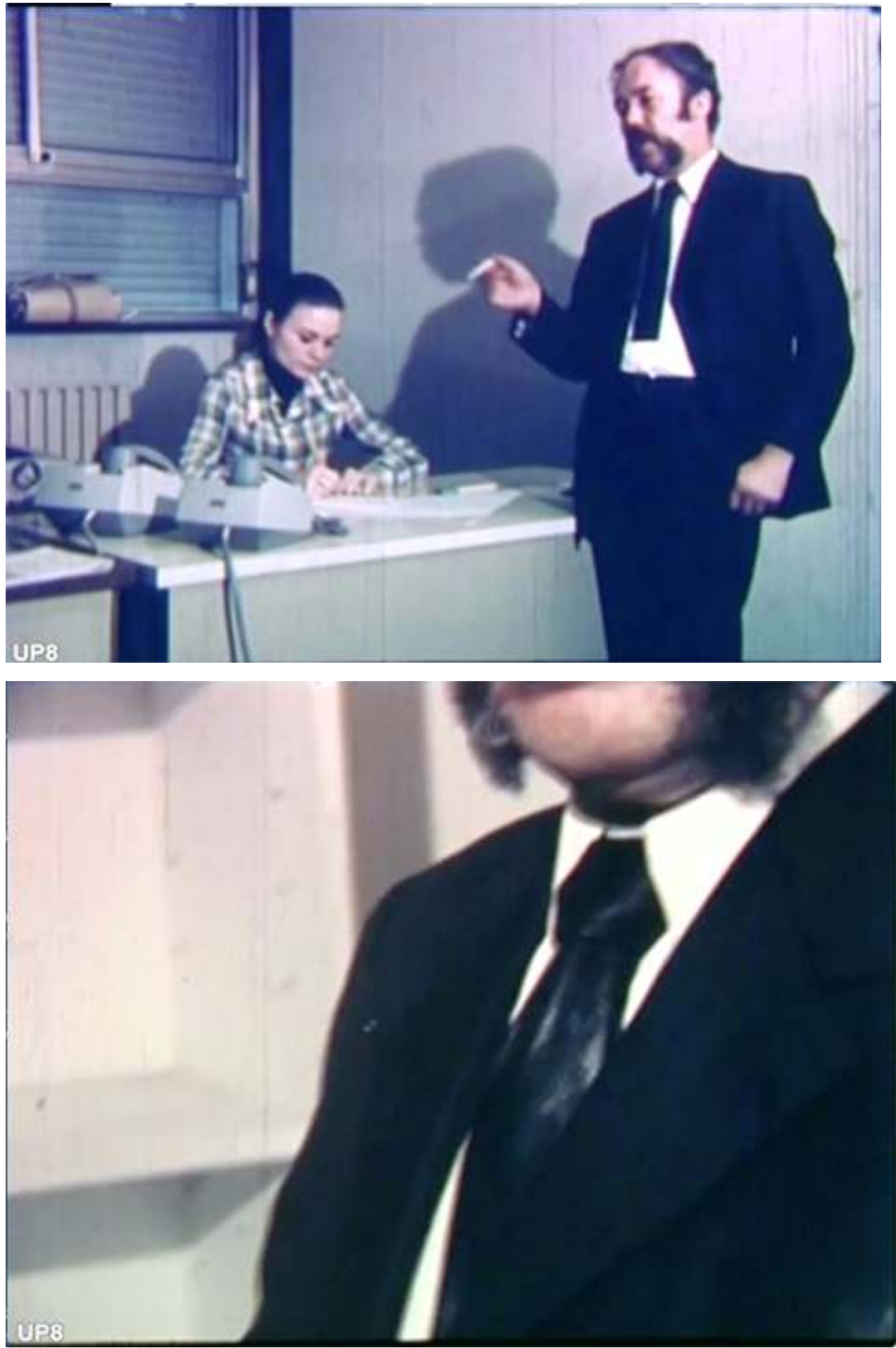

https://les-films-du-beret.jimdofree.com

55 Ce recours à la fiction prend parfois une dimension encore plus audacieuse, lorsque, dans La Guerre du lait, pour mettre en image la mise sous tutelle de l'agriculture capitaliste, le film propose, outre des caricatures (fig. 29), une séquence étrange où un acteur - statue - bouge lentement sur fond de building, tandis qu'une voix off d'outretombe reprend le discours « technocratique »: 
Je suis Mansholt, je suis $\operatorname{Vedel}^{23}$, il y a trop d'agriculteurs, il faut supprimer tous ceux qui n'ont pas 25 ha, il y a trop de surfaces cultivées [...]. Le Crédit agricole a trop prêté, à tort et à travers, il réservera ses capitaux aux exploitations les plus compétitives $^{24}$.

Figure 29 : Les visages du capitalisme

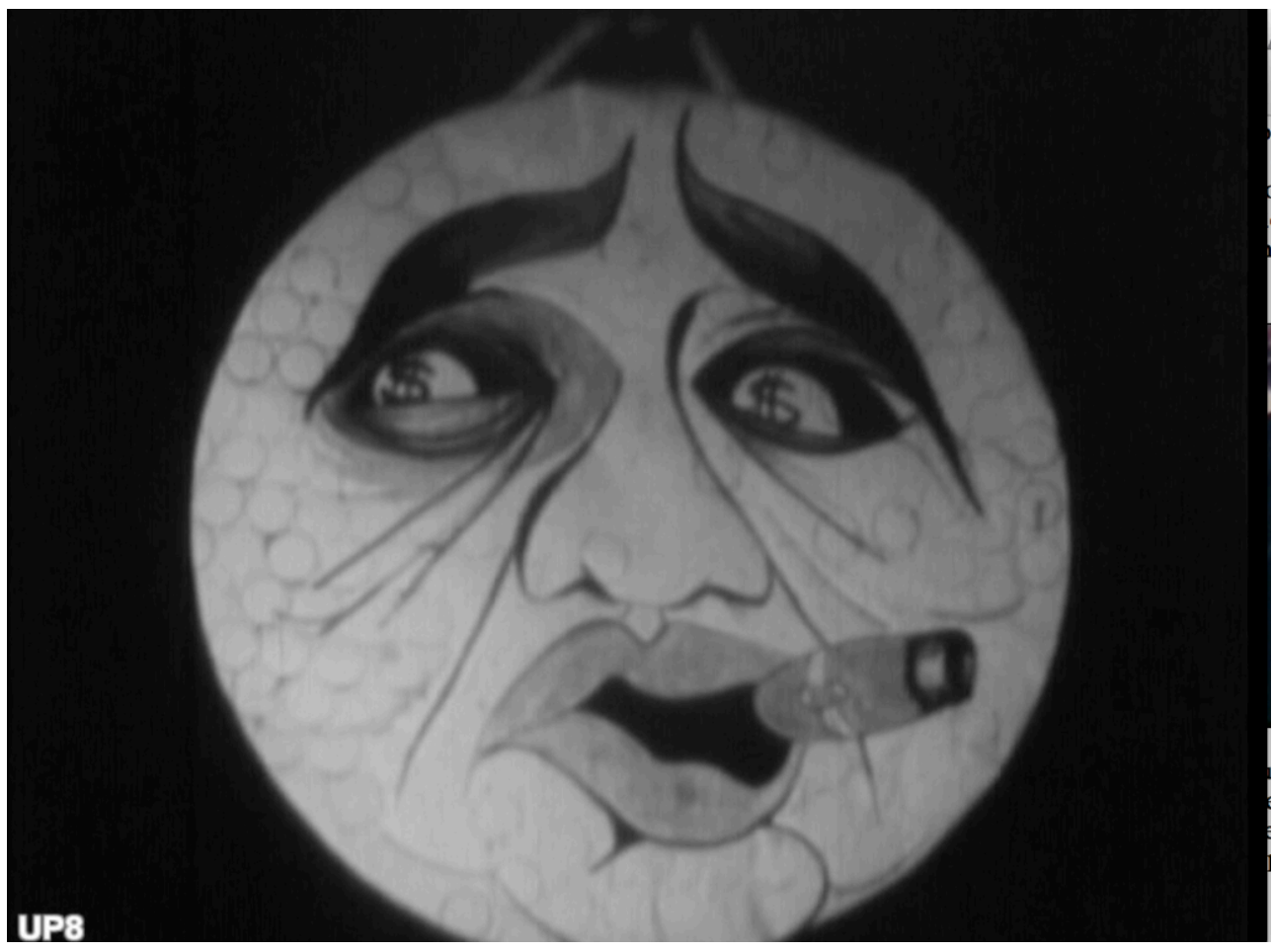

https://les-films-du-beret.jimdofree.com 
Figure $30: . .$. et de la PAC

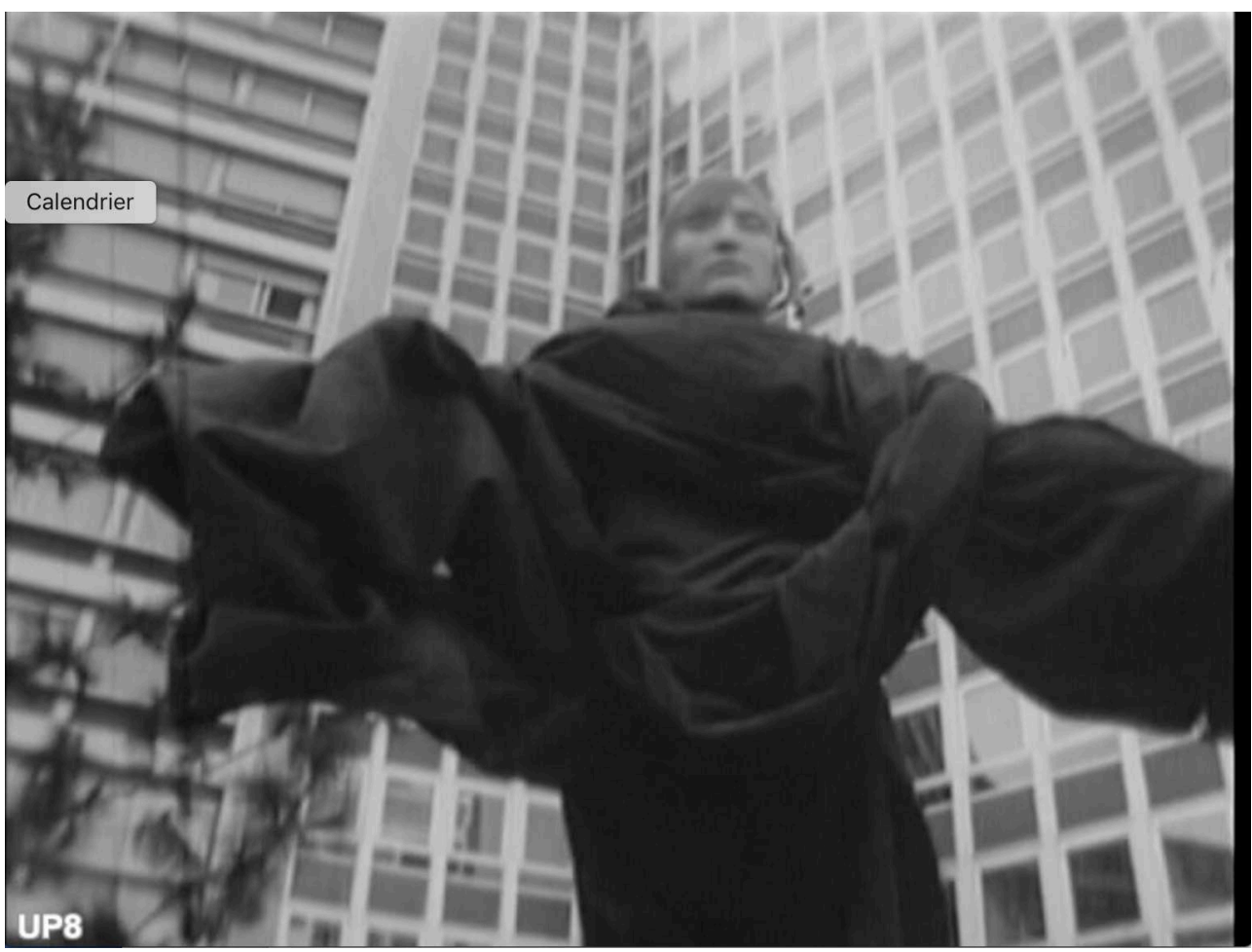

https://les-films-du-beret.jimdofree.com

Le troisième procédé consiste à faire intervenir directement les protagonistes, ce qui nécessite évidemment leur accord de principe. Là encore, on peut observer une certaine gradation dans le procédé : dans La Reprise abusive, la position du propriétaire Charles Douet, interviewé en extérieur, est assez fidèle à la réalité, même au tout début de la séquence, où la caméra rejoint $C$. Douet dans son champ, donnant un sentiment de « fuite ». Certes, les questions posées offrent la possibilité à $C$. Douet de dire tout le mal qu'il pense des militants Paysans travailleurs, "feignants et hors la loi », mais sans animosité particulière. D'où l'accent mis, dans la séquence suivante, sur des «cumulards» plus conformes au standard idéologique, mais nettement moins convaincants, en l'occurrence les moines de l'abbaye de la Meyneraie, qui sont eux aussi interrogés, mais où le fossé est grand entre la teneur de l'interview, sur fond de chant liturgique, qui porte sur le type de culture des moines et leur usage (un jardin potager nourricier) (fig. 32), et la voix off qui souhaite évidemment dénoncer ces exploiteurs, avec un long panoramique sur le mur de clôture. La séquence suivante est consacrée au comte de R., avec une voix off qui énumère ses multiples propriétés, en France et en Angleterre, sur fond de son du cor et d'images de chasse à courre (fig. 33). Ici, des images peu explicites servent davantage de prétexte à la dénonciation d'un adversaire exemplaire. 
Figure 31 : Le goupillon

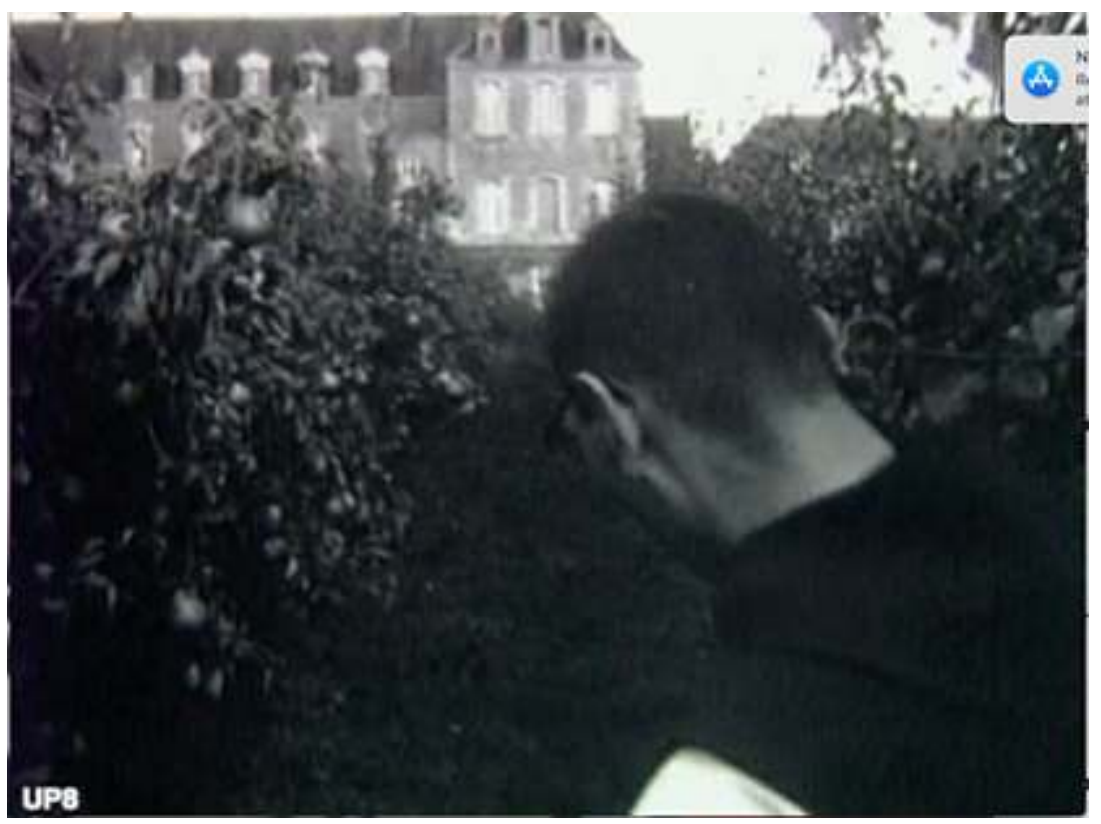

Image du capitalisme terrien dans La Reprise abusive.

Figure 32 : Le blason

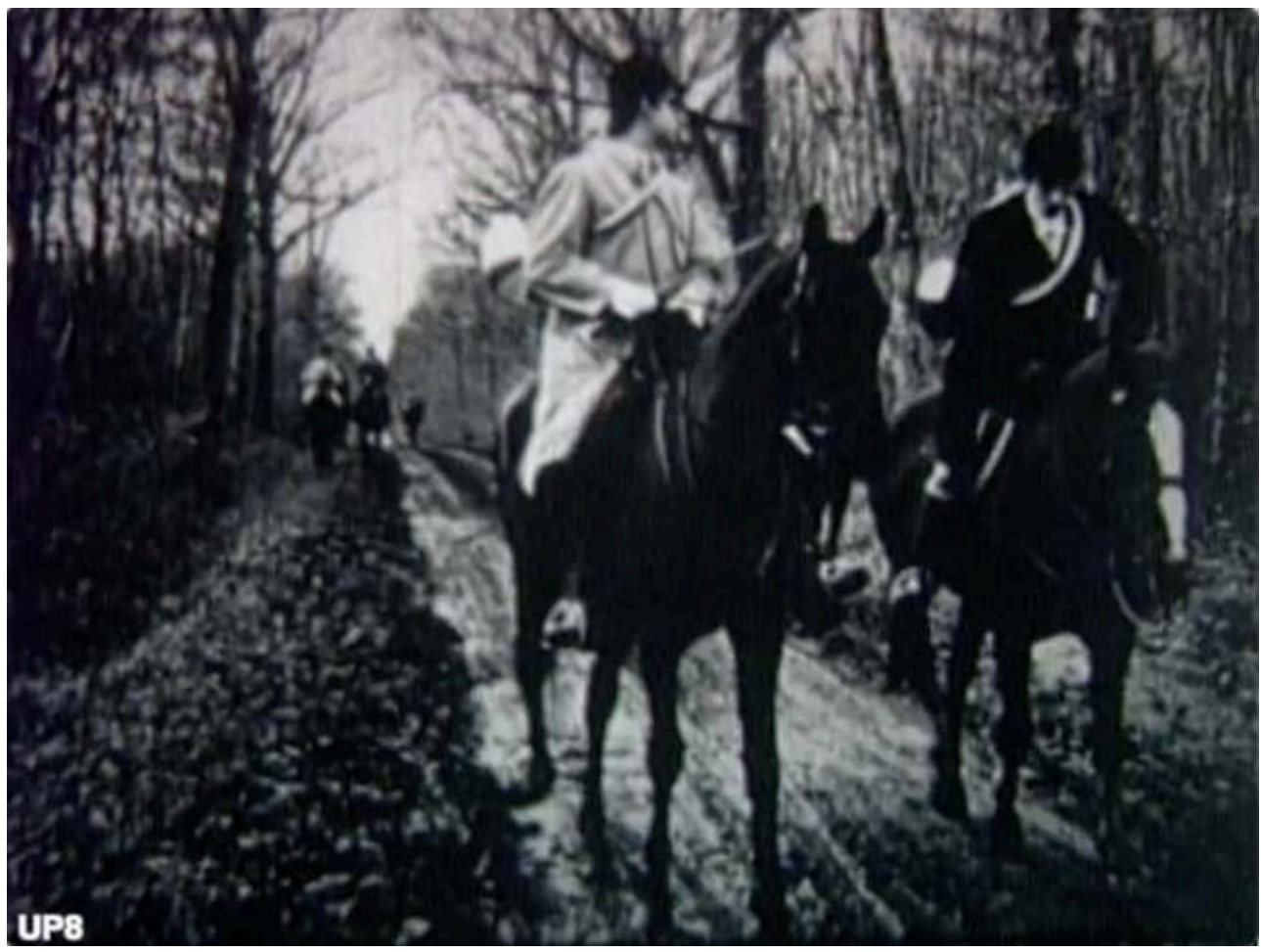

Image du capitalisme terrien dans La Reprise abusive

https://les-films-du-beret.jimdofree.com

57 Dans la difficulté de mettre en scène ses adversaires, le « hasard » fait parfois bien les choses, en particulier dans La Reprise abusive, lors de la manifestation à la souspréfecture d'Ancenis, où le sous-préfet, sous la pression des paysans, peine à trouver le 
ton juste et doit subir les saillies de ses adversaires (fig. 33). Héros malgré lui, tout comme le responsable local de la gendarmerie qui, arrivant sur les lieux de manière inopinée, se voit proposer un tract qu'il range maladroitement dans sa poche. Ici, pas besoin de voix off, c'est la musique, sautillante et espiègle, l'attitude des protagonistes qui soulignent l'incongruité de la scène avec la force d'une séquence saisie sur le vif.

Figure 33 : Le sous-préfet... au champ (La Reprise abusive)

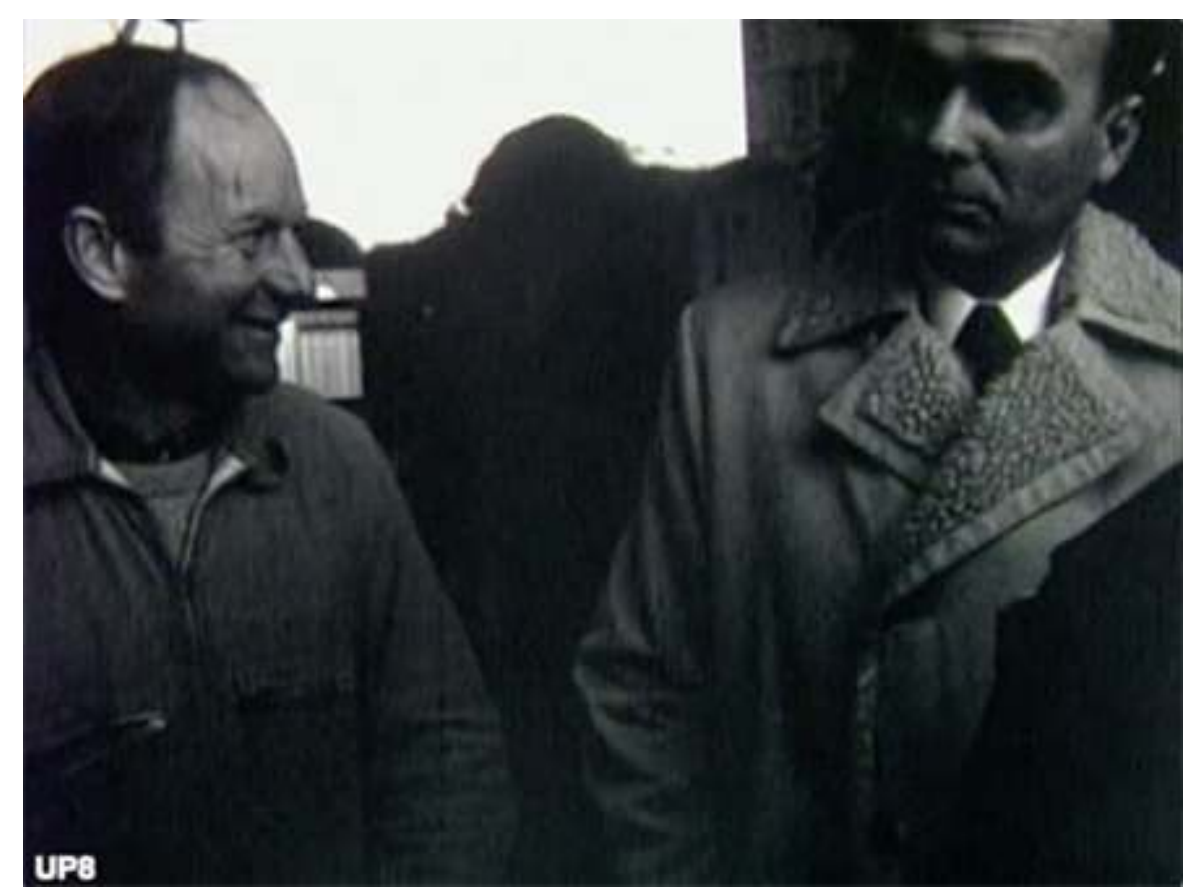

https://les-films-du-beret.jimdofree.com 
Figure 34 : Le gendarme... attrapé (La Reprise abusive)

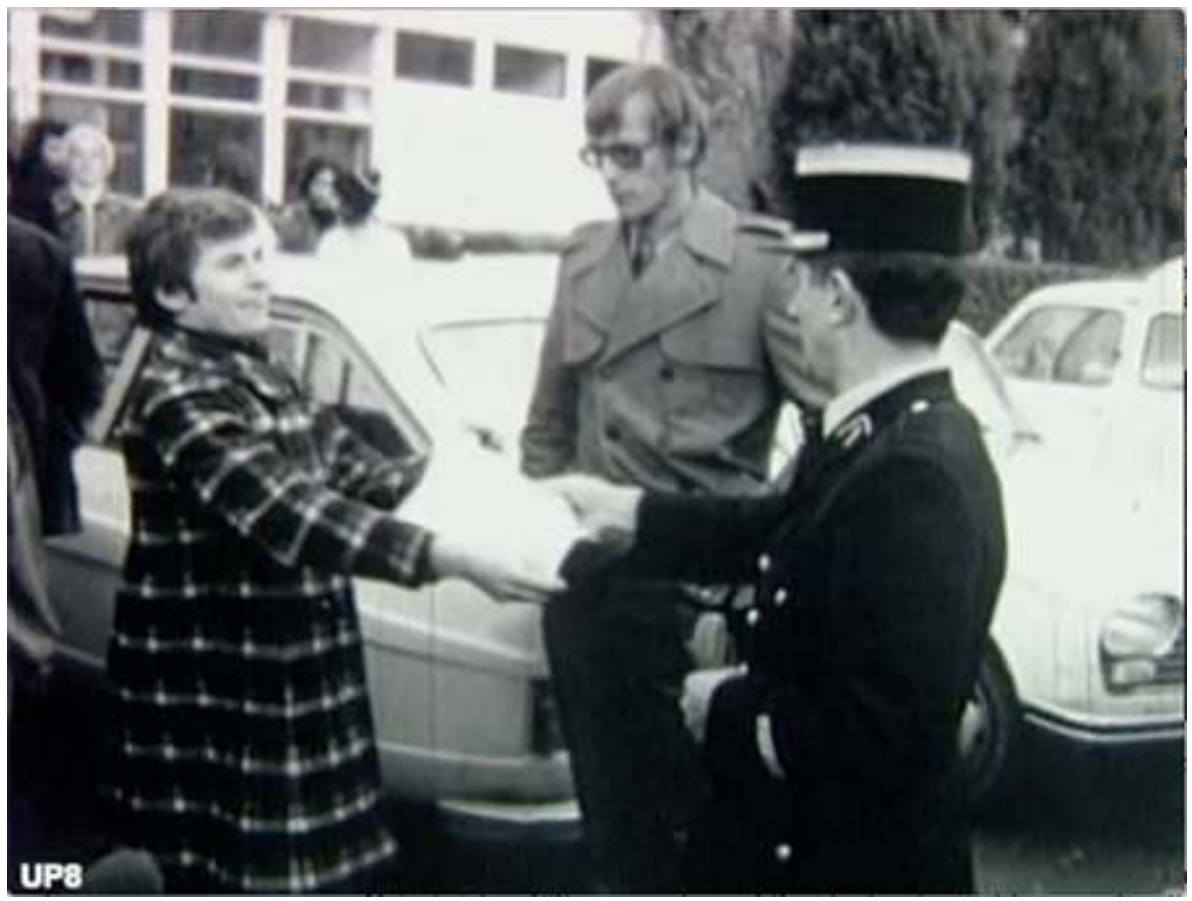

https://les-films-du-beret.jimdofree.com

Mais c'est dans N'y a pro que le procédé est le plus abouti. Là encore, deux figures différentes, celle d'un viticulteur Bruel, ancien pied noir ayant « réussi » et qui expose ses succès dans son magasin de la Grande Motte. Cependant, comme dans La Reprise abusive, le portrait n'est pas trop à charge, à l'exception de la première scène où la caméra le suit sur le trottoir, montant dans sa - belle - voiture, tout sourire, sur fond d'immeubles touristiques, pendant que la voix off le décrit comme l'un des fossoyeurs de la viticulture méridionale. Durant l'entretien, l'énumération de toutes ses responsabilités, associatives et professionnelles, permet de construire en miroir le portrait de ces arrivistes qui contrôlent tous les leviers à leur seul profit. En revanche, la mise en image d'une grande propriétaire, Mme Laneluc Samson, apparaît au bout d'une demi-heure, au cœur de la séquence sur les adversaires, où elle énonce, au milieu de ses chaix et avec fierté ses propriétés, ses titres et ses relations. La séquence juxtapose le double rapport de domination, celui de la viticulture capitaliste sur les petits vignerons, mais aussi au sein de l'exploitation, avec la figure du « régisseur » qui se fait le porte-parole maladroit et servile de la parole patronale (fig. 36). Le jeu de la caisse sur laquelle monte et descend la protagoniste (fig. 35), à l'invitation du réalisateur, crée un puissant effet, à la fois humoristique et ridicule, qui fait mouche et fera même naitre une tentative de censure, lors d'une diffusion publique, pour atteinte à l'image de cette héroïne involontaire. 
Figure 35 : Rapport de caisse (N'y a pro)

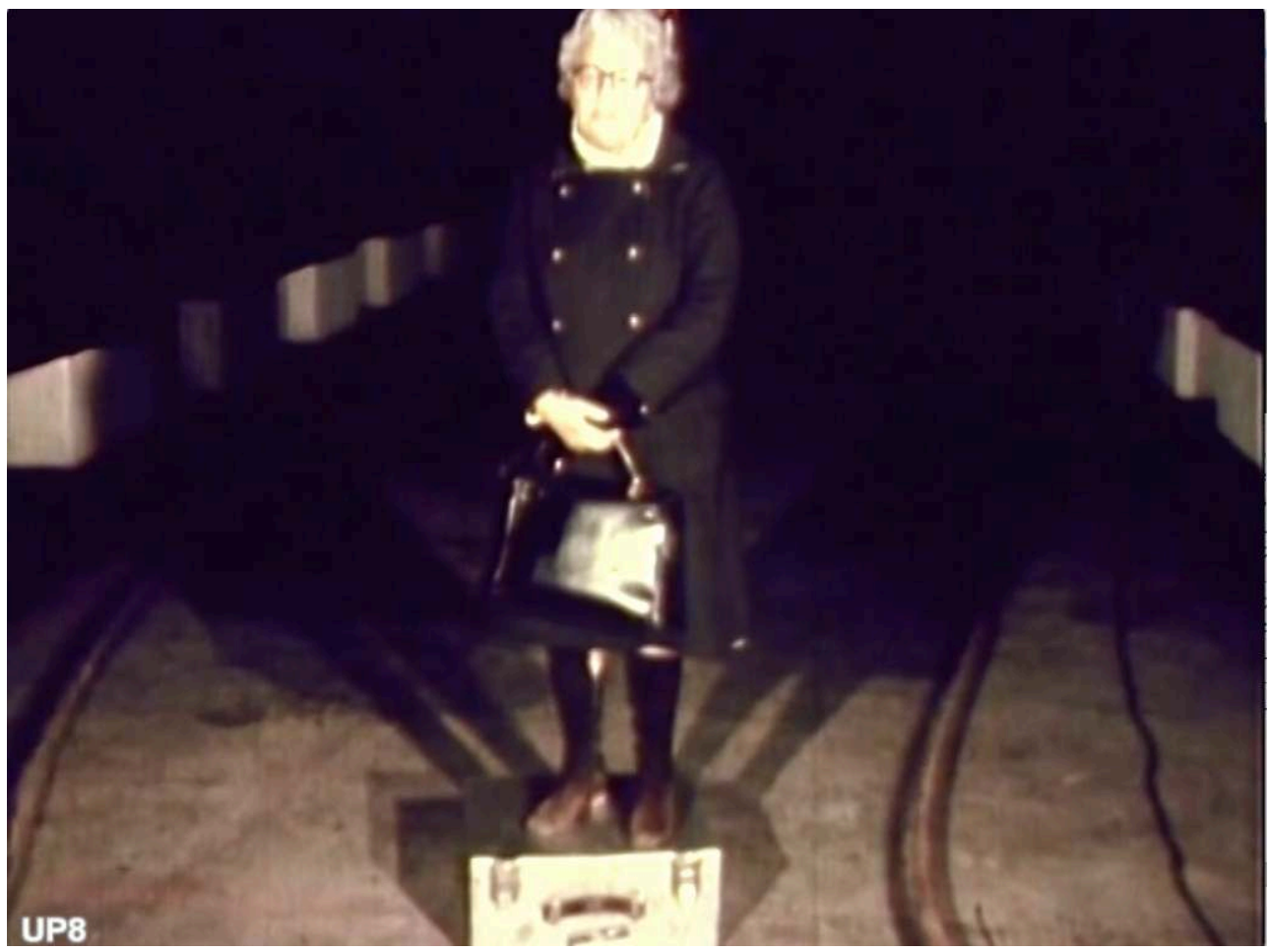

https://les-films-du-beret.jimdofree.com

Figure 36 : Rapport de classe ( $N$ 'y a pro)

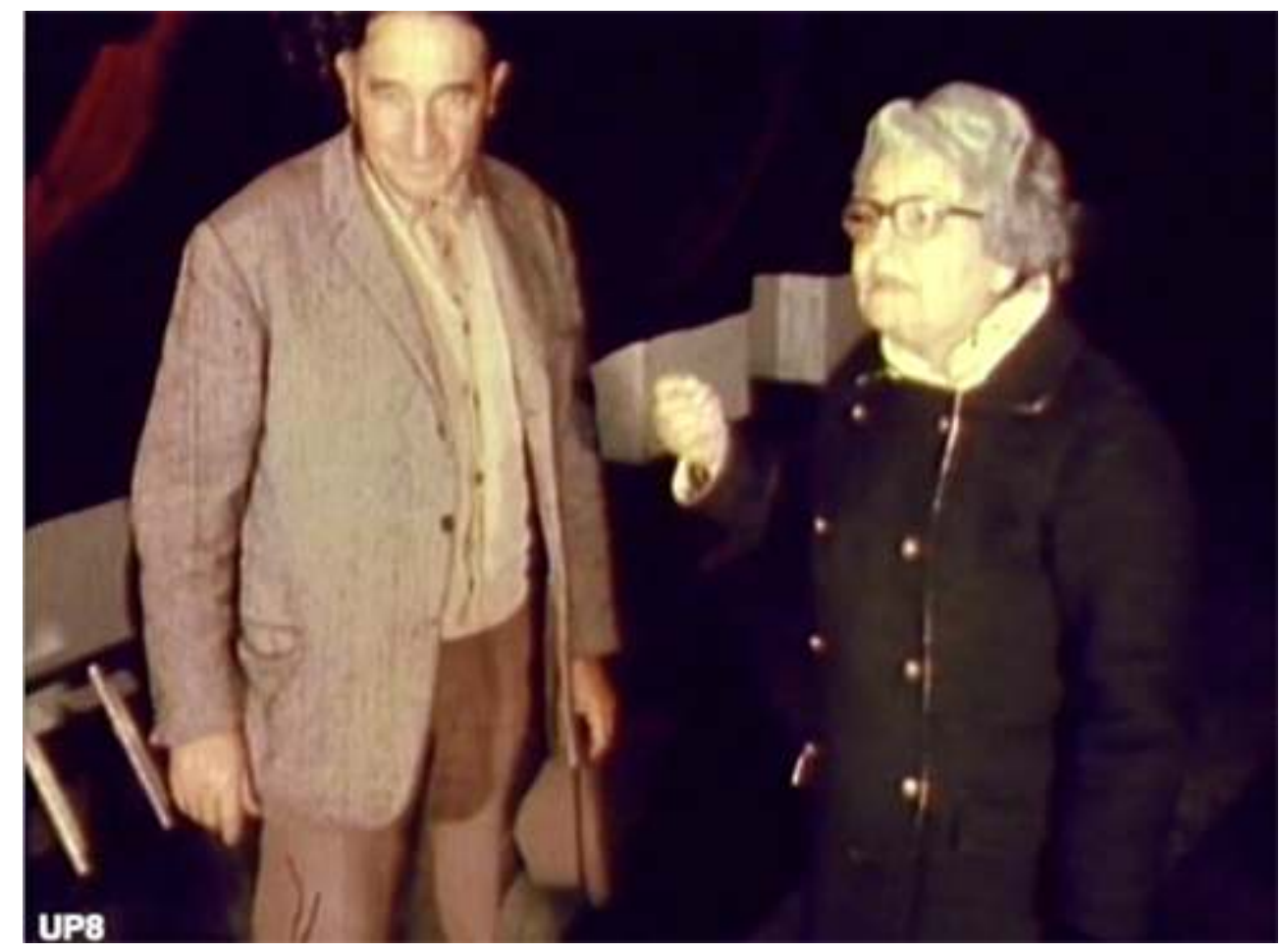

https://les-films-du-beret.jimdofree.com 


\subsection{Se démarquer d'un syndicalisme gestionnaire, « L'action syndicale, c'est l'affaire de tous ${ }^{25}$ »}

Le dernier élément qui caractérise la dimension militante de ces quatre films est la place accordée à la défense et à la valorisation de la ligne syndicale des Paysans travailleurs et par là même la mise en cause des majoritaires de la FNSEA accusés de trahir la cause des paysans. C'est une autre illustration d'une pratique assez classique de la propagande militante mettant en difficulté ses concurrents, par le verbe ou par les faits. La charge est particulièrement forte dans La Guerre du lait, conflit à forte dimension intersociale, où les coopératives laitières, ciblées par les protestataires, sont un des piliers de la profession organisée. Et ce sont ces dernières qui sont directement accusées par les protagonistes d'avoir saboté les négociations avec le gouvernement comme l'explique l'un des responsables :

je pense que les agriculteurs ont pris conscience de l'importance de la lutte qu'ils menaient et surtout je pense qu'ils ont très très bien senti à travers les différents colloques et réunions qu'il y a eu, en particulier entre l'administration, les pouvoirs publics et les laiteries au niveau du colloque de Rennes, qu'il y avait certainement une entente entre ces différentes laiteries et le gouvernement pour casser le mouvement ${ }^{26}$.

Un autre interlocuteur accuse plus directement les responsables départementaux de la FNSEA dans certains départements de lutter contre l'expansion du mouvement, argument repris par la voix off. Dans une dimension plus "positive ", la présentation de l'extension du mouvement sur le reste du territoire, figurée par une carte des départements et commentée en voix off, s'achève sur l'exemple du Puy-de-Dôme et de la laiterie de Richemond, dirigée par Michel Debatisse.

Moins centrales, ces luttes d'influence n'en sont pas moins présentes dans les autres films: dans La Reprise abusive, l'affaire Pellerin permet de mettre en avant les différentes stratégies des organisations locales ou régionales et les réticences de la fédération à s'engager à fond, et notamment d'emboiter le pas à l'action directe préconisée. Une longue séquence voit se succéder les deux argumentaires faisant la part belle à la stratégie des Paysans travailleurs. Et la tension se dénoue en faveur de ces derniers à la faveur d'une nouvelle séquence où la voix off explique le ralliement du syndicat local à la stratégie de protestation, en mettant en avant à plusieurs reprises le ralliement de la "base ", désavouant une direction plus frileuse et prête à faire jouer la solidarité des travailleurs de la terre. 
Figure 37 : De la discussion...

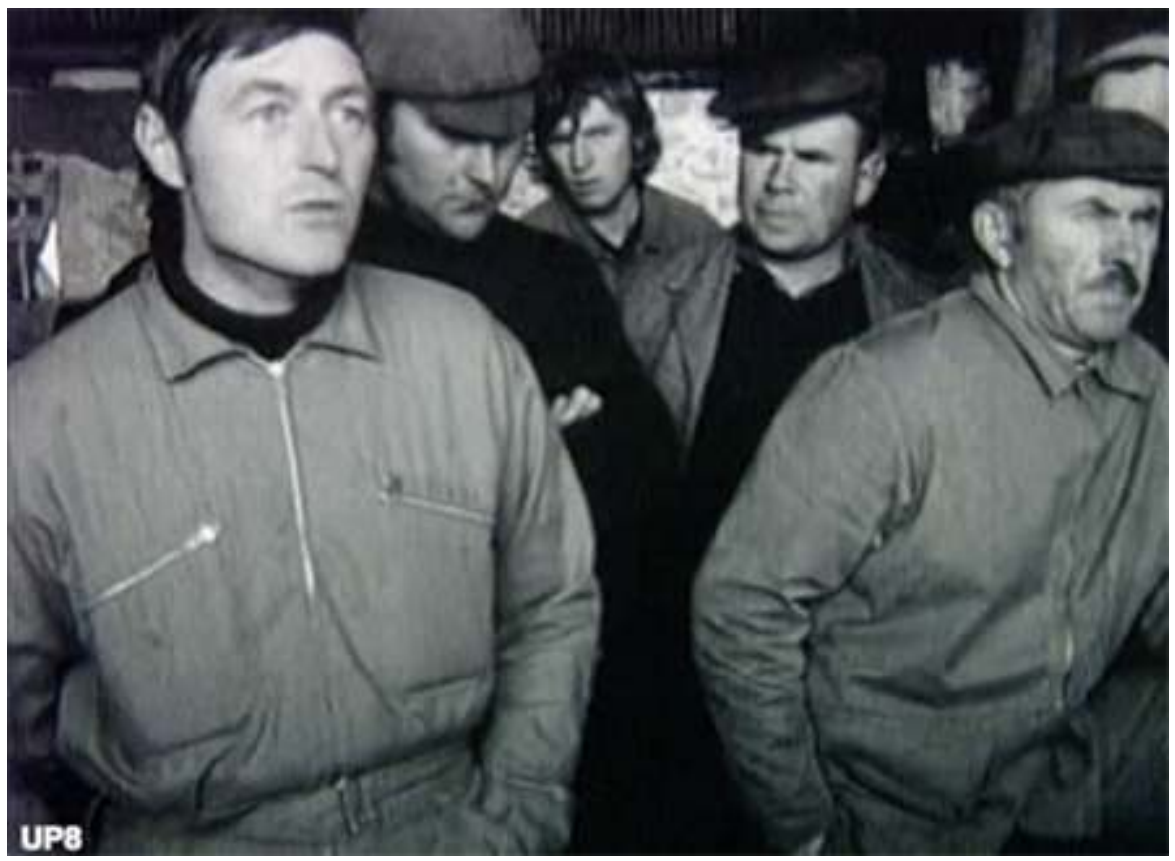

https://les-films-du-beret.jimdofree.com

Figure 38 : ... à l'accord final

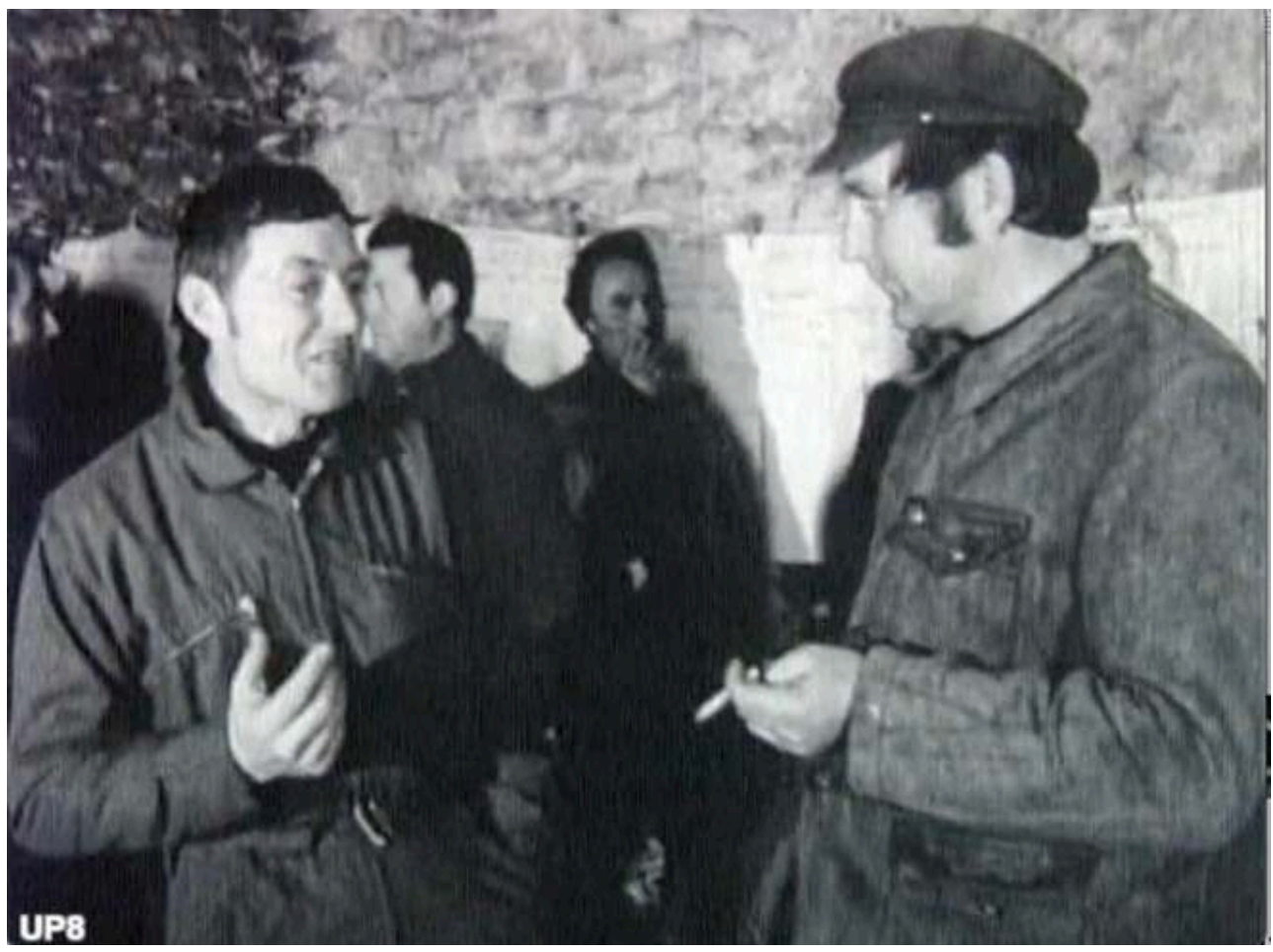

https://les-films-du-beret.jimdofree.com

62 Dans Des dettes pour salaire, le déclenchement de la résistance des éleveurs a pour point de départ les limites de la "défense » opérée par la fédération départementale qui se contente de renvoyer les victimes vers un avocat, qui n'obtiennent que partiellement gain de cause. Ce qui conduit les producteurs floués à se tourner vers les «jeunes », 
membres du CNJA, qui prennent en main la mobilisation sur des positions plus « radicales » à la fois en termes d'actions collectives mais aussi d'organisation de la lutte. C'est l'occasion d'expliciter la spécificité de leur démarche :

Le CDJA n'est qu'un moyen, ce qui importe, c'est que l'initiative reste aux intéressés directs, c'est-à-dire dans le cas présent aux éleveurs. Comme pour la justice, il ne s'agit pas de s'en remettre à quelques responsables syndicaux qui seraient soidisant des spécialistes de la défense. L'action syndicale, c'est l'affaire de tous ${ }^{27}$.

Figure 39 : L'affirmation d'un syndicalisme à la base

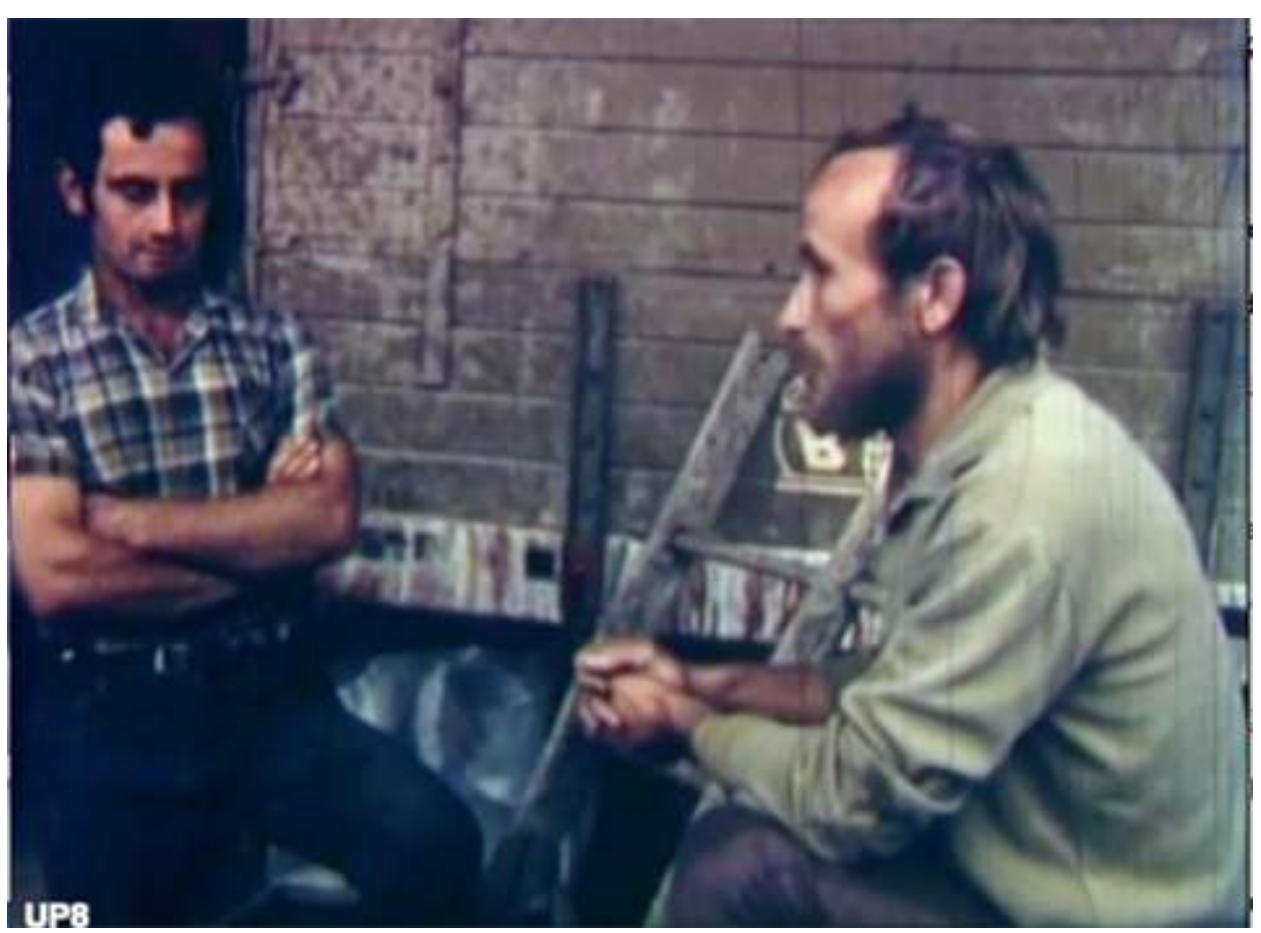

https://les-films-du-beret.jimdofree.com 
Figure 40 : Des coopératives dévoyées

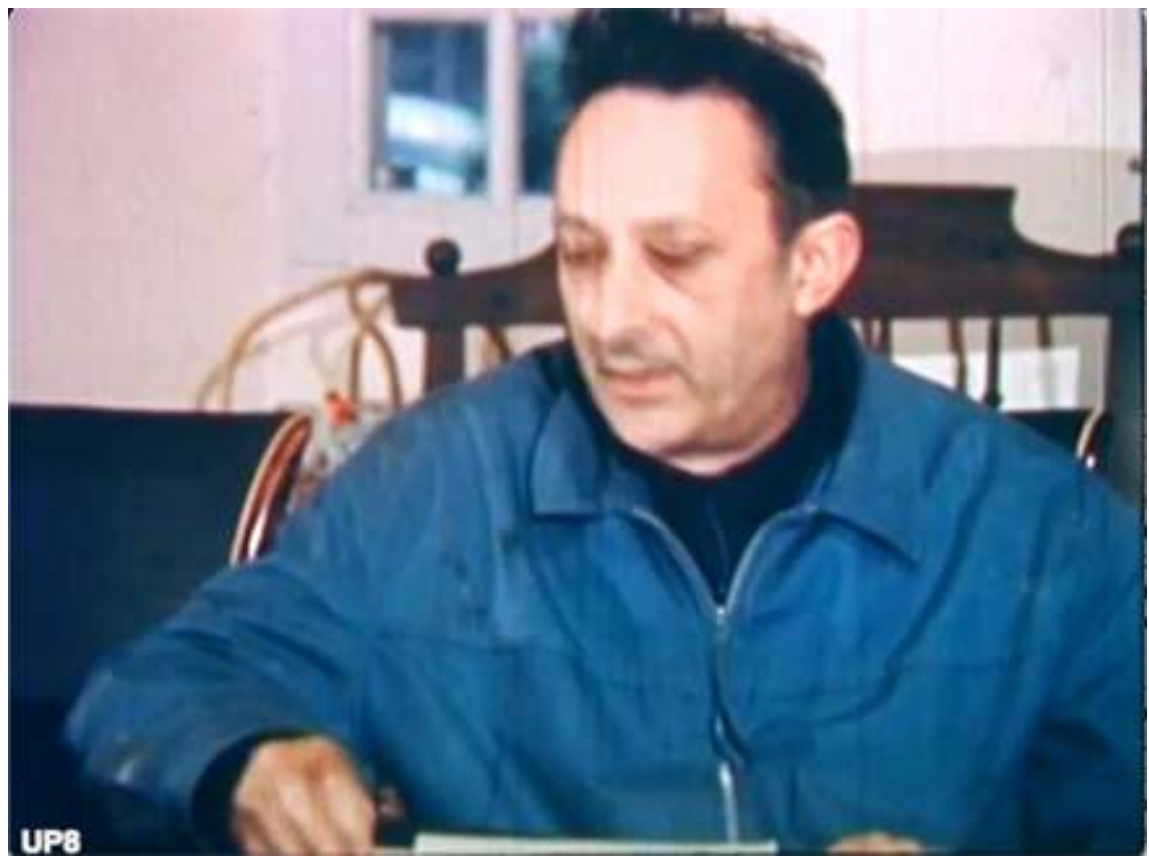

https://les-films-du-beret.jimdofree.com

Dès la séquence suivante, un autre militant enfonce le clou :

La seconde raison, c'est que nous remettons en cause par cette action Sanders la forme syndicaliste traditionnelle, qui actuellement ne joue qu'un rôle d'arbitraire [sic].

Et l'on enchaine sur la présentation du collectif des éleveurs engagés dans la lutte, tous assis sur des chaises identiques, sans hiérarchie aucune, sous la forme d'un long travelling, collectif explicité par la voix off « pour atteindre ces objectifs, les éleveurs avec les paysans travailleurs constituent l'association de défense des éleveursagriculteurs avec à sa tête, un collectif et non pas un président responsable ${ }^{28}$ ».

Enfin, comme dans la grève du lait, c'est aussi le système coopératif dévoyé qui est mis en cause, car obéissant aux mêmes règles d'exploitation que les firmes industrielles (Fig. 40).

- Pourtant, les coopératives, vous pouvez être administrateur et contrôler quand même ce qu'il s'y passe?

- Ah, on pouvait contrôler dans les coopératives dans le temps, quand elles étaient petites, quand c'était vraiment la chose des paysans, des agriculteurs. Or maintenant c'est plus ça, ce sont des gros groupes financiers qui font plusieurs milliards de chiffre d'affaires ${ }^{29}$.

Et le film s'achève, nous l'avons évoqué par une profession de foi en faveur des Paysans travailleurs.

Même dans N'y a pro, où la problématique syndicale n'est pas identique aux trois films précédents, la mise en avant du Mivoc n'empêche pas de régler quelques comptes avec les organisations traditionnelles. Dans le film, cela s'appuie sur le témoignage du grand-père qui raconte son expérience de 1907 et la nécessaire méfiance des " petits » et des ouvriers face à une mobilisation interclassiste : « et là nous avons vu les plus gros fraudeurs qui étaient en tête, alors méfie-toi, toi si, que ce soit pas la même chose ${ }^{30}$ ». Et cette mise en garde est reprise par Jean Huillet devant ses camarades : 
Si les viticulteurs ne bougent pas, si vous ne vous sentez pas concernés, vous allez laisser faire deux possibilités : soit les responsables actuels vont caracoler en tête et faire leur politique viticole, pour leurs propres intérêts [...]. Donc on a intérêt, ne serait-ce que pour contrôler les gens qui nous représentent, d'être motivés et d'être mobilisés.

La critique des organisations traditionnelles est également présente dans leur appui aux politiques de modernisation et de formation qui entretiennent l'illusion d'une issue favorable, avec le témoignage d'un viticulteur engagé dans cette voie qui ne lui a rien apporté. Enfin, comme dans les autres films, les coopératives sont mises en cause, car en dépit de leur création par le mouvement syndical afin de contrôler la commercialisation, elles ne parviennent pas à défendre les producteurs, selon l'analyse qu'en fait le chercheur de l'Inra, graphique à l'appui.

Nous nous sommes efforcé à travers cette analyse, nécessairement partielle d'une source aussi complexe et riche, sur une période qui ne l'est pas moins, de montrer comment une fraction $\mathrm{du}$ mouvement social agricole s'empare de l'outil cinématographique, dans un moment bref et sans équivalent de convergence et de rencontre entre des pratiques militantes et des formes nouvelles de diffusion. Parce qu'ils sont d'abord pensés et construits comme des films de lutte (Layerle, 2008), nous avons fait le choix d'insister sur leur rôle de relais de l'action militante, notamment dans le choix des thématiques et des choix stratégiques. En dépit de leur position infériorisée dans le champ des luttes sociales, ces films témoignent des dynamiques et des circulations au sein d'un monde paysan souvent laissé de côté.

La richesse du médium cinématographique et ses nombreux niveaux de lecture ouvrent bien d'autres pistes d'études pour ces films du Front paysan: celles, plus cinématographiques, peuvent davantage s'intéresser aux processus d'écriture et de construction, entre contraintes matérielles et positionnements théoriques, y compris en élargissant le corpus des films. Dans le champ politique et militant, les questions de diffusion, de discussion, de circulation mériteraient un développement à part entière, d'autant que les images circulent aussi de film en film. Enfin, parce que la caméra, audelà des objectifs idéologiques et des usages, saisit des »morceaux du réel » qui fournissent aux historiens un matériel particulièrement riche et irremplaçable pour saisir une société paysanne à la fois proche, mais déjà lointaine.

\section{BIBLIOGRAPHIE}

Barres D., Coulomb P. et Nallet H. (1973) Le Conflit du lait en Bretagne, mai-septembre 1972, 2 vol. dact., Inra.

Belloin G. (1993) Renaud Jean, le tribun des paysans, Paris, Éditions de l'Atelier.

Braud P. (1993) « La violence politique, repères et problèmes », Cultures et conflits, $\mathrm{n}^{\circ}$ 9-10. 
Breton B. (2013) « Un conflit par le droit : l'entreprise Doux et les éleveurs intégrés en 2002 », dans Jalibert L. et Patillon C. (dir.), Mouvements paysans face à la politique agricole commune et la mondialisation, 1957-2011, Rennes, PUR.

Bruneau I. (2006) La Confédération paysanne : s'engager à "juste" distance, Thèse de doctorat en histoire, Université Paris X-Nanterre.

Chapouillié G. (2017) « L'Azegado : les raisons d'un engagement, entretien avec Guy Chapouillié par Edouard Lynch », Études rurales, n 199 : « La caméra explore les champs », p. 111-128.

Conord F. (2008) « Mobilisation paysanne et relais politiques : le comité de Guéret (1953-1974) », dans Antoine A. et Mischi J. (dir.), Sociabilité et politique en milieu rural, Rennes, PUR, p. 213-223.

Debatisse M. (1962) La Révolution silencieuse, Paris, Calmann Levy.

Duclos N. (1995) La Fin des violences paysannes, Paris, Économica.

Frader L.L. (1991) Peasants and Protest: Agricultural Workers, Politics, and Unions in the Aude, 1850-1914, Berkeley.

Gauthier G., Heller H. et Layerle S. et Martineau-Hennebelle M. (2004) « Le cinéma militant reprend le travail », CinémAction, $\mathrm{n}^{\circ} 110$.

Grant P. D. (2016) Cinéma Militant: Political Filmmaking and May 1968, Londres, New York, Columbia University Press.

Gratton P. (1971) La Lutte des classes dans les campagnes, Paris, Anthropos.

Guiheneuf F. (2019) Bernard Lambert, héraut paysan (1931-1984), Mémoire de Master 2 en histoire, sous la direction de F. Georgi, Université de Paris I.

Hennebelle G. (1976) «Cinéma militant », Cinéma d'aujourd'hui, nº 5-6, avril, p. 100-107.

Lagrave R.-M. (1990) « Les gauches syndicales (MODEF, CNSTP, FNSP) », dans Coulomb P. et al. (dir.), Les Agriculteurs et la Politique, Paris, Presses de la FNSP, p. 355-369.

Lambert B. (2005) Les Paysans dans la lutte des classes, Nantes, CHT.

Layerle S. (2008) « Un cinéma en lutte pour des gens en lutte : Cinélutte, histoire d'un collectif », Le Cinéma de Mai 68, une histoire, coffret DVD, vol. 2, Paris, Éditions Montparnasse.

Layerle S. (2008) Caméras en lutte en mai 68 : par ailleurs le cinéma est une arme, Paris, Nouveau Monde.

Lecler R. (2013) « Gauchir le cinéma : un cinéma militant pour les dominés du champ social (19671980) », Participations, $n^{\circ}$ 7, p. 97-125.

Luneau G. (2004) La Forteresse agricole. Une histoire de la FNSEA, Paris, Fayard.

Lynch É. (2011) «Les manifestations paysannes en Mai 1968 : "si loin, si proche" ?", dans Morin G., Richard G., Vergnon G., Benoit B. et Chevandier C. (dir.), À chacun son Mai ? Le tour de France de mai-juin 1968, Rennes, PUR.

Lynch É. (2020) Insurrections paysannes, Paris, Vendémiaire.

Martin J.-P. (2008) « Confédération paysanne et tradition viticole en Languedoc-Roussillon », Pour, no 196-197, p. 295-301.

Martin J.-P. (2005) Histoire de la nouvelle gauche paysanne. Des contestations des années 1960 à la Confédération paysanne, Paris, La Découverte. 
Martin J.-P. (2014) « Les contestations paysannes autour de 1968. Des luttes novatrices, mais isolées ", Histoire \& Sociétés rurales, vol. 41, n 1, p. 89-136.

Martin J.-P. et Drouet Y. (2010) « Un militantisme paysan à gauche. Des réseaux paysans de Bernard Lambert (au PSU) à ceux de l'OC-GOP (années 1960-années 1970) », dans Kernalegenn T. (dir.), Le PSU vu d'en bas. Réseaux sociaux, mouvement politique, laboratoire d'idées (années 1950-années 1980), Rennes, PUR.

Paxton R.-O. (1997) Le Temps des chemises vertes, Paris, Le Seuil.

Péré B. (2016) « Des dettes pour salaire », dans Piot C. (dir.), Figures paysannes en France, Mythes, Regards, Sociétés, t. II, Nérac, Éditions d'Albret, p. 377-386.

Perron T. (2000) «À la recherche du cinéma ouvrier : périodisation, typologie, définition », Les cahiers de la cinémathèque (Cinémathèque de Perpignan), $\mathrm{n}^{\circ} 71$.

Porhel V. (2008) Ouvriers bretons. Conflits d'usines, conflits identitaires en Bretagne dans les années 1968, Rennes, PUR.

Sagnes J. (1980) Le Mouvement ouvrier du Languedoc, Toulouse, Privat.

Sainclivier J. (2011) « La grève du lait de 1972 », dans Sainclivier J. et Richard G. (dir.), La Mutation du système partisan français après Mai-68 : printemps 1971-automne 1974, Rennes, PUR.

Stellati P. et Piot C. (2016) « Le cinéma, saisir pour transmettre. Entretien avec Guy Chapouillié, un paysan venu de la ville ", dans Piot C. (dir.), Figures paysannes en France. Mythes, Regards, Sociétés, t. II, Nérac, Éditions d'Albret, p. 321-377.

Vigna X. (2007) L'Insubordination ouvrière dans les années 1968. Essai d'histoire politique des usines, Rennes, PUR.

\section{NOTES}

1. Mouvante, elle est composée en 1975, selon le générique de N’y a pro de Dominique Bricard, Robert Boarts, Jeanine Caniou, Guy Chapouillié, Nadine Charesson, Hubert Guipouy, Yves Lachaud, Bernard Pellefigue. Celui de La Reprise abusive mentionne également Joëlle Le Moigne. Deux des films, N'y a pro et Des dettes pour salaire sont tournés en couleur.

2. https://les-films-du-beret.jimdofree.com

3. http://www-artweb.univ-paris8.fr/?Hommage-a-Claude-Bailble

4. La Révolte des gueux, film de Raymond Lamy, 1949 (21').

5. Congrès national de la JAC, Paris, film réalisé par Germain Sachsé, 1950.

6. Les Paysans en colère, film de Roger Louis et J. L. Richard, 1971 (41'50).

7. Entretien avec G. Chapouillié, 17 mai 2021.

8. Ibid.

9. Ibid.

10. Une première grève du lait a été initiée par la FNSEA en 1964, mais selon des modalités et des objectifs différents. Voir Lynch É., « Détruire pour exister : les grèves du lait en France (1964, 1972 et 2009) », Politix, vol. 26, n 103, 2013, p. 99-24. En 1964 et 2001, il s'agissait de faire pression sur l'État pour qu'il augmente le prix du lait.

11. Entretien avec G. Chapouillié, 21 mai 2021.

12. Christian Rouaud, Paysan et rebelle, un portrait de Bernard Lambert, réalisé en 2002.

13. Entretien avec G. Chapouillié, 17 mai 2021.

14. Des dettes pour salaire (26'01). 
15. Sur cette typologie, voir Tartakoswky D., Les Manifestations de rue en France, 1918-1968, Paris, Presses de la Sorbonne, 1997, et l'« adaptation » au logiciel paysan que j'en propose.

16. En fait, le film réunit deux affaires différentes, et notamment celle de Pellerin, la plus connue. 17. N'y a pro (24'18).

18. L'Olivier, film réalisé par Ali Akika, Guy Chapouillié, Danièle Dubroux, Serge Le Péron, Jean Narboni, Dominique Villain, 1975.

19. N'y a pro, (10'14).

20. Filiu J.-P., Mai 68 à l'ORTF, Paris, Nouveau Monde, 2008.

21. La Guerre du lait.

22. Entretien avec G. Chapouillié, 17 mai 2021.

23. Le premier, commissaire européen à l'Agriculture, concentre l'hostilité du monde paysan pour avoir évoqué la nécessaire disparition des petites exploitations paysannes pas suffisamment productives, position partiellement reprise en France dans le rapport Vedel (1968).

24. La Guerre du lait (51'20).

25. Des dettes pour salaire.

26. La Guerre du lait.

27. Des dettes pour salaire (13'05).

28. Des dettes pour salaire (13'52).

29. Des dettes pour salaire (21'49).

30. N'y a pro (20'50).

\section{RÉSUMÉS}

Les années 1970 sont marquées en France par une mobilisation originale d'une fraction du syndicalisme agricole qui, rompant avec la stratégie unanimiste du syndicat majoritaire, la FNSEA, s'engage dans une série de lutte pour dénoncer les effets dévastateurs de l'industrialisation de l'agriculture. Ces luttes portent notamment sur la question foncière, la perte de contrôle des marchés du vin et du lait, ou les dérives de l'agriculture intégrée. Cette période est aussi très originale par le rôle du cinéma militant dans la mobilisation et la conduite de luttes, analysées ici à travers 4 films du Front paysan. Des films qui sont à la fois des mises en image de luttes exemplaires et des outils de mobilisation syndicale et collective.

The 1970s were marked in France by an original mobilization of a fraction of agricultural unionism, which, breaking with the unanimous strategy of the majority trade union, the FNSEA, engages in a series of struggles to denounce the devastating effects of the industrialization of agriculture. These struggles include the land dispute, the loss of control of the wine and milk markets by peasants, or the drifts of integrated agriculture. This period is also really original by the role of militant cinema in the mobilization and conduct of struggles, analyzed here through 4 films of the Front paysan. Movies that are both exemplary images of struggle and tools for union and collective mobilization. 


\section{INDEX}

Mots-clés : films militants, grèves agricoles, syndicalisme agricole, pratiques syndicales, conflits fonciers

Keywords : militant movies, agricultural strikes, farm union movement, union practice, land disputes

\section{AUTEUR}

\section{ÉDOUARD LYNCH}

Édouard Lynch est professeur d'histoire contemporaine à l'université Lumière Lyon 2, membre du Laboratoire d'Études rurales. Il est spécialiste de l'histoire politique et sociale de la paysannerie française au xxe siècle; il a notamment étudié l'histoire des manifestations agricoles (Insurrections paysannes, Vendémiaire, 2020). Il mobilise depuis plusieurs années les sources audiovisuelles (TV, films documentaires, films militants) (Études rurales, $n^{\circ} 99$ : La Caméra explore les champs) à la fois comme support à la production scientifique, mais aussi pour accompagner la création de documentaires historiques (Nous paysans, Flammarion, 2022). 